\title{
Confirming your worst fears
}

\author{
Citation for published version (APA):
}

Fliek, L. (2020). Confirming your worst fears: The relation between parenting behaviors, fear-enhancing cognitive biases, and anxiety in children. [Doctoral Thesis, Maastricht University]. Ridderprint BV. https://doi.org/10.26481/dis.20200124lf

Document status and date:

Published: 01/01/2020

DOI:

10.26481/dis.20200124lf

Document Version:

Publisher's PDF, also known as Version of record

\section{Please check the document version of this publication:}

- A submitted manuscript is the version of the article upon submission and before peer-review. There can be important differences between the submitted version and the official published version of record.

People interested in the research are advised to contact the author for the final version of the publication, or visit the DOI to the publisher's website.

- The final author version and the galley proof are versions of the publication after peer review.

- The final published version features the final layout of the paper including the volume, issue and page numbers.

Link to publication

\footnotetext{
General rights rights.

- You may freely distribute the URL identifying the publication in the public portal. please follow below link for the End User Agreement:

www.umlib.nl/taverne-license

Take down policy

If you believe that this document breaches copyright please contact us at:

repository@maastrichtuniversity.nl

providing details and we will investigate your claim.
}

Copyright and moral rights for the publications made accessible in the public portal are retained by the authors and/or other copyright owners and it is a condition of accessing publications that users recognise and abide by the legal requirements associated with these

- Users may download and print one copy of any publication from the public portal for the purpose of private study or research.

- You may not further distribute the material or use it for any profit-making activity or commercial gain

If the publication is distributed under the terms of Article $25 \mathrm{fa}$ of the Dutch Copyright Act, indicated by the "Taverne" license above, 


\section{CONFIRMING YOUR WORST FEARS}

The relation between parenting behaviors, fear-enhancing cognitive biases, and anxiety in children

Lorraine Fliek 


\section{Confirming your worst fears}

The relation between parenting behaviors, fear-enhancing cognitive biases, and anxiety in children

PROEFSCHRIFT

ter verkrijging van de graad van doctor aan de Universiteit Maastricht, op gezag van de Rector Magnificus, Prof.dr. Rianne M. Letschert

volgens het besluit van het College van Decanen,

in het openbaar te verdedigen

op vrijdag 24 januari 2020 om 12.00 uur

door

Lorraine Fliek

Cover design: Julie (10 jaar), Emma-Fay (9 jaar), Saar (8 jaar), Lex (4 jaar) \& Renée (3 jaar)

Layout and design: Daniëlle Balk, www.persoonlijkproefschrift.n

Printed by: Ridderprint BV, www.ridderprint.nl

C) Lorraine Fliek, Maastricht 2020

ISBN: 978-94-6375-628-0 


\section{Promotor}

Prof. dr. Peter E.H.M. Muris

\section{Copromotor}

Dr. Jeffrey Roelofs

\section{Beoordelingscommissie}

Prof. dr. Frenk P.M.L. Peeters (voorzitter)

Prof. dr. Frans J.M. Feron

Prof. dr. Sandra A.A.N. Mulkens

Prof. dr. Maaike H. Nauta (Rijksuniversiteit Groningen)

Dr. Danielle Remmerswaal (Erasmus Universiteit Rotterdam)

\section{Table of contents}

Chapter 1 General introduction

Chapter 2 Rough-and-Tumble Play and Other Parental Factors as Correlates of Anxiety Symptoms in Preschool Children

Chapter 3 Fear-Related Confirmation Bias in Children: A Comparison Between Neutral- and Dangerous-Looking Animals

Chapter 4 Cognitive Bias as a Mediator in the Relation Between FearEnhancing Parental Behaviors and Anxiety Symptoms in Children: A Cross-Sectional Study

Chapter 5 A Longitudinal Study on the Relations Among Fear-Enhancing Parenting, Cognitive Biases, and Anxiety Symptoms in NonClinical Children

Chapter 6 Summary and General Discussion

Valorization addendum

Nederlandse samenvatting

Dankwoord 


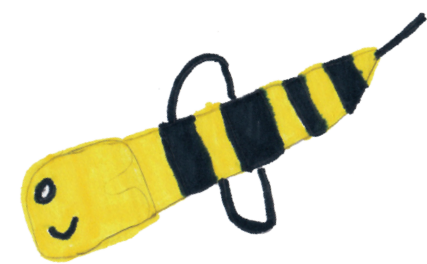

है

州

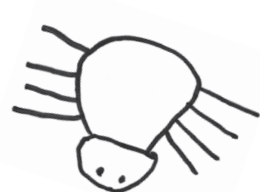

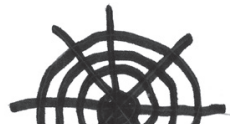

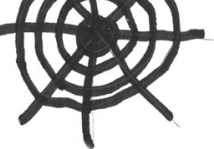

Chapter 1

General Introduction 


\section{Anxiety in children}

Fear and anxiety can be defined as specific sets of emotional responses arising from the anticipation of a real or imagined threat. Fear is characterized by a direct response to an aversive stimulus or situation, whereas anxiety is related to the anticipation of a potential threat (American Psychiatric Association, 2013). Fear and anxiety are common during childhood and tend to follow a predictable course during development. At a young age, children may be anxious of loud noises and separation from their caregivers. At preschool age, anxiety becomes more complex and children begin to fear animals, the dark, and fantasy creatures. From age 8 onwards, children may develop anxiety and worries about physical injury, fitting in socially, as well as their performance at school. In adolescence and adulthood, fears typically involve themes of social acceptance, achievement, and death (Muris, Merckelbach, Meesters, \& van den Brand, 2002; Vasey, 1993; Westenberg, Drewes, Goedhart, Siebelink, \& Treffers, 2004). Most of these fears are normal, adaptive, and transient phenomena that evolve in parallel to the social-emotional and cognitive development of children. However, in a substantial minority of children, the fear and anxiety becomes too intense, too frequent, and too persistent, thereby developing into a full-blown anxiety disorder.

According to the current Diagnostic and Statistical Manual of Mental Disorders (DSM-5; American Psychiatric Association, 2013), the following anxiety disorders can be discerned: separation anxiety disorder (an unusually strong fear or anxiety to get separated from attachment figures), selective mutism (a consistent failure to speak in specific social situations in which there is an expectation for speaking despite speaking in other situations), specific phobia (an intense and irrational fear of a specified object or situation), social phobia (a marked and persistent fear of socia or performance situations in which embarrassment may occur and where someone can possibly be negatively evaluated or scrutinized by others), panic disorder (based primarily on the occurrence of panic attacks, which are episodes of intense fear that occur without an obvious external reason), agoraphobia (a disproportionate fear of public places), and generalized anxiety disorder (excessive anxiety and worry about a variety of topics, events, or activities).

Anxiety disorders are among the most common psychological disorders in children and adolescents (Costello, Mustillo, Erkanli, Keeler, \& Angold, 2003; Ford, Goodman, \& Meltzer, 2003; Polanczyk, Salum, Sugaya, Caye, \& Rohde, 2015; Roza, Hofstra, van der Ende, \& Verhulst, 2003). About 29\% of the general population has experienced an anxiety disorder at least once during their lifetime (Kessler et al., 2005). For children

1 In the remainder of this dissertation, the term "children" will be used to refer to children as well as adolescents. under the age of 16, this percentage is around 10\% (Costello et al., 2003). This means that these children at some point during their development, have experienced such severe fear and anxiety symptoms that they are significantly impaired in their emotional, social, academic, and later occupational functioning (Essau, Conradt, \& Petermann, 2000). Anxiety disorders often follow a chronic course into adulthood with an early age of onset at an average of 11 years and a high projected risk percentage of $31.5 \%$ (indicating the percentage of people in the population who would ever have experienced an anxiety disorder by age 75; Kessler et al., 2005). The risk for other types of psychopathology, in particular depression, will also be increased (Cole, Peeke, Martin, Truglio, \& Seroczynski, 1998; Cummings, Caporino, \& Kendall, 2014).

Given the high prevalence of anxiety disorders and their serious impact on children's life, it is important to get more insight into the risk/vulnerability as well as protective factors that play a role in the development of this type of psychopathology The main purpose of the studies presented in this dissertation is to add to this knowledge. In this introductory chapter, theories on the etiology of anxiety pathology in children will be discussed, focusing on cognitive vulnerability factors (in particular threat-related cognitive biases) and the transmission of anxiety via parents. It is important to note that the etiology of anxiety disorders is multifactorial in nature (Field \& Lester, 2010), and therefore additive and interactive effects of parenting behaviors and cognitive biases on childhood anxiety will also be extensively discussed. The chapter concludes with the outline and aims of the studies that were performed for this research project.

\section{Threat-related cognitive biases and their role in the development and maintenance of childhood anxiety}

Cognitive theories propose that biases in information processing and cognitive contro deficits play an important role in the etiology of anxiety disorders (e.g., Mathews \& MacLeod, 2005). Insight regarding the occurrence of anxiety and its underlying cognitive processes could lead to better methods for preventing or treating anxiety. Therefore, knowledge of the predictive value of cognitive biases in childhood anxiety is important. So far, the evidence for the relation between threat-related cognitive biases and anxiety problems has been mainly based on cross-sectional, correlational research, meaning that no conclusions about the directionality of the relationships can be drawn (see review by Puliafico \& Kendall, 2006). It remains unclear whether these biases really play a causal role in the pathogenesis of anxiety. However, researchers do agree on the fact that cognitive biases play a role in the maintenance and exacerbation of anxiety disorders. 
Crick and Dodge (1994) described a social information-processing (SIP) model consisting of six subsequent stages describing how information about the external and internal world is processed: (1) encoding, (2) interpretation, (3) clarification of goals, (4) response search or construction, (5) response selection, and eventually (6) enactment. Based on this model, anxiety-related cognitive biases are concerned with overactive schemas involving the themes of threat and danger (Harvey, Watkins, Mansell, \& Shafran, 2004), which manifest themselves as cognitive distortions that mainly occur during stage 1 and 2 (e.g., Daleiden \& Vasey, 1997).

In the encoding stage, during which information about the internal or external world is automatically perceived and encoded, anxious individuals tend to show an attention bias, meaning that they are more likely to shift their attention towards potentially threatening cues (e.g., Mathews \& MacLeod, 1985). This occurs on a subconscious level and may distort the information processing in subsequent stages. A typical way to assess this attention bias is the dot-probe task. The rationale underlying this task is that individuals are faster to respond to probe stimuli presented in an attended rather than an unattended region of the visual display. Threatening and neutral words or pictures are briefly presented on a computer screen. Anxious individuals respond faster to probes that replace threat rather than neutral stimuli, reflecting vigilance for threat, which is indeed supported by results of studies using this paradigm (Asmundson \& Stein, 1994; Vassilopoulos, 2005). A vigilance-avoidance pattern was found by Vassilopoulos (2005) who showed that high social anxiety was associated with an initial attentional tendency towards social threat words that were presented for 200 milliseconds, followed by attentional bias away from the same stimulus word type at 500 milliseconds. Attention bias is often already present early in life: preschool children (LoBue \& DeLoache, 2008) and even infants under the age of 1 year (LoBue \& DeLoache, 2010; Rakison \& Derringer, 2008; Thrasher \& LoBue, 2016) have been shown to display such attentional biases to snakes, spiders and threatening faces.

Following the encoding stage, meaning is attached to the information in the interpretation stage. Interpretation bias takes place at a more conscious level of awareness, and in the case of anxiety implies that ambiguous/neutral information is interpreted in a threatening way (Muris \& Field, 2013). For this bias, more cognitive and language abilities are needed, a well-developed theory of mind, and children have to be aware that there can be multiple outcomes for a given situation (Field \& Lester, 2010). Interpretation bias has typically been shown in children from age 7 onwards (see reviews by Muris, 2010; Muris \& Field, 2008). The most widely used method for measuring interpretation bias is the ambiguous stories paradigm, in which participants read a series of ambiguous sentences about everyday situations that end with an ambiguous word fragment that has to be completed. Children are asked to score the perceived level of threat or indicate how they would respond in such situations. From both types of responses it can be inferred whether children interpret the ambiguous scenarios as threatening or not. Interpretation bias has been demonstrated to be present in high-anxious non-referred children (e.g., Bell-Dolan, 1995; Bögels \& Zigterman, 2000; Muris, Luermans, Merckelbach, \& Mayer, 2000) as well as in children with anxiety disorders (e.g., Cannon \& Weems, 2010; Waters, Wharton, Zimmer-Gembeck, \& Craske, 2008). A study on the relation between interpretation bias and childhood anxiety has been conducted by Miers, Blöte, Bögels, and Westenberg (2008), who compared 37 socially anxious adolescents to a contro group of 36 non-socially anxious individuals aged 11-16 years. Both groups had to rate the likelihood of different interpretations of ambiguous social and non-social situations. The results indicated that negative interpretations of social situations were indicated as more likely by the high-anxious children, as compared to the control group. No difference between the high- and low-anxious children was found with regard to positive interpretations. The study also showed a content-specific interpretation bias: that is, socially anxious adolescents only showed the bias in response to social situations, and not to non-social situations. Similar results were obtained by other researchers (Constans, Penn, Ihen, \& Hope, 1999; Stopa \& Clark, 2000; Voncken, Bögels, \& de Vries, 2003).

A further bias occurring after the interpretation stage is confirmation bias. Confirmation bias refers to the phenomenon that anxious individuals tend to rely on information that confirms their beliefs about the dangerousness of the situation, while ignoring information that might disconfirm this threat (De Jong, Mayer, \& Van Den Hout, 1997). This type of bias is typically measured using an information search paradigm, in which participants can look for additional negative or positive information in relation to a potential threatening stimulus (often an unknown animal) or situation. A threat-related confirmation bias, indicated by the search of more negative information and less positive information, has been linked to childhood anxiety in several studies (e.g., Dibbets, Fliek, \& Meesters, 2015; Dibbets \& Meesters, 2017; Remmerswaal, Huijding, Bouwmeester, Brouwer, \& Muris, 2014). The information search paradigm is explained in a study by Remmerswaal et al. (2014). In this study, 171 non-clinical children between 8-13 years were first provided with threatening, ambiguous, or positive information about an unknown animal (i.e., cuscus, quoll, or quokka). Participants then conducted a computerized information search task during which they had the possibility to collect additional negative, neutral, or positive information about the animal. Fear levels were repeatedly assessed during the task, making it possible for the researchers to examine temporal relations between bias 
and anxiety. The results indicated that a confirmation bias, indicated by a stronger tendency to search for negative information, led to higher levels of fear, that in turn further enhanced the search for negative information. Thus, these researchers found evidence for a reciprocal relation between confirmation bias and fear in children.

The different types of cognitive biases can be measured in various ways. More automatic biases that occur earlier in information processing are mostly assessed by means of reaction time paradigms, while biases that occur later are mostly measured by self-report-based tasks. In the current dissertation, emphasis will be put on the latter (i.e. interpretation bias and confirmation bias). These biases are related to different types of anxiety disorders (e.g., Bögels \& Zigterman, 2000; Remmerswaal et al., 2014) and tend to emerge in the middle childhood years (around the age of 7). Previous research on cognitive biases mostly used animals as stimuli. In this dissertation, we will also use stories relating to situations of children's everyday life, thereby increasing the ecological validity of the studies. Furthermore, whereas most research in this domain has focused on studying only one type of bias, our research included two biases, providing the opportunity to examine whether such biases are inter-related and make independent contributions to anxiety.

\section{Parenting factors in the development and maintenance of childhood anxiety}

There is evidence indicating that heritability plays a significant role in the etiology of childhood fear and anxiety problems, with behavioral-genetic studies showing that about $30 \%$ of the variation in anxiety disorders can be ascribed to genetic influences (Eley \& Gregory, 2004). This leaves substantial room for environmental factors to play a role in the development of children's fear and anxiety problems, and among these factors parenting behaviors are considered to be particularly relevant (Murray, Creswell, \& Cooper, 2009).

An important notion related to parenting factors is related to the involvement of both parents in research. The studies in this dissertation in which parents were involved all included both mothers and fathers, while previous studies have mostly included only mothers. The role of fathers has often been neglected in this research area, although there is evidence pointing out that fathers do have a unique and often different role in the development of anxiety in children (e.g., Bögels \& Phares, 2008)

A variety of parental risk factors have been proven to be related to childhood anxiety, among which overprotection, overcontrol, inconsistency, hostility, lack of warmth, anxious modeling and threat information transmission (Fisak \& GrillsTaquechel, 2007; Hudson \& Rapee, 2001; Moore, Whaley, \& Sigman, 2004; Moss, Cyr, \& Dubois-Comtois, 2004; Wolfradt, Hempel, \& Miles, 2003). Next to these parental risk factors for the development of anxiety, protective parenting may be at work as well. As opposed to parental risk factors, protective factors could prevent the child from developing anxiety.

One of these protective parenting factors is rough-and-tumble (R\&T) play, which refers to the phenomenon that parents expose their children to a physically vigorous set of behaviors such as chase, jump, and play fight, accompanied by positive affect from the players towards each other (Pellegrini, 1995). Next to the physical play, it also involves a socio-emotional component that includes parental behavior such as competing with the child or teasing. Parents who frequently engage in R\&T play are believed to learn their children to interpret the internal arousal that is elicited during these exciting activities (e.g., accelerated heart rate) as 'fun and pleasure' rather than 'fear and anxiety', thereby making them more tolerant to such arousal in other socially and physically challenging situations (Bögels \& Perotti, 2011; Bögels \& Phares, 2008).

Next to R\&T play as a potential protective factor against the development of childhood anxiety, this dissertation will focus on two parental risk factors: modeling and threat information transmission. Both factors have been described as indirect pathways to fear in the three pathways model to fear by Rachman $(1977,1991)$, the third of which is constituted by the direct path of classical conditioning (which will not be addressed in current dissertation).

Parental modeling of anxiety can be described as the visual display of fear or the verbal expression of their own anxiety in the presence of the child (Fisak \& Grills-Taquechel, 2007). One of the first experiments on the modeling of fear was conducted by Mineka, Davidson, Cook, and Keir (1984). In this animal study, young rhesus monkeys acquired a persistent fear of snakes after they had seen their parents' fearful response to real, toy, or model snakes. In humans, there is also research investigating the influence of fearful modeling responses of mothers on young children's behavior. For instance, Gerull and Rapee (2002) confronted toddlers between 15 and 20 months old with rubber toy animals (i.e., spider, snake), while their mother maintained either a negative or a positive facial expression. After a brief delay, children were exposed to the toy animals for a second time to measure fear and avoidance reactions. This time their mother was not present. The results showed that toddlers showed more fear and avoidance when the toy animals had been previously paired with a negative expression of their mother than the toddlers for whom the toy animals had been paired with a positive facial expression of their mother (see also Dubi, Rapee, Emerton, \& Schniering, 2008). These findings are consistent with other studies, which have shown that anxiety can be induced by means of anxious modeling (Burstein \& Ginsburg, 2010; Muris, Merckelbach, \& Collaris, 1997; Muris, Steerneman, Merckelbach, \& Meesters, 1996; Ollendick \& King, 1991). 
The second indirect pathway, threat information transmission, can be defined by parents installing fear and anxiety in their offspring by telling them directly about the dangerousness of particular stimuli and situations. A recent study in which an experimental approach was adopted has investigated this pathway in more detail (Muris, van Zwol, Huijding, \& Mayer, 2010). The effects of threat information transmission from parents to children aged between 8 and 13 years $(N=88)$ was studied. Parents were provided with either negative, positive, or ambiguous information about an unknown animal after which they were presented with a number of openended vignettes describing hypothetical confrontations with the animal. Parents were then instructed to tell their children what would happen in these situations. Results demonstrated that parents who had received negative information provided more threatening narratives about the animal and thereby installed higher levels of fear in their child than parents who had received positive information. With regard to ambiguous information, parents' trait anxiety levels predicted the transmission of fear: that is, the higher the trait anxiety level of the parents, the more they were inclined to share negative information about the unknown animal on the basis of the ambiguous information, thereby producing higher fear levels in the child. Several other studies have also shown that anxiety can be induced in non-anxious individuals by providing them with negative information (Muris, Mayer, Borth, \& Vos, 2013; Remmerswaal \& Muris, 2011; Remmerswaal, Muris, \& Huijding, 2013). Altogether it can be stated that there is a steadily growing body of evidence showing that the two parenting behaviors of parental modeling and threat information transmission can enhance fear and anxiety in children (see reviews by Askew \& Field, 2008; Muris \& Field, 2010).

\section{Threat-related cognitive biases, parenting behaviors, and childhood anxiety}

As already explained in the previous section, anxiety can be transmitted via modeling and threat information transmission from parents to their offspring. However, the exact mechanism of how anxiety is transmitted from parents to children remains unclear, as are the origins of threat-related cognitive biases. Like anxiety problems, the origins of anxiety-related cognitive biases are assumed to be rooted in genetic and environmental factors that also interact with each other (Hadwin \& Field, 2010; Muris \& Field, 2008).

We already discussed evidence from survey- as well as experimental studies on the relation between detrimental parenting (modeling and threat information transmission) and the development of anxiety in the previous section (e.g., Askew \& Field, 2008; Muris \& Field, 2010). Research has furthermore shown that parental modeling and threat information transmission could also induce cognitive biases in non-anxious individuals (Muris \& Field, 2013; Muris, Huijding, Mayer, \& Hameetman, 2008; Muris, Huijding, Mayer, Remmerswaal, \& Vreden, 2009a; Muris et al., 2009b; Remmerswaal, Muris, Mayer, \& Smeets, 2010).

From the previously mentioned findings (on the relations between detrimental parenting and cognitive biases as well as between cognitive biases and childhood anxiety) and current theoretical notions, we can deduce that cognitive biases could act as a potential mediator in the relation between detrimental parenting and childhood anxiety. There is evidence showing that genetic factors are associated with cognitive biases in the early stages of information processing (i.e., attentional biases; PérezEdgar et al., 2010; Thomason et al., 2010), whereas the contribution of heritability to anxiety-related cognitive biases during the later stages of information processing (such as interpretation bias and confirmation bias) has been shown to be more modest (Zavos, Rijsdijk, Gregory, \& Eley, 2010). For these biases, it seems more plausible to study the role of environmental factors such as familial influences of which parenting can be considered as highly relevant.

The role of parenting factors in the development of anxiety disorders in childhood was also highlighted in a review of Murray, Creswell, and Cooper (2009). The authors have outlined a cognitive-behavioral model in which parents' distorted cognitions during later stages of information processing (e.g., threat interpretation bias) fuel fearenhancing parenting behaviors such as modeling and threat information transmission, which will ultimately install anxious information processing biases in the child.

Further evidence on the relation between parenting and children's cognitive biases and anxiety was provided in a cross-sectional study (Affrunti \& Ginsburg, 2012) in which 75 parent-child dyads were investigated. All parents were diagnosed with an anxiety disorder, whereas none of the children (aged between 7-12 years) were diagnosed with an anxiety disorder. Children had to complete an ambiguous stories paradigm as an indication of interpretation bias and questionnaires were filled out related to parental overcontrol and children's anxiety. The results demonstrated that children's interpretation bias partially mediated the relation between parental overcontrol and children's anxiety.

Similar results were found in another study (Podină, Mogoaşe, \& Dobrean, 2013). Four-hundred-and-twenty-three mothers and their children with a mean age of 11.69 year $(S D=3.63$ ) participated in the study. Both mothers and children completed questionnaires measuring anxiety symptoms and interpretation bias. Results demonstrated that both mother as well as child interpretation biases were significant mediators in the relation between maternal social anxiety and children's anxiety symptoms 
More recent evidence for the role of parenting variables in the intergenerational transmission of cognitive biases was provided by Remmerswaal, Muris, and Huijding (2016) who investigated the role of parents in the development of cognitive biases and subsequent fear levels in non-clinical children (8 and 13 years). During two experiments children were confronted with a novel animal. In experiment 1 ( $N=122$ ), it was examined whether instructed verbal feedback of mothers could induce a confirmation bias, indicated by a negative search strategy, in their offspring. In experiment $2(N=49)$, the verbal feedback of mothers was spontaneous (driven by their own cognitive distortion), instead of constructed. The results of both studies demonstrated that the verbal feedback of the mothers had a significant effect on children's cognitive bias. More specifically, when mothers verbally encouraged their offspring to search for threat-related information about the animal (either provided on instruction or given spontaneously), children indeed displayed a stronger confirmation bias, that in turn also resulted in increased fear for the unknown animal.

Several other studies yielded similar findings and thus confirm that there are significant links between parental anxiety (and the accompanying detrimenta parenting behaviors) and children's cognitive biases and anxiety symptoms (Barrett, Rapee, Dadds, \& Ryan, 1996; Creswell, Cooper, \& Murray, 2010; Schneider, Unnewehr Florin, \& Margraf, 2002; Sicouri et al., 2017; Van Niekerk et al., 2018). In other words, research has shown that various detrimental parenting styles enhance cognitive biases in children and in turn also promote anxiety. In the current dissertation, the parenting variables of modeling and threat information transmission will be related to interpretation- and confirmation bias, and childhood anxiety.

\section{Aims and outline of the dissertation}

The main aim of the studies presented in this dissertation was to gain more insight in the relations between parenting behaviors, threat-related cognitive biases, and childhood anxiety. Another aim was to take into account the different roles of mothers and fathers, which can be seen as an improvement to previous studies that mainly focused on the role of mothers (e.g., Bögels \& Phares, 2008).

Parental R\&T play as a potential protective factor in the development of childhood anxiety was investigated in Chapter 2 . In this study, mothers and fathers of nonclinical children (aged 2 to 6 years) completed indices of childhood anxiety symptoms and parental trait anxiety and overprotection, as well as the Parental Play and Care Questionnaire (PPCQ), that was developed for the purpose of this study to assess parental R\&T play and care activities. This enabled us to examine (1) differences in R\&T play as well as care activities between both parents, with the expectation that fathers would exhibit more R\&T play with their children, whereas mothers would display more care behaviors. Furthermore, it was examined whether (2) R\&T play activities of both parents would differ depending on the gender of the child. Here we expected that in particular fathers would more often engage in R\&T play with boys than with girls, whereas such a distinction in the gender-specific employment of R\&T play was not predicted for mothers. We also investigated (3) the relations between R\&T play of parents on the one hand, and parental anxiety and overprotection on the other hand. It was hypothesized that more anxious and overprotective parents are more cautious and therefore engage less in R\&T play with their offspring. In addition, we examined (4) whether more R\&T play would be related to lower levels of anxiety symptoms in children, and (5) whether this link would still be present when controlling for common parental risk factors such as parental anxiety and overprotection. Finally, we explored (6) interactive effects of parental R\&T play and other familia risk factors on children's anxiety symptoms, which is in keeping with current theories suggesting that pathological anxiety in children results from a complex interplay of risk and protective factors (e.g., Mian, Wainwright, Briggs-Gowan, \& Carter, 2011) We anticipated that levels of anxiety symptoms would be particularly high in those children for which parents showed high risk behaviors (i.e., high levels of dispositional anxiety and overprotection) and low protective behaviors (i.e., low R\&T play).

The relation between a threat-related confirmation bias and anxiety was investigated in Chapter 3. Previous research has examined confirmation bias by (in) directly providing negative information. Providing such information might influence confirmation bias results due to a memory component. In this study, confirmation bias in children was examined without explicitly inducing fear. Non-clinical children (7-13 years) were shown pictures of a neutral animal (quokka) and two dangerouslooking animals (aye aye and possum). Levels of perceived fear and threat for each of the animals were measured by means of questionnaires and visual analogue scales. As an indication of confirmation bias, children were given the opportunity to request additional threatening or non-threatening information for the animals. A behavioral approach test (BAT) was included as a behavioral measure of fear. The aim of this study was to examine confirmation bias in children without providing threatening pre-information. It was expected that in case of perceived threat children would show an increased search for threatening information and a decreased search for nonthreatening information.

Another important aim of this dissertation was to investigate the mediational role of cognitive biases in the relation between detrimental parenting behaviors and childhood anxiety. This was tested cross-sectionally (Chapter 4) as well as longitudinally (Chapter 5). 
The cross-sectional study in Chapter 4 explored relations between parenting behaviors (modeling and verbal threat information transmission) and child anxiety symptoms, while taking into account the role of two types of cognitive biases: confirmation bias and interpretation bias. Participants were non-clinical children aged 7-12 years and both of their parents. Children and parents completed the Parental Enhancement of Anxious Cognitions (PEAC) questionnaire, which measures parental modeling and threat information transmission, while children also filled in a scale for assessing anxiety symptoms. In addition, a number of computerized tasks for measuring confirmation and interpretation bias were completed by the children. Parents also completed measures of trait anxiety and overprotection. This study adds to our knowledge in four ways: (1) a newly developed questionnaire was used, making it possible to simultaneously examine both modeling and threat information transmission as predictors of children's cognitive biases and anxiety symptoms; (2) The fear-enhancing parental behaviors of both parents were investigated, which has been an omission in previous studies; (3) Two types of cognitive biases (interpretation bias and confirmation bias) were assessed. Most research has focused on only one type of bias, thereby neglecting the issue of whether such biases are inter-related and make independent contributions to anxiety; (4) We furthermore investigated to what extent the fear-enhancing parental behaviors of modeling and threat information transmission were associated with parental trait anxiety and overprotection; two well-known parental correlates of childhood anxiety problems (Hudson \& Rapee, 2001: Last, Hersen, Kazdin, Orvaschel, \& Perrin, 1991). Based on previous studies we expected that higher levels of fear-enhancing parenting behaviors would be associated with higher levels of trait anxiety and overprotection of parents.

Longitudinal associations between fear-enhancing parenting behaviors (modeling and threat information transmission) and children's cognitive biases and anxiety symptoms were investigated in Chapter 5 . In this study, these relations were explored on three subsequent time points over a one-year period. Participants were nonclinical children (7-12 years) and their mothers and/or fathers. On each time point, children and parents completed the same measures as the ones indicated in the crosssectional study of the previous chapter. The difference from the cross-sectional study was that we only took the child-reported data into account for this longitudinal study, a procedure that was followed because cross-informant correlations were generally weak and in most cases non-significant. Based on the most current theoretica notions and the findings of previous studies (Barrett et al., 1996; Fliek, Dibbets, Roelofs, \& Muris, 2017; Hadwin \& Field, 2010; Remmerswaal et al., 2016), it was hypothesized (1) to find support for a longitudinal mediational model in which the cognitive distortions of interpretation bias and confirmation bias mediate the relation between parenting behaviors (modeling and threat information transmission) and children's anxiety symptoms. We furthermore expected (2) that children's cognitive biases and anxiety symptoms would be stable over time. Another hypothesis was (3) that the cognitive biases would predict anxiety symptoms on subsequent time points (Beck, 1976; Harvey et al., 2004), as well as the other way around, (4) that these anxiety problems are in turn likely to lead to more cognitive biases (e.g., Remmerswaal et al., 2014)

Chapter 6 will provide a general overview and integration of the main findings of the studies described in Chapters 2-5, including possible implications and genera limitations, as well as recommendations for future research. 


\section{References}

Affrunti, N. W., \& Ginsburg, G. S. (2012). Exploring parental predictors of child anxiety: The mediating role of child interpretation bias. Child and Youth Care Forum, 41(6), 517-527. doi: 10.1007/s10566-012-9186-6

American Psychiatric Association. (2013). Diagnostic and statistical manual of mental disorders. (5th ed.). Washington, DC

Askew, C., \& Field, A. P. (2008). The vicarious learning pathway to fear 40 years on. Clinical Psychology Review, 28(7), 1249-1265. doi: 10.1016/j.cpr.2008.05.003

Asmundson, G. J. G., \& Stein, M. B. (1994). Selective processing of social threat in patients with generalized social phobia: Evaluation using a dot-probe paradigm. Journal of Anxiety Disorders, 8(2), 107-117. doi: 10.1016/0887-6185(94)90009-4

Barrett, P. M., Rapee, R. M., Dadds, M. M., \& Ryan, S. M. (1996). Family enhancement of cognitive style in anxious and aggressive children. Journal of Abnormal Child Psychology 24(2), 187-203. doi: 10.1007/BF01441484

Beck. A. T. (1976). Cognitive therapy and the emotional disorders. New York: International Universities Press.

Bell-Dolan, D. J. (1995). Social cue interpretation of anxious children. Journal of Clinical Child Psychology, 24(1), 2-10. doi: 10.1207/s15374424jccp2401_1

Bögels, S. M., \& Perotti, E. C. (2011). Does father know best? A formal model of the paterna influence on childhood social anxiety. Journal of Child and Family Studies, 20(2), 171-181. doi: 10.1007/s10826-010-9441-0

Bögels, S. M., \& Phares, V. (2008). Fathers' role in the etiology, prevention and treatment of child anxiety: A review and new model. Clinical Psychology Review, 28(4), 539-558, doi: 10.1016/i.cpr.2007.07.011

Bögels, S. M., \& Zigterman, D. (2000). Dysfunctional cognitions in children with social phobia, separation anxiety disorder, and generalized anxiety disorder. Journal of Abnormal Child Psychology, 28(2), 205-211. doi: 10.1023/a:1005179032470

Burstein, M.. \& Ginsburg, G. S. (2010). The effect of parental modeling of anxious behaviors and cognitions in school-aged children: An experimental pilot study. Behaviour Research and Therapy, 48(6), 506-515. doi: 10.1016/j.brat.2010.02.006

Cannon, M. F., \& Weems, C. F. (2010). Cognitive biases in childhood anxiety disorders: Do interpretive and judgment biases distinguish anxious youth from their non-anxious peers? Journal of Anxiety Disorders, 24(7), 751-758. doi: 10.1016/j.janxdis.2010.05.008

Cole, D. A., Peeke, L. G., Martin, J. M., Truglio, R., \& Seroczynski, A. D. (1998). A longitudinal look at the relation between depression and anxiety in children and adolescents. Journa of Consulting and Clinical Psychology, 66(3), 451-460. doi: 10.1037/0022-006x.66.3.451

Constans, J. I. Penn, D. L, Ihen, G.H. \&Hope, D. A. (1999). Interpretive biases for ambiguous stimuli in social anxiety. Behaviour Research and Therapy, 37(7), 643-651. doi: 10.1016/ S0005-7967(98)00180-6

Costello, E., Mustillo, S., Erkanli, A., Keeler, G., \& Angold, A. (2003). Prevalence and development of psychiatric disorders in childhood and adolescence. Archives of General Psychiatry, 60(8), 837-844. doi: 10.1001/archpsyc.60.8.837

Creswell, C., Cooper, P., \& Murray, L. (2010). Intergenerational transmission of anxious information processing biases. In J. A. Hadwin \& A. P. Field (Eds.), Information processing biases and anxiety. A developmental perspective (pp. 279-296): Chichester, UK: Wiley.
Crick, N. R., \& Dodge, K. A. (1994). A review and reformulation of social information-processing mechanisms in children's social adjustment. Psychological Bulletin, 115(1), 74-101. doi: 10.1037/0033-2909.115.1.74

Cummings, C. M., Caporino, N. E., \& Kendall, P. C. (2014). Comorbidity of anxiety and depression in children and adolescents: 20 years after. Psychological Bulletin, 140(3) 816 845 doi: 10.1037/a0034733

Daleiden, E. L., \& Vasey, M. W. (1997). An information-processing perspective on childhood anxiety. Clinical Psychology Review, 17(4), 407-429. doi: 10.1016/S0272-7358(97)00010-X

De Jong, P. J., Mayer, B., \& Van Den Hout, M. (1997). Conditional reasoning and phobic fear: Evidence for a fear-confirming reasoning pattern. Behaviour Research and Therapy, 35(6), 507-516. doi: 10.1016/S0005-7967(96)00124-6

Dibbets, P., Fliek, L., \& Meesters, C. (2015). Fear-related confirmation bias in children: A comparison between neutral-and dangerous-looking animals. Child Psychiatry and Human Development, 46(3), 418-425. doi: 10.1007/s10578-014-0481-3

Dibbets, P. \& Meesters, C. (2017). The influence of stimulus valence on confirmation bias in children. Journal of Behavior Therapy and Experimental Psychiatry, 54, 88-92. doi: 10.1016/j. jbtep.2016.07.007

Dubi, K., Rapee, R., Emerton, J., \& Schniering, C. (2008). Maternal modeling and the acquisition of fear and avoidance in toddlers: Influence of stimulus preparedness and child temperament. Journal of Abnormal Child Psychology, 36(4), 499-512. doi: 10.1007/ s10802-007-9195-3

Eley, T. C., \& Gregory, A. M. (2004). Behavioral genetics. In T. M. Morris \& J. S. March (Eds.) Anxiety disorders in children and adolescents (pp. 71-97). New York: Guilford Press.

Essau, C. A., Conradt, J., \& Petermann, F. P. (2000). Frequency, comorbidity, and psychosocia impairment of anxiety disorders in german adolescents. Journal of Anxiety Disorders, 14(3) 263-279. doi: 10.1016/S0887-6185(99)00039-0

Field, A. P., \& Lester, K. J. (2010). Is there room for 'development' in developmental models of information processing biases to threat in children and adolescents? Clinical Child and Family Psychology Review, 13(4), 315-332. doi: 10.1007/s10567-010-0078-8

Fisak, B., \& Grills-Taquechel, A. E. (2007). Parental modeling, reinforcement, and information transfer: Risk factors in the development of child anxiety? Clinical Child and Family Psychology Review, 10(3), 213-231. doi: 10.1007/s10567-007-0020-x

Fliek, L., Dibbets, P., Roelofs, J., \& Muris, P. (2017). Cognitive bias as a mediator in the relation between fear-enhancing parental behaviors and anxiety symptoms in children: A crosssectional study. Child Psychiatry and Human Development, 48(1), 82-93. doi: 10.1007/ s10578-016-0655-2

Ford, T., Goodman, R., \& Meltzer, H. (2003). The British child and adolescent mental health survey 1999: The prevalence of DSM-IV disorders. Journal of the American Academy of Child and Adolescent Psychiatry, 42(10). 1203-1211. doi: 10.1097/00004583-200310000-00011

Gerull, F. C. \& Rapee, R. M. (2002). Mother knows best: Effects of maternal modelling on the acquisition of fear and avoidance behaviour in toddlers. Behaviour Research and Therapy, 40(3), 279-287. doi: 10.1016/S0005-7967(01)00013-4

Hadwin, J. A., \& Field, A. P. (2010). Information processing biases and anxiety: A developmenta perspective. Chichester: Wiley-Blackwell.

Harvey, A. G., Watkins, E., Mansell, W., \& Shafran, R. (2004) Cognitive behavioural processes across psychological disorders: A transdiagnostic approach to research and treatment. Oxford: Oxford University Press 
Hudson, J. L., \& Rapee, R. M. (2001). Parent-child interactions and anxiety disorders: An observational study. Behaviour Research and Therapy, 39(12), 1411-1427. doi: 10.1016/ S0005-7967(00)00107-8

Kessler, R. C., Berglund, P., Demler, O., Jin, R., Merikangas, K. R., \& Walters, E. E. (2005). Lifetime prevalence and age-of-onset distributions of DSM-IV disorders in the National Comorbidity Survey Replication. Archives of General Psychiatry, 62(6), 593-602. doi: 10.1001/archpsyc.62.6.593

Last, C. G., Hersen, M., Kazdin, A., Orvaschel, H., \& Perrin, S. (1991). Anxiety disorders in children and their families. Archives of General Psychiatry, 48(10), 928-934. doi: 10.1001/ archpsyc.1991.01810340060008

LoBue, V., \& DeLoache, J. S. (2008). Detecting the snake in the grass: Attention to fearrelevant stimuli by adults and young children. Psychological Science, 19(3), 284-289. doi: 10.1111/j.1467-9280.2008.02081.x

LoBue, V., \& DeLoache, J. S. (2010). Superior detection of threat-relevant stimuli in infancy. Developmental Science, 13(1), 221-228. doi: 10.1111/j.1467-7687.2009.00872.x

Mathews, A., \& MacLeod, C. (1985). Selective processing of threat cues in anxiety states. Behaviour Research and Therapy, 23(5), 563-569. doi: 10.1016/0005-7967(85)90104-4

Mathews, A., \& MacLeod, C. (2005). Cognitive vulnerability to emotional disorders. Annual Review of Clinical Psychology, 1, 167-195. doi: 10.1146/annurev.clinpsy.1.102803.143916

Mian, N. D., Wainwright, L., Briggs-Gowan, M. J., \& Carter, A. S. (2011). An ecological risk mode for early childhood anxiety: The importance of early child symptoms and temperament. Journal of Abnormal Child Psychology, 39(4), 501-512. doi: 10.1007/s10802-010-9476-0

Miers, A. C., Blöte, A. W., Bögels, S. M., \& Westenberg, P. M. (2008). Interpretation bias and social anxiety in adolescents. Journal of Anxiety Disorders, 22(8), 1462-1471. doi: 10.1016/J. janxdis.2008.02.010

Mineka, S., Davidson, M.. Cook, M. \& Keir. R. (1984). Observational conditioning of snake fear in rhesus monkeys. Journal of Abnormal Psychology, 93(4), 355-372. doi: 10.1037/0021 843x.93.4.355

Moore, P. S., Whaley, S. E., \& Sigman, M. (2004). Interactions between mothers and children: Impacts of maternal and child anxiety. Journal of Abnormal Psychology, 113(3), 471-476. doi: 10.1037/0021-843x.113.3.471

Moss, E., Cyr, C., \& Dubois-Comtois, K. (2004). Attachment at early school age and developmental risk: examining family contexts and behavior problems of controlling caregiving, controlling-punitive, and behaviorally disorganized children. Developmental Psychology, 40(4), 519-532. doi: 10.1037/0012-1649.40.4.519

Muris, P. (2010). Anxiety-related reasoning biases in children and adolescents. In J. Hadwin \& A. P. Field (Eds.), Information processing biases and anxiety: A developmental perspective. Chichester: Wiley-Blackwell.

Muris, P. \& Field, A. (2013). Information processing biases. In Essau C. A. \& Ollendick T. H. (Eds.), The Wiley-Blackwell handbook of the treatment of childhood and adolescent anxiety (pp. 141-156). Chichester: Wiley-Blackwel.

Muris, P., \& Field, A. P. (2008). Distorted cognition and pathological anxiety in children and adolescents Cognition and Emotion, 22(3), 395-421 doi: 10.1080/02699930701843450

Muris, P., \& Field, A. P. (2010). The role of verbal threat information in the development of childhood fear. "Beware the Jabberwock!". Clinical Child and Family Psychology Review. 13(2), 129-150. doi: 10.1007/s10567-010-0064-1
Muris, P., Huijding, J., Mayer, B., \& Hameetman, M. (2008). A space odyssey: experimental manipulation of threat perception and anxiety-related interpretation bias in children. Child Psychiatry and Human Development, 39(4), 469-480. doi: 10.1007/s10578-008-0103-z

Muris, P. Huijding, J., Mayer, B., Remmerswaal, D. \& Vreden, S. (2009a). Ground control to Major Tom: Experimental manipulation of anxiety-related interpretation bias by means of the "space odyssey" paradigm and effects on avoidance tendencies in children. Journal of Anxiety Disorders, 23(3), 333-340. doi: 10.1016/i.janxdis.2009.01.004

Muris, P., Luermans, J., Merckelbach, H., \& Mayer, B. (2000). "Danger is lurking everywhere". The relation between anxiety and threat perception abnormalities in normal children. Journal of Behavior Therapy and Experimental Psychiatry, 31(2), 123-136. doi: 10.1016/ s0005-7916(00)00016-1

Muris, P., Mayer, B., Borth, M., \& Vos, M. (2013). Nonverbal and verbal transmission of disgust from mothers to offspring: Effects on children's evaluation of a novel animal. Behavior Therapy, 44(2), 293-301. doi: 10.1016/j.beth.2012.10.002

Muris, P., Merckelbach, H., \& Collaris, R. (1997). Common childhood fears and their origins. Behaviour Research and Therapy, 35(10), 929-937. doi: 10.1016/S0005-7967(97)00050-8

Muris, P., Merckelbach, H., Meesters, C., \& van den Brand, K. (2002). Cognitive development and worry in normal children. Cognitive Therapy and Research, 26(6), 775-787. doi: 10.1023/a:1021241517274

Muris, P., Rassin, E., Mayer, B., Smeets, G., Huijding, J., Remmerswaal, D., \& Field, A. (2009b). Effects of verbal information on fear-related reasoning biases in children. Behaviour Research and Therapy, 47(3), 206-214. doi: 10.1016/j.brat.2008.12.002

Muris, P., Steerneman, P., Merckelbach, H., \& Meesters, C. (1996). The role of parental fearfulness and modeling in children's fear. Behaviour Research and Therapy, 34(3), 265 268. doi: 10.1016/0005-7967(95)00067-4

Muris, P., van Zwol, L., Huijding, J., \& Mayer, B. (2010). Mom told me scary things about this animal: Parents installing fear beliefs in their children via the verbal information pathway. Behaviour Research and Therapy, 48(4), 341-346. doi: 10.1016/j.brat.2009.12.001

Murray, L., Creswell, C., \& Cooper, P. J. (2009). The development of anxiety disorders in childhood: An integrative review. Psychological Medicine, 39(9), 1413-1423. doi: 10.1017/ s0033291709005157

Ollendick, T. H., \& King, N. J. (1991). Origins of childhood fears: An evaluation of Rachman's theory of fear acquisition. Behaviour Research and Therapy, 29(2), 117-123. doi 10.1016/0005-7967(91)90039-6

Pellegrini, A. D. (1995). A longitudinal study of boys' rough-and-tumble play and dominance during early adolescence. Journal of Applied Developmental Psychology, 16(1), 77-93. doi: 10.1016/0193-3973(95)90017-9

Pérez-Edgar, K., Bar-Haim, Y., McDermott, J. M., Gorodetsky, E., Hodgkinson, C. A., Goldman, D..... Fox, N. A. (2010). Variations in the serotonin-transporter gene are associated with attention bias patterns to positive and negative emotion faces. Biological Psychology, 83(3), 269-271. doi: 10.1016/j.biopsycho.2009.08.009

Podină, I. R., Mogoașe, C., \& Dobrean, A. (2013). Intergenerational transmission of anxiety: Evidence for the mediating role of the negative interpretation bias. Journal of Cognitive and Behavioral Psychotherapies, 13(2), 309-320. 
Polanczyk, G. V., Salum, G. A., Sugaya, L. S., Caye, A., \& Rohde, L. A. (2015). Annual Research Review: A meta-analysis of the worldwide prevalence of mental disorders in children and adolescents. Journal of Child Psychology and Psychiatry, 56(3), 345-365. doi: 10.1111 jcpp.12381

Puliafico, A. C., \& Kendall, P. C. (2006). Threat-related attentional bias in anxious youth: A review. Clinical Child and Family Psychology Review, 9(3), 162-180. doi: 10.1007/s10567006-0009-x

Rachman, S. (1977). The conditioning theory of fearacquisition: A critical examination. Behaviour Research and Therapy, 15(5), 375-387. doi: 10.1016/0005-7967(77)90041-9

Rachman, S. (1991). Neo-conditioning and the classical theory of fear acquisition. Clinical Psychology Review, 11(2), 155-173. doi: 10.1016/0272-7358(91)90093-A

Rakison, D. H., \& Derringer, J. (2008). Do infants possess an evolved spiderdetection mechanism? Cognition, 107(1), 381-393. doi: https://doi.org/10.1016/j. cognition.2007.07.022

Remmerswaal, D., Huiiding, J., Bouwmeester, S., Brouwer, M., \& Muris, P. (2014). Cognitive bias in action: Evidence for a reciprocal relation between confirmation bias and fear in children Journal of Behavior Therapy and Experimental Psychiatry, 45(1), 26-32. doi: 10.1016/j. jbtep.2013.07.005

Remmerswaal, D., \& Muris, P. (2011). Children's fear reactions to the 2009 Swine Flu pandemic: The role of threat information as provided by parents. Journal of Anxiety Disorders, 25(3) 444-449. doi: 10.1016/.j.janxdis.2010.11.008

Remmerswaal, D., Muris, P., \& Huijding, J. (2013). "Watch out for the gerbils, my child!” The role of maternal information on children's fear in an experimental setting using real animals. Behavior Therapy, 44, 317-324. doi: 10.1016/j.beth.2013.01.001

Remmerswaal, D., Muris, P., \& Huijding, J. (2016). Transmission of cognitive bias and fear from parents to children: An experimental study. Journal of Clinical Child and Adolescent Psychology, 45(5), 642-654. doi: 10.1080/15374416.2014.987378

Remmerswaal, D., Muris, P., Mayer, B., \& Smeets, G. (2010). "Will a Cuscus bite you, if he shows his teeth?" Inducing a fear-related confirmation bias in children by providing verbal threat information to their mothers. Journal of Anxiety Disorders, 24(5), 540-546. doi: 10.1016/j. janxdis.2010.03.012

Roza, S. J., Hofstra, M. B., van der Ende, J., \& Verhulst, F. C. (2003). Stable prediction of mood and anxiety disorders based on behavioral and emotional problems in childhood: A 14year follow-up during childhood, adolescence, and young adulthood. American Journal of Psychiatry, 160(12), 2116-2121. doi: 10.1176/appi.ajp.160.12.2116

Schneider, S., Unnewehr, S., Florin, I., \& Margraf, J. (2002). Priming panic interpretations in children of patients with panic disorder. Journal of Anxiety Disorders, 16(6), 605-624. doi: 10.1016/S0887-6185(02)00126-3

Sicouri, G., Sharpe, L., Hudson, J. L., Dudeney, J., Jaffe, A., Selvadurai, H..... Hunt, C. (2017). Threat interpretation and parental influences for children with asthma and anxiety. Behaviour Research and Therapy, 89, 14-23. doi: 10.1016/j.brat.2016.11.004

Stopa, L., \& Clark, D. M. (2000). Social phobia and interpretation of social events. Behaviour Research and Therapy, 38(3), 273-283. doi: 10.1016/S0005-7967(99)00043-1

Thomason, M. E., Henry, M. L., Hamilton, J. P., Joormann, J., Pine, D. S., Ernst, M..... Britton, J. C. (2010). Neural and behavioral responses to threatening emotion faces in children as a function of the short allele of the serotonin transporter gene. Biological Psychology, 85(1), 38-44. doi: 10.1016/j.biopsycho.2010.04.009
Thrasher, C., \& LoBue, V. (2016). Do infants find snakes aversive? Infants' physiological responses to "fear-relevant" stimuli. Journal of Experimental Child Psychology, 142, 382 390. doi: https://doi.org/10.1016/j.jecp.2015.09.013

Van Niekerk, R. E., Klein, A. M., Allart-van Dam, E., Rinck, M., Souren, P. M., Hutschemaekers, G. J. M., \& Becker. E. S. (2018). Biases in interpretation as a vulnerability factor for children of parents with an anxiety disorder. Journal of the American Academy of Child and Adolescent Psychiatry, 57(7), 462-470. doi: 10.1016/j.jaac.2018.04.009

Vasey, M. W. (1993). Development and cognition in childhood anxiety: The example of worry. Advances in Clinical Child Psychology, 15, 1-39.

Vassilopoulos, S. P. (2005). Social anxiety and the vigilance-avoidance pattern of attentiona processing. Behavioural and Cognitive Psychotherapy, 33(1), 13-24 doi: $10.1017 /$ s1352465804001730

Voncken, M. J., Bögels, S. M., \& de Vries, K. (2003). Interpretation and judgmental biases in social phobia. Behaviour Research and Therapy, 41(12), 1481-1488. doi: https://dol. org/10.1016/S0005-7967(03)00143-8

Waters, A. M., Wharton, T. A., Zimmer-Gembeck, M. J., \& Craske, M. G. (2008). Threat-based cognitive biases in anxious children: Comparison with non-anxious children before and after cognitive behavioural treatment. Behaviour Research and Therapy, 46(3), 358-374. doi: 10.1016/j.brat.2008.01.002

Westenberg, P. M., Drewes, M. J., Goedhart, A. W., Siebelink, B. M., \& Treffers, P. D. A. (2004) A developmental analysis of self-reported fears in late childhood through mid-adolescence: social-evaluative fears on the rise? Journal of Child Psychology and Psychiatry 45(3), 481 495. doi: 10.1111/j.1469-7610.2004.00239x

Wolfradt, U., Hempel, S., \& Miles, J. N. V. (2003). Perceived parenting styles, depersonalisation, anxiety and coping behaviour in adolescents. Personality and Individual Differences, 34(3), 521-532. doi: 10.1016/S0191-8869(02)00092-2

Zavos, H. M., Rijsdijk, F. V., Gregory, A. M., \& Eley, T. C. (2010). Genetic influences on the cognitive biases associated with anxiety and depression symptoms in adolescents. Journa of Affective Disorders, 124(1), 45-53. doi: 10.1016/j.jad.2009.10.030 


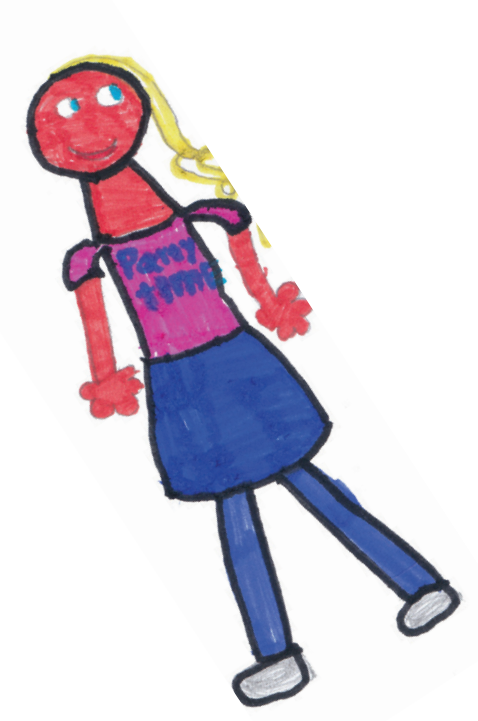

ChAPTER 2

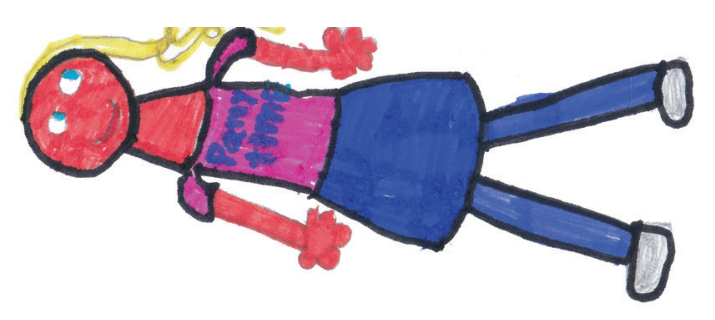

Rough-and-Tumble Play and Other Parental Factors as

Correlates of Anxiety Symptoms in Preschool Children

Lorraine Fliek, Ellen Daemen, Jeffrey Roelofs, Peter Muris

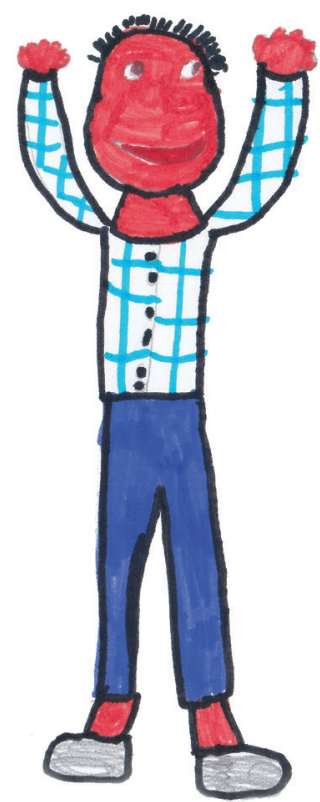




\section{Abstract}

The present study investigated the relationship between parental rough-and-tumble (R\&T) play and young children's anxiety symptoms. Parents of 105 non-clinical children ( 61 boys and 44 girls aged between 2 and 6 years) completed indices of childhood anxiety symptoms and parental trait anxiety and overprotection, as wel as the Parental Play and Care Questionnaire (PPCQ), which was developed for the purpose of this study to assess parental R\&T play and care activities. Results showed that fathers exhibited more R\&T play towards their offspring, while mothers more often engaged in care activities. As predicted, trait anxiety and overprotection of mothers were positively related to child anxiety symptoms. No support was found for the idea that parental R\&T play would be negatively related to childhood anxiety However, an interaction effect of fathers' trait anxiety and R\&T play on anxiety symptoms of the child was found: children tended to display higher levels of anxiety symptoms when their low trait anxious fathers were more involved in R\&T play. The results provide support for the notion that mothers and fathers have unique parenting roles, which may have a differential impact on the development of anxiety symptoms in children.

Keywords: children's anxiety; rough-and-tumble play; parental anxiety; overprotective parenting

\section{Introduction}

Fear and anxiety are common in childhood (Muris \& Field, 2011). In general, these phenomena have a normative character as they occur in response to developmental challenges which children usually learn to master within a relatively short period of time. However, a sizable minority of the children develop an anxiety disorder: in these cases the emotional symptoms become so chronic and intense that they start to interfere with daily functioning (Costello, Mustillo, Erkanli, Keeler, \& Angold, 2003). It is a well-established fact that fear, anxiety, and their disorders run in families. According to top-down studies, children of parents with anxiety disorders are more likely to suffer from anxiety problems than children of non-anxious parents (e.g., Micco et al., 2009). Bottom-up studies have revealed that the reverse is also true: anxiety disorders are more prevalent in parents of anxious children than in parents of non-anxious children (e.g., Cooper, Fearn, Willetts, Seabrook, \& Parkinson, 2006). Part of this relationship can be attributed to heritability (Eley, 2001), but a significant proportion is thought to be accounted for by learning mechanisms that occur within the family, including parental modeling, reinforcement, and threat information transmission (Fisak \& Grills-Taquechel, 2007)

Within the context of the family, a considerable amount of research has also focused on overprotective parenting as a variable that increases the risk for anxiety problems in young people (for reviews, see McLeod, Wood, \& Weisz, 2007; Van der Bruggen, Stams, \& Bögels, 2008). It is assumed that parents with this style try to shield their child from potential danger by intrusively providing unnecessary help and restricting exposure to a broad range of situations. The net effect is that the child's fear and anxiety are enhanced because parents increase the awareness of danger, reduce the level of perceived control, and promote avoidance behavior in their offspring (Rapee, 1997). Research has indeed demonstrated that overprotective parenting is associated with or even predictive of anxiety problems in youths (Edwards, Rapee, \& Kennedy, 2010a; Hudson \& Rapee, 2001, 2002), and it has been suggested that this may be especially true in the preschool years (Lewis-Morrarty et al., 2012) when the family environment plays a dominant role in children's lives (Baumrind, 1967).

Besides parental influences that promote fear and anxiety in children, there may also be factors within the family that shield offspring from developing these emotiona problems. In a theoretical model specifying the parental influences in the etiology of childhood anxiety, Bögels and Phares (2008) advanced 'physical and challenging play' as a parental variable that protects children against fear and anxiety. 'Roughand-tumble' (R\&T) play is a specific type of this physical and challenging play, which is defined as a physically vigorous set of behaviors such as chase, jump, and play fight, 
accompanied by positive affect from the players towards one another (Pellegrini, 1995). Parents who frequently engage in R\&T play would learn their children to interpret the internal arousal that is elicited during these exciting activities (e.g., accelerated heart rate) as 'fun and pleasure' rather than 'fear and anxiety', thereby making them more tolerant to such arousal in other socially and physically challenging situations (Bögels \& Perotti, 2011; Bögels \& Phares, 2008).

Studies investigating parental influences on childhood anxiety have typically focused on mothers while neglecting the role of fathers, which is likely to be the result of the fact that the former are more easy to recruit than the latter. Although this has been partly justified by pointing out that mothers are the main caregivers as they usually spend more time with their child, it can also be considered as an important shortcoming of this research because there are good reasons to assume that fathers play a quite different role than mothers in the upbringing of their offspring. From an evolutionary perspective it has been argued that mothers try to establish an attachment relationship with their children by engaging in care activities, whereas fathers try to form an activation relationship with their children and thus promote their offspring to conduct physical and socially competitive behaviors (Dumont \& Paquette, 2013; Paquette, 2004). There are indications that these differential roles of mothers and fathers indeed exist and already are present at a fairly young age (Verhoeven, Bögels, \& Van der Bruggen, 2012). Furthermore, it is generally assumed that parents have a significant impact on the formation of children's gender roles (Witt, 1997). This implies that both mothers and fathers are more inclined to enhance physical play behaviors in their sons, while they have a stronger tendency to promote care behaviors in their daughters (Möller, Majdandžić, De Vente, \& Bögels, 2013), although it has also been found that fathers differentiate more strongly in their gender yping behavior towards boys and girls than mothers (Jacklin, DiPietro, \& Maccoby, 1984; Lindsey \& Mize, 2001). Altogether, as there are sufficient indications for the differential roles of mothers and fathers in the upbringing of children, it is clear that the strong focus on mothers in previous studies has yielded an incomplete picture of the effects of parenting on childhood anxiety. So it seems important to consider the contribution of parenting behaviors of both mothers and fathers to the development of this type of child psychopathology (Bögels \& Phares, 2008; Paquette, 2004).

Research examining the relation between arousing and challenging play and the development of internalizing disorders is sparse. One exception is a study by Gaumon and Paquette (2013) who employed the Risky Situation procedure to assess the father-child activation relationship in 51 children aged between 2 and 5 years. The Risky Situation procedure (Paquette \& Bigras, 2010) consists of challenging social (i.e. interacting with a stranger) and non-social (i.e., climbing a stepladder) activities, during which it can be observed to what extent fathers encourage their offspring to explore the environment and to engage in risk-taking behaviors. Results demonstrated that those children who were under-activated by their fathers exhibited higher scores on the internalizing symptoms scale (which includes items about fears and anxiety) of the Child Behavior Checklist (Achenbach \& Rescorla, 2000) than children who were properly activated by their fathers. This result fits nicely with the idea that children are less prone to display fear and anxiety symptoms in case fathers stimulate them to face possible challenges in the external world.

Another study by Majdandžić, Möller, Vente, Bögels, and Van den Boom 2014) investigated the relation between parental challenging activities and child social anxiety in 94 families. Fathers and mothers were separately observed while interacting with one of their two children aged 2 and 4 years, who had to conduct a series of novel activities. Children's social anxiety was measured by observing their response to a stranger at Time 1 , and half a year later at Time 2 . Only in the 4-yearold children significant effects were documented, but in line with the predictions, the results showed that fathers' challenging parenting behavior predicted lower levels of subsequently observed social anxiety. Surprisingly, however, mothers' challenging parenting behavior predicted higher levels of observed social anxiety, which further underlines the idea that parenting behaviors of mothers and fathers may have a quite different impact on child anxiety.

It is important to note that the Gaumon and Paquette (2013) and the Majdandžic et al. (2014) study employed an observational approach to assess the social-emotiona challenging behaviors of parents, thereby neglecting physical play and challenge such as R\&T play) activities, which according to the model proposed by Bögels and Phares (2008) are so pertinent within the context of childhood anxiety. The present study was conducted to fill this gap, and further explored the relationship between challenging parenting - in particular R\&T play - and childhood anxiety. Parents of 105 2- to 6-year-old children were asked to complete the Parental Play and Care Questionnaire (PPCQ), a scale that was specifically designed for the purpose of this study to measure mothers' and fathers' challenging/encouraging activities, R\&T play, and care behaviors towards their offspring. In addition, parents filled out measures of their own dispositional anxiety and overprotective rearing behavior as well as an index of anxiety symptoms in their children. This enabled us to study (1) differences in R\&T play as well as care activities between both parents, with the expectation that fathers would exhibit more R\&T play with their children, while mothers would display more care behaviors. Furthermore, we examined whether (2) the R\&T play activities of both parents would differ depending on the gender of the child. Here we expected that in particular fathers would more often engage in R\&T play with boys 
than with girls, while such a distinction in the gender-specific employment of R\&T play was not predicted for mothers. We also investigated (3) the relations between R\&T play of parents on the one hand, and parental anxiety and overprotection on the other hand. The hypothesis was that these relations would be negative, which is in keeping with the notion that more anxious and overprotective parents are more cautious and thus engage less in R\&T play with their offspring. In addition, we examined (4) whether R\&T play would show the expected negative relationship with children's anxiety symptoms, and (5) whether this link would still be present when controlling for parental anxiety and overprotection. The latter would suggest that R\&T play makes a unique contribution to the development of childhood anxiety that is independent of other family risk factors. Finally, we explored (6) interactive effects of parental R\&T play and other familial risk factors on children's anxiety symptoms, which is in keeping with current theories suggesting that pathological anxiety in children results from a complex interplay of risk and protective factors (e.g, Mian, Wainwright, Briggs-Gowan, $\&$ Carter, 2011). We anticipated that levels of anxiety symptoms would be particularly high in those children for which parents showed high levels of dispositional anxiety and overprotection (i.e., high risk) and low R\&T play (i.e., low protection).

\section{Method}

\section{Participants}

Parents (105 mothers and 97 fathers; mean ages being 35.12 years, SD $=5.99$ and 38.05 years, $S D=5.80$, respectively, range $22-56$ years) of 105 non-clinical children ( 61 boys and 44 girls) aged between 2 and 6 years $(M=4.27, S D=1.07$ ) participated in this study. The vast majority of the caregivers were the biological parents of the children; only 3 stepmothers and 2 stepfathers filled out the questionnaires. Based on information as provided by both parents about their professions, it was estimated that $45 \%$ and $41 \%$ of respectively mothers and fathers had a low, $45 \%$ and $53 \%$ had a medium, while $10 \%$ and $6 \%$ had a high educational level.

\section{Procedure}

Parents were recruited via three Belgian preschools and the Union of Babysitting in the eastern, Flemish part of Belgium. Informed consent letters were sent to the parents. About 39\% of parents gave permission to participate. Parents were asked to complete several questionnaires at home and to return these to the researchers. The study was approved by the Ethical Committee of Psychology at Maastricht University, The Netherlands.

\section{Measures}

As noted in the introduction, the Parental Play and Care Questionnaire (PPCQ) was construed for the purpose of the present study. The questionnaire initially contained 25 items about activities of parents with their children. Parents have to indicate the frequency of these activities on a four-point Likert scale $(0=$ never, 1 = sometimes, 2 = often, 3 = always). Exploratory factor analyses with direct oblimin rotation were performed on the separate mother and father data of the current sample and an additional sample of 95 non-clinical children (41 boys and 54 girls) aged between 7 and 13 years old $(M=10.69, S D=1.64$; total $N=200)$. Inspection of the eigenvalues and the scree plots yielded three consistent factors for mothers and fathers, retaining 18 of the items (see Appendix for a copy of the final questionnaire). The factors were R\&T play (6 items; range 0-18), care (8 items; range 0-24) and challenge/encouragement (4 items; range 0-12), for which scores can be computed by summing across relevant items. In the current study, Cronbach's alphas of the three factors/subscales were .67, .61 , and .60 for mothers, and .80, .75, and .74 for fathers, indicating that the PPCQ has sufficient to good reliability.

The Preschool Anxiety Scale-Revised (PAS-R; Edwards, Rapee, Kennedy, \& Spence, 2010b) was used to measure the level of anxiety symptoms in children. The PAS-R is a slightly modified version of the Preschool Anxiety Scale (Spence, Rapee, McDonald, \& Ingram, 2001). Parents respond to the 30 items of this scale using a five-point Likert scale $(0=$ not at all true, 1 = rarely true, 2 = sometimes true, 3 = quite often true, 4 = very often true). The PAS-R includes items referring to symptoms of separation anxiety (5 items; e.g., "My child would be upset when sleeping away from home"), socia anxiety (7 items; e.g., "My child worries that he/she will do something to look stupid in front of other people), obsessive-compulsive symptoms (2 items; e.g., "My child becomes distressed by thoughts or images in his/her head"), generalized anxiety (7 items; e.g., "My child has difficulty stopping him/herself from worrying"), and specific fears (9 items; e.g., "My child is afraid of the dark"). A total score can be obtained by summing all items (range 0-120). Research has shown that the PAS-R generally has good internal consistency, test-retest reliability, and validity (Edwards et al., 2010a; Edwards et al., 2010b). In the current study, the Cronbach's alpha of the PAS-R total score was .88 for mothers and .87 for fathers, which confirms the satisfactory internal consistency of the scale.

The Parental Overprotection Measure (POM; Edwards, 2007) is a questionnaire for assessing parenting behaviors that restrict the child's exposure to situations of perceived physical or social threat. Thus, all 19 items refer to overprotective rearing behaviors (e.g., "I do not allow my child to climb in trees" and "I protect my child from criticism"), and are scored on a five-point Likert scale ( 0 = not at all, 1 = a little, 
2 = somewhat, 3 = quite often, 4 = very often). A total score can be obtained by summing all items (range 0-76). The scale was found to have high internal consistency, strong test-retest reliability, and good validity (Edwards, 2007). In the current study reliability was good, with Cronbach's alphas of .90 for the mothers and .88 for the fathers.

The Y2-version of the Spielberger State-Trait Anxiety Inventory (STAI; Dutch translation by Van der Ploeg, Defares, \& Spielberger, 1980) was used to assess trait anxiety in parents. The questionnaire includes 20 statements (e.g., "I feel nervous" and "I worry too much about little things") that have to be answered on a four-point Likert scale ( 1 = almost never, 2 = sometimes, 3 = often, 4 = almost always). After recoding the positively phrased items, a total score can be obtained (range 20-80). There is clear support for the psychometric properties of the STAI (Spielberger, Gorsuch, Lushene, Vagg, \& Jacobs, 1983). Cronbach's alphas in the present sample were .88 for the mothers and .93 for the fathers, indicating good reliability.

\section{Data analyses}

One mother and one father did not complete various items of the STAI and one father did not fill out several items of the POM (missing items were more than 15\%). As a result, these participants were excluded from the data analysis involving these scales. Descriptive statistics were computed and the distributions of all variables were checked for violations of normality. Some questionnaires were clearly skewed and in these cases analyses on log transformed data were carried out. Paired $t$-tests were conducted to examine whether mothers and fathers differed in terms of parental R\&T play, challenging, and care activities as well as other variables. Independent samples t-tests were performed to evaluate differences between boys and girls for relevant questionnaires. To examine the relations between parental R\&T play and all other variables, partial correlations (corrected for child gender and age) were computed. Hierarchical regression analyses were performed for mothers and fathers separately to investigate (unique) main and interactive effects involving parental R\&T play on child anxiety. For the regression analyses, transformations were not undertaken, because transformed variables are often difficult to interpret and regression analysis is robust against violations of normality (Kirk, 1982).

\section{Results}

Parental agreement on anxiety symptoms of the child was quite high, as indicated by a strong correlation between mothers and fathers $(r=.67, p<.001)$, although scores of mothers ( $M=55.59, S D=13.08)$ were significantly higher than scores of fathers
$(M=53.46, S D=12.17)[t(96)=2.26, p<.05]$. A positive correlation between the scores of parents was also found for overprotective parenting $(r=.59, p<.001)$. A paired $t$-test revealed that overprotection scores also differed between fathers and mothers, with mothers $(M=36.28, S D=12.86)$ reporting significantly higher scores than fathers $(M=32.74, S D=11.55)[t(95)=3.12, p<.01]$. The correlation between mothers' and fathers' trait anxiety was not significant $(r=.14, p=.16)$. However mothers had significantly higher trait anxiety scores $(M=35.40, S D=7.22)$ than fathers $(M=33.39, S D=9.15)[t(96)=2.63, p<.01]$.

Differences in R\&T play, challenging activities and care between mothers and father Paired $t$-tests were conducted to examine hypothesis 1 on differences in R\&T play, challenging, and care activities between both parents. As can be seen in Figure 1 significant differences between mothers and fathers were found with regard to two subscales of the PPCQ: on the R\&T subscale, fathers $(M=8.13, S D=2.71)$ scored higher than mothers ( $M=6.57, S D=2.17)[t(96)=5.63, p<.001]$, whereas on the care subscale, mothers $(M=18.30, S D=2.67)$ scored higher than fathers $(M=10.89$ $S D=3.88)[t(96)=14.94, p<.001]$. No significant sex differences were found with regard to the challenge/encouragement scale of the PPCQ $[t(96)=1.61 p=.11]$. A correlational analysis revealed positive associations between the scores of fathers and mothers on the R\&T play $(r=.39, p<.001)$ and the challenge/encouragement $(r=.45, p<.001)$ subscales; no significant association existed between mothers' and fathers' care activities $(r=-.08, p=.44)$.

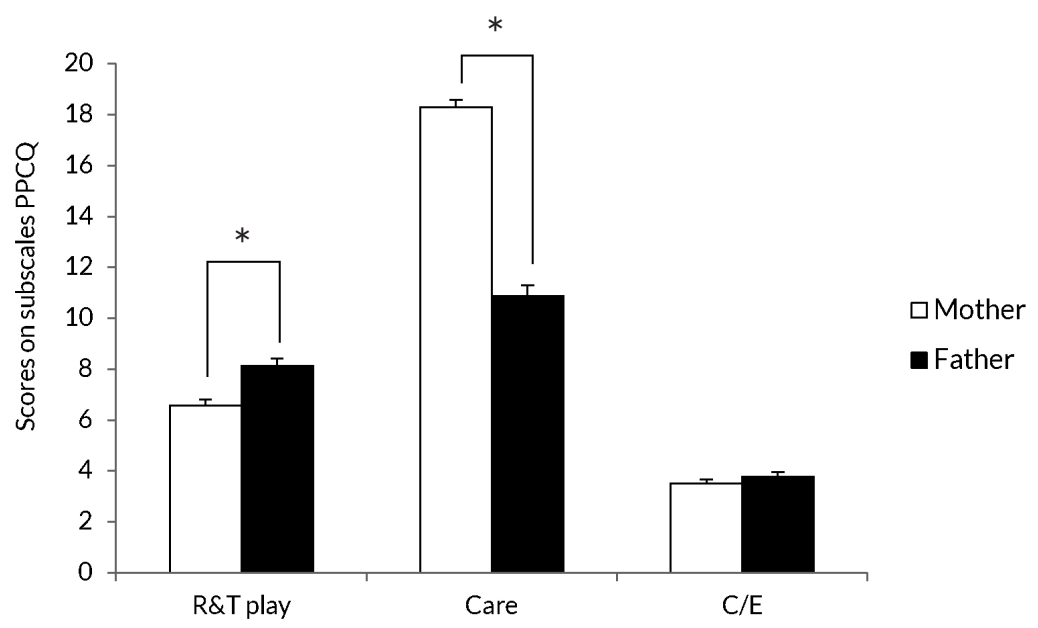

Figure 1 Mean scores (standard errors) of mothers and fathers on the three subscales of the PPCQ. Note. N's were 97. PPCQ = Parental Play and Care Questionnaire; R\&T = Rough-and-Tumble. $\mathrm{C} / \mathrm{E}=$ Challenge/Encouragement. ${ }^{*} p<.001$ 


\section{Children's age and gender effects}

Correlational analyses revealed that children's age was significantly correlated to mothers' anxiety level $(r=-.21, p<.05)$. Furthermore, the girls in the sample were significantly older $(M=4.55, S D=1.00)$ than the boys $(M=4.07, S D=1.08)$ $[t(103)=2.32, p<0.05]$. When comparing sons' and daughters' scores for mothers and fathers separately on all relevant scales, we found that mothers of boys had significantly higher anxiety levels $(M=36,70, S D=6.81)$ than mothers of girls $(M=33.64, S D=7.46)[t(103)=2.18, p<0.05]$. Fathers of boys scored them as more anxious $(M=55.92, S D=12.07)$ than fathers of daughters $(M=49.66, S D=11.47)$ $[t(95)=2.54, p<0.05]$. With regard to hypothesis 2 about whether R\&T play activities of both parents would differ depending on the gender of the child, it was found that mothers of boys $(M=12.95, S D=2.22)$ reported higher scores on the $R \& T$ play subscale of the PPCQ than mothers of girls $(M=11.98, S D=1.86)[t(103)=2.37$, $p$ $<0.05]$. In contrast with our expectations, no difference between boys and girls was found in R\&T play as reported by the fathers $[t(95)=1.56, p=.12]$.

\section{Correlations among parental anxiety, parenting, and child anxiety}

Table 1 displays partial correlation coefficients (corrected for child gender and age) among the main variables of this study, calculated for mothers and fathers separately. In this table, the results concerning our third and fourth hypotheses can be found. As can be seen, the mother data did not show the expected negative correlations between R\&T play on the one hand and maternal overprotection and trait anxiety on the other hand. Surprisingly, a significant positive correlation was found between maternal trait anxiety and scores on the challenge/encouragement subscale (partial $r=.30, p<.01$ ), which suggests that high anxious mothers were more challenging and encouraging to their children. The father data, however, did reveal a significant negative correlation between paternal overprotection and R\&T play (partial $r=-.20$, $p<.05$ ), which provides some support for hypothesis 3 demonstrating that at least in fathers a stronger tendency towards overprotective parenting was associated with less engagement in R\&T play. Further, neither the mother nor the father data provided evidence to substantiate hypothesis 4 on the expected negative correlation between R\&T play and child anxiety symptoms.
Table 1 Mean scores (standard deviations) onvarious questionnaires used in this study, and partial correlations (corrected for gender and age) among various scales computed for mothers and fathers separately

\begin{tabular}{lclllll}
\hline & $M(S D)$ & $(1)$ & $(2)$ & $(3)$ & $(4)$ & $(5)$ \\
\cline { 2 - 7 } Mother report & & & & & & \\
1. PAS-R & $55.59(13.08)$ & & & & & \\
2. POM & $36.28(12.86)$ & $0.25^{*}$ & & & & \\
3. STAI & $35.40(7.22)$ & $0.31^{* *}$ & 0.02 & & & \\
4. PPCQ-R\&T & $6.57(2.17)$ & 0.00 & 0.04 & 0.12 & & \\
5. PPCQ-C & $18.30(2.67)$ & $0.23^{*}$ & $0.27^{* *}$ & -0.05 & 0.08 & \\
6. PPCQ-C/E & $3.50(1.42)$ & 0.14 & -0.07 & $0.30^{* *}$ & $0.46^{* * *}$ & 0.05 \\
Father report & & & & & & \\
1. PAS-R & $53.46(12.17)$ & & & & & \\
2. POM & $32.74(11.55)$ & 0.06 & & & & \\
3. STAI & $33.39(9.15)$ & 0.08 & 0.11 & & & \\
4. PPCQ-R\&T & $8.13(2.71)$ & 0.11 & $-0.20^{*}$ & 0.11 & & \\
5. PPCQ-C & $10.89(3.88)$ & -0.03 & 0.16 & -0.12 & 0.12 & \\
6. PPCQ-C/E & $3.77(1.66)$ & 0.03 & -0.19 & 0.10 & $0.38^{* * *}$ & $0.24^{*}$ \\
\hline
\end{tabular}

Note. N's were 105 for mothers and 97 for fathers. PAS-R = Preschool Anxiety Scale-Revised $\mathrm{POM}=$ Parental overprotection measure; STAI = State-Trait Anxiety Inventory; $\mathrm{PPCQ}=$ Parental Play and Care Questionnaire, $R \& T=$ Rough-and-Tumble play subscale; $C=$ Care subscale; $C / E=$ Challenge $/$ Encouragement subscale. $p<.05, \quad p<.01, *+*<<.001$

A number of additional findings can be found in Table 1 that deserve some attention. First, the mother-report data revealed that anxiety symptoms of the child were positively correlated to maternal trait anxiety (partial $r=.31, p<.01$ ), which means that higher levels of anxiety symptoms of the child were associated with higher levels of trait anxiety of the mother. Second, the mother-report data also indicated that anxiety symptoms of the child were positively correlated to overprotection (partial $r=.25, p<.05$ ) and care (partial $r=.23, p<.05$ ), implying that higher levels of anxiety symptoms of the child were associated with higher levels of overprotection and care behaviors of the mother. Third, a significant positive correlation was found between overprotection and care (partial $r=.27, p<.05$ ), indicating that in mothers higher levels of overprotective behaviors were associated with higher levels of care behaviors. Fourth, another significant correlation was found between mothers scores on the R\&T play and the challenge/encouragement subscales (partial $r=.46, p<.001$ ), showing that mothers who engaged more in R\&T play were also more challenging and encouraging. Fifth, although the father-report data generally revealed few significant correlations, it was still found that the challenge/encouragement subscale of the PPCQ was positively related to the R\&T (partial $r=.38, p<.001$ ) and the care subscales (partial $r=.24, p=.05$ ), indicating that challenging/encouraging behaviors were associated with higher levels of R\&T play as well as care behaviors. 


\section{Unique and interactive effects of parenting behaviors on child anxiety}

The unique and interactive effects between R\&T play and child anxiety, as stated in hypothesis 5 and 6, will be discussed next. Hierarchical regression analyses were carried out on the mother- and father-report data separately, in which age and gender of the child (step 1), parental overprotection and anxiety (step 2), R\&T play, care, and challenge/encouragement (step 3), and the interactions of R\&T play with moderators parental anxiety and parental overprotection (step 4) were predictors. Anxiety of the child was the dependent variable. Inspection of tolerance and variance inflation factor (VIF) statistics showed that there was no multicollinearity problem in the regression models. To enhance a meaningful interpretation of the regression coefficients, all continuous predictors were centered around the mean.

As shown in Table 2, the analysis performed on the mother-report data revealed that anxiety of the mother $(p<.01)$, overprotection $(p<.05)$, and care behaviors ( $p$ $<.05)$ were all significant and unique, positive predictors of child anxiety. Besides the fact that R\&T play did not make a unique contribution, this parenting variable neither had an interactive effect in combination with any of the two moderators on child anxiety

Table 2 Results of hierarchical regression examining the relative contributions of various maternal factors to children's anxiety levels

\begin{tabular}{llll}
\hline & & & \\
Step 1 & & $\beta$ & $\Delta R^{2}$ \\
\cline { 2 - 4 } Sex & $-0.66(2.68)$ & -.03 & .00 \\
Age & $-0.53(1.24)$ & -.04 & \\
Step 2 & & & $.15^{*}$ \\
STAl & $0.57(0.17)$ & $.31^{* *}$ & \\
POM & $0.24(0.09)$ & $.24^{*}$ & \\
Step 3 & & & .05 \\
PPCQ-R\&T & $-0.66(0.65)$ & -.11 & \\
PPCQ-C & $1.03(0.47)$ & $.21^{*}$ & \\
PPCQ-C/E & $1.15(1.00)$ & .12 & \\
Step 4 & & & .01 \\
STAIXPPCQ-R\&T & $-0.09(0.07)$ & -.13 & \\
POM XPPCQ-R\&T & $-0.01(0.05)$ & -.02 & \\
\hline
\end{tabular}

Note. $N=96 . P P C Q=$ Parental Play and Care Questionnaire, R\&T = Rough-and-Tumble play subscale; $C=$ Care subscale; $\mathrm{C} / \mathrm{E}=$ Challenge/Encouragement subscale $:$ STAI = State-Trait Anxiety Inventory ; POM = Parental overprotection measure: Betas reported are those from the step at which the variable
The analysis of the father-report data (see Table 3) only revealed a significant main effect of child gender $(p<.01)$; that is, fathers of sons rated them as more anxious than fathers of daughters. Interestingly, the analysis did yield a significant interaction effect: paternal anxiety appeared to be a significant moderator in the relation between R\&T play and child anxiety $(p<.05)$. A follow-up analysis of simple slopes was conducted at one standard deviation above and below the moderator (STAI) mean, using the MODPROBE macro for SPSS designed by Hayes and Matthes (2009). This analysis revealed that there was only a significant effect of R\&T play on child anxiety for low trait anxious fathers $(p<.01)$, whereas no significant effect was found for high anxious fathers. As shown in Figure 2, children displayed higher levels of anxiety symptoms when their low trait anxious fathers displayed higher levels of R\&T play.

Table 3 Results of hierarchical regression examining the relative contributions of various paternal factors to children's anxiety levels

\begin{tabular}{llll}
\hline & $B(S E)$ & $\beta$ & $\Delta R^{2}$ \\
\cline { 2 - 4 } Step 1 & & & $.09^{*}$ \\
Sex & $-7.42(2.54)$ & $-.30^{* *}$ & \\
Age & $1.77(1.13)$ & .16 & \\
Step 2 & & & .01 \\
STAl & $0.09(0.14)$ & .07 & \\
POM & $0.06(0.11)$ & .05 & \\
Step 3 & & & .02 \\
PPCQ-R\&T & $0.57(0.50)$ & .13 & \\
PPCQ-C & $-0.16(0.34)$ & -.05 & \\
PPCQ-C/E & $-0.04(0.84)$ & -.01 & \\
Step 4 & & & \\
STAI x PPCQ-R\&T & $-0.12(0.05)$ & $-.23^{*}$ & \\
POM XPPCQ-R\&T & $-0.01(0.03)$ & -.04 & \\
\hline
\end{tabular}

Note. $\mathrm{N}=96 . \mathrm{PPCQ}=$ Parental Play and Care Questionnaire, $\mathrm{R} \& \mathrm{~T}=$ Rough-and-Tumble play subscale; $C=$ Care subscale; $\mathrm{C} / \mathrm{E}=$ Challenge/Encouragement subscale; STAI = State-Trait Anxiety Inventory; POM = Parental overprotection measure; Betas reported are those from the step at which the variable was entered into the equation. ${ }^{*} p<.05,{ }^{* *} p<.01$ 


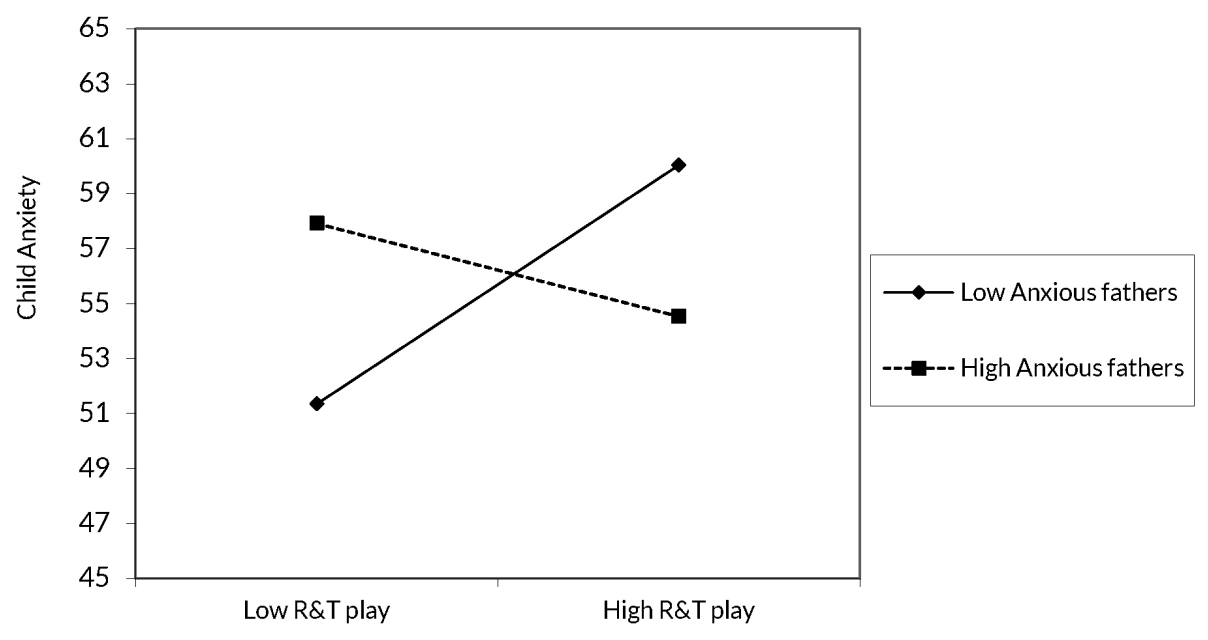

Figure 2 Plot showing the interactive effect of paternal anxiety and R\&T play on anxiety level of the child. Only the line for low anxious fathers is significant.

\section{Discussion}

The present study explored the relation between R\&T play and child anxiety. A questionnaire specifically construed to measure this type of parenting behavior was administered to the fathers and mothers of 105 non-clinical children aged 2 to 6 years, along with scales assessing other parental risk factors (i.e., trait anxiety, overprotection) and child anxiety symptoms.

The results first of all indicated that fathers engaged more in R\&T play, while mothers were more involved in care activities. This is in accordance with our first hypothesis and confirms current views on parenting roles which posit that fathers are more engaged in physical play activities with their offspring, whereas mothers stil fulfill the more caring role in the upbringing of their children (Bögels \& Phares, 2008; Paquette, Carbonneau, Dubeau, Bigras, \& Tremblay, 2003). Empirical studies have also demonstrated that fathers are more engaged in play activities, while mothers are more involved in care (Lindsey \& Mize, 2001; MacDonald \& Parke, 1986). On the challenge/encouragement subscale of the PPCQ, no differences were found between mothers and fathers, suggesting that these behaviors do not necessarily differ between both parents. Examination of whether R\&T play activities are dependent on the gender of the child (hypothesis 2 ) indicated that only mothers engaged more in R\&T play with boys than with girls, while no such difference was documented for the fathers. These results were somewhat surprising as most research has indicated that especially fathers exhibit more R\&T play towards boys as compared to girls, while mothers do not distinguish between boys and girls with respect to this specific type of parenting activity (Jacklin et al., 1984; Lindsey \& Mize, 2001). Thus, altogether, these findings are only partly in accordance with the activation relationship theory of Paquette (2004), which assumes that fathers will show more R\&T play with their children than mothers, and that this type of parenting behavior will be more often exhibited towards boys than towards girls.

Some support was found for our expectation that there would be negative relations between R\&T play on the one hand and parental anxiety and overprotection on the other hand (hypothesis 3). More specifically, fathers' R\&T play was negatively correlated to paternal overprotection, although it should be immediately admitted that no significant correlation was documented between R\&T play and paternal anxiety and that for mothers, none of these correlations were significant. The father findings are in accordance with the view of Gaumon and Paquette (2013), who noted that overprotective behaviors of fathers are associated with an underactivation attitude towards their children in the Risky Situation procedure, which is characterized by discouragement of exploration and prevention of risk-taking behaviors.

Hypothesis 4 stated that R\&T play would be negatively related to child anxiety, and hypothesis 5 that this relationship would be independent of the other family risk factors of parental anxiety and overprotection. Both hypotheses were not substantiated by the data. Obviously, this is in disagreement with the notion that this parental variable would operate as a protective mechanism against the development of this type of psychopathology (Bögels \& Phares, 2008). One explanation for the absence of a relation between R\&T play and child anxiety could be that our operationalization of R\&T play was too 'narrow'. That is, the PPCQ subscale assessing this type of parenting did not include social elements such as teasing or more extreme parental behaviors such as the promotion of risk taking, which have been shown relevant in previous research (Gaumon \& Paquette, 2013; Majdandžić et al., 2014 Paquette \& Dumont, 2013)

With regard to hypothesis 6 , only the regression analysis performed on the fatherreport data revealed a significant interaction effect of R\&T play and paternal trait anxiety on child anxiety, suggesting that anxiety of the father might act as a moderator in the relation between R\&T play and anxiety of the child. Inspection of this interaction revealed that low trait anxious fathers who showed more R\&T play had children who tended to display higher levels of anxiety symptoms, which is a result that is quite difficult to explain. It may well be that low anxious parents might be less sensitive to detect the anxiety signals of their child when they play too rough and too physical with them, but the bottom line here is again that the result is not in keeping with what we had expected. When also acknowledging the mixed findings as obtained by Majdandžić et al. (2014), 
the tentative conclusion seems to be that the role of R\&T play in childhood anxiety might be more complicated than previously thought, and that further refinement of the theory is needed. Obviously, more research is needed to examine the conditions under which this type of parenting has negative or positive effects on child anxiety.

Apart from the main results of this study, a number of additional interesting findings were documented. To begin with, the correlational analysis revealed significant positive associations between maternal trait anxiety, overprotection, and care on the one hand, and child anxiety on the other hand. Higher levels of anxiety and overprotective and caring behaviors of the mother were associated with higher levels of trait anxiety symptoms in the child. Most of these links are well in line with what has been previously reported in the literature (Hudson \& Rapee, 2001, 2002; McLeod et al., 2007; Van der Bruggen et al., 2008), but the relation between materna care and child anxiety has not been found before. As it is not very plausible that typical care behaviors such as cuddling, buying new clothes, and preparing dinner promote anxiety in the child, it seems best to conclude that care of the mothers may increase when they observe that their child is frequently or intensely anxious. For fathers, no significant relations between parenting variables and child anxiety were documented. Other studies have obtained inconsistent findings with regard to the role of paternal behaviors in relation to child anxiety. Some studies have shown that paternal behaviors (e.g., over-control) are involved in the development of child anxiety (Verhoeven et al., 2012), while other studies have demonstrated that father behaviors do not play a significant role in the etiology of child anxiety (Hudson \& Rapee, 2002)

Further, fathers rated boys as more anxious than girls, which is somewhat at odds with the results of the mother-report data and other research examining gender differences in childhood anxiety which generally show that girls are scored as more anxious than boys (Craske, 2003). However, other studies can be found that have also documented that mothers and fathers provide quite different anxiety scores for their offspring (Treutler \& Epkins, 2003).

Finally, an unexpected finding emerged indicating that high trait anxious mothers reported that they were more challenging and encouraging towards their children. It is possible that high anxious mothers show this behavior on purpose, because they know that they should challenge and encourage their offspring to prevent them from becoming also anxious. On the other hand, it is also possible that anxious mothers interpret many ambiguous situations as threatening and thus find that they expose their children quite often to potentially dangerous events.

It should be admitted that the present study suffers from various limitations. One imitation pertains to the fact that our study focused on the quantity of R\&T play activities by asking parents to complete a rating scale on which they had to indicate how often they engaged in this type of behaviors. However, it has been argued that the quality of the R\&T play behaviors is more important than the quantity of these activities (Paquette et al., 2003). Thus, it seems preferable that future studies not only include rating scales for assessing frequency but also measure the quality of the parenting behaviors by observing parents and children in a naturalistic setting (e.g., Majdandžić et al., 2014). A second limitation of the study is that parents of boys were compared to parents of girls. For future studies, it would probably be better to compare the behavior of the same parents towards their sons and daughters, in order to avoid that data are influenced by possible confounding variables (e.g., in our study, mothers of boys were significantly more anxious than mothers of girls). Another imitation is that we relied on a non-clinical population. Given our explicit interest in anxiety pathology, it would be interesting to include clinically referred children in this research. Despite these limitations, this is one of the few studies exploring the presumed protective role of R\&T play within the context of childhood anxiety. The results support the idea that fathers and mothers differ in the extent to which they typically engage in specific parenting behaviors related to the development of anxiety in children (Bögels \& Phares, 2008), but we did not find evidence for the proposed protective effect of R\&T play. Meanwhile the results provide several new leads that can be addressed in future research. 


\section{References}

Achenbach, T. M., \& Rescorla, L. A. (2000). Manual for the ASEBA preschool forms \& profiles: Burlington, VT: University of Vermont, Research center for children, youth, \& families.

Baumrind, D. (1967). Child care practices anteceding three patterns of preschool behavior. Genetic Psychology Monographs, 75(1), 43-88.

Bögels, S. M., \& Perotti, E. C. (2011). Does father know best? A formal model of the paterna influence on childhood social anxiety. Journal of Child and Family Studies, 20(2), 171-181. doi: 10.1007/s10826-010-9441-0

Bögels, S. M., \& Phares, V. (2008). Fathers' role in the etiology, prevention and treatment of child anxiety: A review and new model. Clinical Psychology Review, 28(4), 539-558. doi 10.1016/j.cpr.2007.07.011

Cooper, P. J., Fearn, V., Willetts, L., Seabrook, H., \& Parkinson, M. (2006). Affective disorder in parents of a clinic sample of children with anxiety disorders. Journal of Affective Disorders, 93, 205-212. doi: 10.1016/j.jad.2006.03.017

Costello, E., Mustillo, S., Erkanli, A., Keeler, G., \& Angold, A. (2003). Prevalence and development of psychiatric disorders in childhood and adolescence. Archives of Genera Psychiatry, 60(8), 837-844. doi: 10.1001/archpsyc.60.8.837

Craske, M. G. (2003). Origins of phobias and anxiety disorders: Why more women than men. Oxford: Elsevier.

Dumont, C., \& Paquette, D. (2013). What about the child's tie to the father? A new insight into fathering, father-child attachment, children's socio-emotional development and the activation relationship theory. Early Child Development and Care, 183(3-4), 430-446. doi: 10.1080/03004430.2012.711592

Edwards, S. L. (2007). Temperament and environmental risk factors contributing to anxiety symptoms in preschool-aged children. Unpublished Ph.D. Thesis, Macquarie University, Australia.

Edwards, S. L., Rapee, R. M., \& Kennedy, S. (2010a). Prediction of anxiety symptoms in preschool-aged children: examination of maternal and paternal perspectives. Journal of Child Psychology and Psychiatry, 51(3), 313-321. doi: 10.1111/j.1469-7610.2009.02160.x

Edwards, S. L., Rapee, R. M., Kennedy, S. J., \& Spence, S. H. (2010b). The assessment of anxiety symptoms in preschool-aged children: The revised preschool anxiety scale. Journal of Clinical Child \&Adolescent Psychology, 39(3), 400-409. doi: 10.1080/1537441100369170

Eley, T. C. (2001). Contributions of behavioural genetics research: Quantifying genetic, shared environment and nonshared environmental influences. In M. W. Vasey \& M. R. Dadds (Eds.) The developmental psychopathology of anxiety (pp. 45-59). London: Oxford University Press.

Fisak, B., \& Grills-Taquechel, A. E. (2007). Parental modeling, reinforcement, and information transfer: Risk factors in the development of child anxiety? Clinical Child and Family Psychology Review, 10(3), 213-231. doi: 10.1007/s10567-007-0020-x

Gaumon, S., \& Paquette, D. (2013). The father-child activation relationship and internalising disorders at preschool age. Early Child Development and Care, 183(3-4), 447-463. doi: 10.1080/03004430.2012.711593

Hayes, A. F., \& Matthes, J. (2009). Computational procedures for probing interactions in OLS and logistic regression: SPSS and SAS implementations. Behavior Research Methods, 41 924-936. doi: 10.3758/BRM.41.3.924
Hudson, J. L., \& Rapee, R. M. (2001). Parent-child interactions and anxiety disorders: An observational study. Behaviour Research and Therapy, 39(12), 1411-1427. doi: 10.1016/ s0005-7967(00)00107-8

Hudson, J. L., \& Rapee, R. M. (2002). Parent-child interactions in clinically anxious children and their siblings. Journal of Clinical Child \& Adolescent Psychology, 31(4), 548-555. doi: 10.1207/S15374424JCCP3104 13

Jacklin, C. N., DiPietro, J. A., \& Maccoby, E. E. (1984). Sex-typing behavior and sex-typing pressure in child/parent interaction. Archives of Sexual Behavior, 13, 413-425. doi: 10.1007/ bf01541427

Kirk, R. E. (1982). Experimental Design: Procedures for the behavioral sciences. (2nd ed.). Belmont, CA.: Wadsworth.

Lewis-Morrarty, E., Degnan, K., Chronis-Tuscano, A., Rubin, K., Cheah, C. L., Pine, D., ... Fox N. (2012). Maternal over-control moderates the association between early childhood behavioral inhibition and adolescent social anxiety symptoms. Journal of Abnormal Child Psychology, 40(8), 1363-1373. doi: 10.1007/s10802-012-9663-2

Lindsey, E. W., \& Mize, J. (2001). Contextual differences in parent-child play: Implications for children's gender role development. Sex Roles, 44(3-4), 155-176. doi 10.1023/a:1010950919451

MacDonald, K., \& Parke, R. (1986). Parent-child physical play: The effects of sex and age of children and parents. Sex Roles, 15(7-8), 367-378. doi: 10.1007/bf00287978

Majdandžić, M., Möller. E. L., Vente, W.. Bögels, S. M.. \& van den Boom, D. C. (2014). Fathers challenging parenting behavior prevents social anxiety development in their 4-year-old children: A longitudinal observational study. Journal of Abnormal Child Psychology, 42(2), 301-310. doi: 10.1007/s10802-013-9774-4

McLeod, B. D., Wood, J. J., \& Weisz, J. R. (2007). Examining the association between parenting and childhood anxiety: A meta-analysis. Clinical Psychology Review, 27(2), 155-172. doi: 10.1016/j.cpr.2006.09.002

Mian, N. D., Wainwright, L., Briggs-Gowan, M. J., \& Carter, A. S. (2011). An ecological risk model for early childhood anxiety: The importance of early child symptoms and temperament. Journal of Abnormal Child Psychology 39(4), 501-512 doi: 10.1007/s10802-010-9476-0

Micco, J. A., Henin, A., Mick, E., Kim, S., Hopkins, C. A., Biederman, J., \& Hirshfeld-Becker, D. R. (2009). Anxiety and depressive disorders in offspring at high risk for anxiety: A metaanalysis. Journal of Anxiety Disorders, 23(8), 1158-1164. doi: 10.1016/j.janxdis.2009.07.021

Möller, E. L., Majdandžić, M., De Vente, W.. \& Bögels, S. M. (2013). The evolutionary basis of sex differences in parenting and its relationship with child anxiety in western societies. Journal of Experimental Psychopathology, 4(2), 88-117. doi: 10.5127/jep.026912

Muris, P., \& Field, A. (2011). The 'normal' development of fear In W. K. Silverman \& A. P. Field (Eds.), Anxiety Disorders in Children and Adolescents (Vol. second edition, pp. 76-89). Cambridge: Cambridge University Press.

Paquette, D. (2004). Theorizing the father-child relationship: Mechanisms and developmental outcomes. Human Development, 47(4), 193-219. doi: 10.1159/000078723

Paquette, D., \& Bigras, M. (2010). The risky situation: a procedure for assessing the fatherchild activation relationship. Early Child Development and Care, 180(1-2), 33-50. doi: 10.1080/03004430903414687

Paquette, D., Carbonneau, R., Dubeau, D., Bigras, M., \& Tremblay, R. E. (2003). Prevalence of father-child rough-and-tumble play and physical aggression in preschool children. European Journal of Psychology of Education, 18(2), 171-189. doi: 10.1007/BF03173483 
Paquette, D., \& Dumont, C. (2013). Is father-child rough-and-tumble play associated with attachment or activation relationships? Early Child Development and Care, 183(6), 760-773. doi: 10.1080/03004430.2012.723440

Pellegrini, A. D. (1995). A longitudinal study of boys' rough-and-tumble play and dominance during early adolescence. Journal of Applied Developmental Psychology, 16(1), 77-93. do: 10.1016/0193-3973(95)90017-9

Rapee, R. M. (1997). Potential role of childrearing practices in the development of anxiety and depression. Clinical Psychology Review, 17(1), 47-67. doi: 10.1016/S0272-7358(96)00040-2

Spence, S. H., Rapee, R. M., McDonald, C., \& Ingram, M. (2001). The structure of anxiety symptoms among preschoolers. Behaviour Research and Therapy, 39(11), 1293-1316. do: 10.1016/S0005-7967(00)00098-X

Spielberger, C. D., Gorsuch, R. L., Lushene, R., Vagg, P. R., \& Jacobs, G. A. (1983). Manual for the State-Trait Anxiety Inventory (Form Y). Palo Alto, CA: Consulting Psychologists Press.

Treutler, C. M., \& Epkins, C. C. (2003). Are discrepancies among child, mother, and father reports on children's behavior related to parents' psychological symptoms and aspects of parent-child relationships? Journal of Abnormal Child Psychology, 31(1), 13-27. doi: 10.1023/a:1021765114434

Van der Bruggen, C. O., Stams, G. J. J. M., \& Bögels, S. M. (2008). Research review: The relation between child and parent anxiety and parental control: A meta-analytic review. Journal of Child Psychology and Psychiatry, 49(12), 1257-1269. doi: 10.1111/j.14697610.2008.01898.x

Van der Ploeg, H. M., Defares, P. B., \& Spielberger, C. D. (1980). Handleiding bij de zelfbeoordelingsvragenlijst, ZBV:een Nederlandse vertaling van de Spielberger State-Trait Anxiety Inventory. Lisse, The Netherlands: Swets \& Zeitlinger.

Verhoeven, M., Bögels, S., \& Van der Bruggen, C. (2012). Unique roles of mothering and fathering in child anxiety; moderation by child's age and gender. Journal of Child and Family Studies, 21, 331-343. doi: 10.1007/s10826-011-9483-y

Witt, S. D. (1997). Parental influence on children's socialization to gender roles. Adolescence, 32(126), 253-259.

\section{Appendix}

\section{Parental play and care questionnaire (PPCQ)}

\begin{tabular}{|c|c|c|c|c|}
\hline & $\begin{array}{l}\overline{0} \\
\bar{\omega} \\
\frac{0}{z} \\
\end{array}$ & 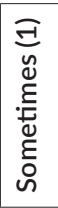 & $\begin{array}{l}\overline{\mathrm{d}} \\
\overline{\bar{d}} \\
\overline{0}\end{array}$ & $\begin{array}{l}\bar{m} \\
\tilde{n} \\
\frac{\pi}{\pi} \\
\frac{3}{<}\end{array}$ \\
\hline 1. I engage in exciting and sometimes scary activities with my child. & & & & \\
\hline $\begin{array}{l}\text { 2. I tell my child that he/she should seek out scary situations (instead of } \\
\text { avoiding them). }\end{array}$ & & & & \\
\hline 3.I prepare dinner. & & & & \\
\hline 4. I encourage my child to seek out novel experiences. & & & & \\
\hline 5.I do my child's laundry. & & & & \\
\hline 6.I talk to my child about his/her feelings. & & & & \\
\hline 7. When my child needs new clothes, I go out shopping with him/her. & & & & \\
\hline $\begin{array}{l}\text { 8. I involve my child in housekeeping activities (vacuuming, cleaning, doing } \\
\text { the dishes). }\end{array}$ & & & & \\
\hline 9. When playing with my child, we talk loudly and scream. & & & & \\
\hline 10. I often engage in competitive play with my child. & & & & \\
\hline 11. I engage in exciting activities with my child. & & & & \\
\hline 12. I accompany my child to the doctor or dentist. & & & & \\
\hline 13. When I engage in an activity with my child, it often gets wild. & & & & \\
\hline 14. I cuddle with my child. & & & & \\
\hline 15. When something bothers my child, he/she comes to me to talk about it. & & & & \\
\hline 16. I tickle my child, and then he/she laughs. & & & & \\
\hline 17. I play roughly with my child. & & & & \\
\hline 18. I throw my child up in the air, and then catch him/her again. & & & & \\
\hline
\end{tabular}

Note. R\&T play: items 9, 10, 13, 16, 17, 18; Care: items 3, 5, 6, 7,8, 12, 14, 15; Challenge/Encouragement: items $1,2,4,11$ 


\section{Chapter 3}

Fear-Related Confirmation Bias in Children:

A Comparison Between Neutral- and

Dangerous-Looking Animals

Pauline Dibbets, Lorraine Fliek, Cor Meesters 


\section{Abstract}

The purpose of this study was to examine confirmation bias in children without explicitly inducing fear. Eighty non-clinical children (7-13 years) were shown pictures of a neutral animal (quokka) and two dangerous-looking animals (aye aye and possum). For each animal, levels of perceived fear, threat and request for additional threatening or non-threatening information were obtained. A behavioral approach test (BAT) was included as behavioral measure of fear. The results indicated that the aye aye and possum were rated as more threatening and fearful than the quokka. For the aye aye and possum higher fear levels coincided with search for more threatening than non-threatening information. This pattern was absent in non-fearful children and for the non-threatening quokka. During the BAT the quokka was more often approached first compared to the aye aye and possum. Our findings suggest that confirmation bias in children can be observed without using verbal fear induction.

Keywords: fear; confirmation bias; children; threat; danger

\section{Introduction}

Fear and anxiety are normal adaptive reactions to (potentially) threatening or harmful stimuli. Identification of these stimuli or situations activates cognitive, affective, physiological, and behavioral processes that foster survival. However, in case of an anxiety disorder, these processes are over-activated and no longer adaptive, hindering daily functioning.

Current cognitive models posit that individual differences in threat-relevant information processing are at the center of the onset and maintenance of anxiety disorders (e.g., Beck \& Clark, 1997; Eysenck, Derakshan, Santos, \& Calvo, 2007). High-anxious persons display various information processing biases (see for a review Ouimet, Gawronski, \& Dozois, 2009). A bias that is highly relevant for the onset and maintenance of anxiety problems is confirmation bias. This is the inclined tendency to selectively search for information that confirms the dangerousness of the feared object or situation, while ignoring information that disconfirms threat. Though such a verification strategy has survival value, the lack of searching for alternative, nonconfirming information hinders the detection of and adaptation to a safe situation. The results of studies on confirmation bias are in line with the cognitive models on threatrelevant information processing. That is, persons that perceive a stimulus or situation as threatening more often search for information that confirms the dangerousness of the dreaded stimulus than for alternative, disconfirming information. In case of an anxiety disorder such a reasoning pattern logically results in the reinforcement and maintenance of the fear (De Jong, Mayer, \& Van Den Hout, 1997; Smeets, de Jong, \& Mayer, 2000)

Fear and anxiety problems are not restricted to adulthood. The age of onset of anxiety disorders is typically in childhood or adolescence (Kessler, Ruscio, Shear, \& Wittchen, 2009) and anxiety disorders are the most common mental disorders in children (Merikangas, Nakamura, \& Kessler, 2009). As in adults, high anxiety and anxiety proneness in children are associated with information processing deficits (Hadwin, Frost, French, \& Richards, 1997; Muris et al., 2000; Waters, Lipp, \& Spence, 2004). Children with these cognitive biases have a higher chance of developing anxiety disorders, because when these children are presented with ambiguous information, they are more likely to process this information in a threat-relevant way. These cognitive biases can influence several steps of information processing. Biased information processing leads to higher levels of anxiety, which in turn enhances the formation of cognitive biases (Muris \& Field, 2013).

Recently, researchers have gained interest in fear-related confirmation bias in children. In several experimental studies fear to an unknown, initially neutral, animal (e.g., cuscus) was induced. This was accomplished by (indirectly) providing negative 
information about the animal (Muris et al., 2009; Remmerswaal, Muris, Mayer, \& Smeets, 2010). Children who received this negative information more often searched for information that confirmed the dangerousness of the unknown animal than children who received positive information. Additionally, they were less inclined to invalidate their negative view (Muris, Huijding, Mayer, van As, \& van Alem, 2011 Muris et al., 2009; Remmerswaal et al., 2010).

Up to now fear-related cognitive biases in children are effectuated by (indirectly) providing negative information. Providing such information might influence the confirmation bias results due to a memory component. For example, providing negative statements as "the cuscus is dangerous" or "the cuscus will attack you" can result in the confirmation of the statement "if you stroke a cuscus, it will bite you", as the child simply applies the remembered information (but see for additional tests, Muris et al., 2009).

However, based on the adult literature, the establishment of a negative view is not a necessary condition to observe confirmation bias. Just the mere perception of threat is already sufficient to activate a threat-confirming strategy (e.g., De Jong et al., 1997). The current study wants to extend these findings to children and examine whether the mere perception of threat is indeed sufficient to induce a confirmation bias. Therefore, the aim of the present study is to examine confirmation bias in children without providing additional information. Based on the previous studies, we expect that only in case of perceived threat children will show an increased search for threatening information and a decreased search for non-threatening information.

\section{Method}

Participants

Participants were 80 non-clinical children (41 boys, 39 girls) aged 7-13 years ( $M=10.18$ $S D=1.51$; age categories: 7 years, $n=7 ; 8$ years, $n=8 ; 9$ years $n=4 ; 10$ years, $n=19$; 11 years, $n=30 ; 12$ years, $n=11 ; 13$ years, $n=1$ ). Children were recruited from four regular primary schools in the Netherlands. All children had the Dutch nationality. Of the parents, the majority was Dutch (> 66\%), 10.6\% had the Turkish nationality, 13.8 $\%$ the Moroccan nationality and the remaining parents had a diversity of nationalities (e.g., Slovenian, Belgian, German, English, American, Indonesian, Gambian, Afghan and Somalian). Informed parental consent was obtained by sending parents an information letter concerning the experiment with an informed consent. Note that only children without anxiety problems and without previous or current psychological anxiety treatment were allowed to participate. The experiment was approved by the Ethical Committee Psychology at Maastricht University (approval code: ECP-110)

\section{Material}

Animals

The three animals used for the present study were selected via a pilot study $(n=14$ 6 different animals). As a neutral stimulus a full color picture of an existing unknown Australian marsupial, the quokka, was used (Muris \& Field, 2010). As potentially dangerous stimuli a color picture of an aye aye, a lemur from Madagascar, and of an angry possum, an Australian marsupial were used (see Figure 1). The latter picture was included to ensure that at least one of the two dangerous animal pictures was perceived as threatening. The pictures $\left(163 \mathrm{~cm}^{2}\right)$ were printed on a separate paper and labeled with the species name.
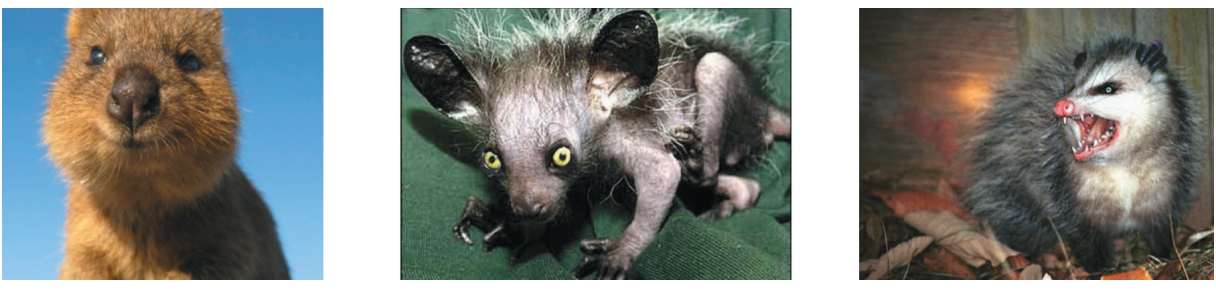

Figure 1 Picture of the quokka (left) aye aye (middle) and possum (right).

Fear Survey Schedule for Children-Revised (FSSC-R)

The overall level of fear vulnerability was measured with a shortened version of the Fear Survey Schedule for Children-Revised (FSSC-R; Ollendick, 1983). The FSSC-R is a 25item self-report questionnaire using a 3-point response scale of "no fear", "some fear" or "a lot fear". The questionnaire consists of five subscales ( 5 items per scale): fear of failure and criticism, fear for the unknown, fear for animals, fear of danger and death and medical fears. The total score can be determined by summing up all scores and ranges from 25 to 75 . In the present study Cronbach's alpha was .88, indicating good reliability.

\section{Threat attitudes towards the animals}

Visual Analogue Scales (VASs, $100 \mathrm{~mm}$, printed on paper) were used to measure the threat attitudes of the children towards the target animals. The VASs were accompanied by a picture of the concerning animal. For each animal a total of four VASs was displayed: three concerning threat-related characteristics of the animal (i.e., perceived dangerousness, likelihood of biting a person and amount of fear encountering the animal) and one referring to a positive, non-threatening characteristic (i.e., perceived kindness). The child was invited to mark the characteristics of each animal. Total threat attitude towards an animal was calculated by averaging only the threat-related items as for each animal Cronbach's alphas increased after deleting the positive (reversed) item, alpha's > .73. 


\section{Fear Beliefs Questionnaire (FBO)}

Three separate Fear Beliefs Questionnaires, FBQs, were used; one for the quokka, one for the aye aye and one for the possum (cf. Muris et al., 2009). A picture of the concerning animal accompanied each questionnaire. The questionnaire consists of 10 items to measure the amount of fear for that particular animal. For example: "Would you find it scary to touch a quokka?" or "Do you think that an aye aye will bite you?". Items have to be rated on a 5-point Likert scale by checking the box accompanying one of the following options: 1 = No, not at all, 2 = No, not really, $3=$ Yes, maybe, $4=$ Yes, probably, and 5 = Yes, definitely. Per animal a total fear score can be calculated by summing the ratings on all items (range: 10-50). Additionally, to test foreknowledge about the animals, the child was asked whether he/she was familiar with the animal. Three open-end options were provided: "No, but I think that this is a(n)..." "Maybe, think that this is a(n)..." and "Yes, I know this is a(n).... Cronbach's alphas of the quokka, aye aye and possum $\mathrm{FBQ}$ were $.89, .93$ and .90 , respectively.

\section{Confirmation bias}

The Search for Additional Information Scale (SAIS) is frequently applied in children as a measure of confirmation bias (e.g., Muris et al., 2011; Muris et al., 2009). Children were asked what kind of additional information they would like to know about each animal. For each animal a list of 14 statements was provided; half of the statements referred to threatening information (e.g., "I would like to know more about the way the quokka kills his prey") and half of the statements concerned non-threatening information (e.g., "I would like to know where the possum sleeps"). The order of threatening and non-threatening statements was at random. Children were asked to indicate for each statement how much they wanted to know about that specific topic on a 5-point Likert scale (range 1 = nothing to 5 = everything), resulting in a total score for additional information about non-threat (7-35) and threat (7-35) information per animal. For the quokka Cronbach's alphas were .88 and .81 , for the aye aye .88 and .85 , and for the possum, .87 and .81 , respectively.

\section{Behavioral approach test}

The behavioral approach test (BAT) was carried out to assess approach and avoidance behavior. The (mock) animals were housed in a cardboard box covered by a lid of wire netting. The animal was hidden underneath sawdust and hay. The child was given a food cup filled with seeds and grain and invited to open one of the cages and to feed the animal. A stepwise fear hierarchy was made to record approach behavior see Table 1). After placing the food cup into the cage, the amount of experienced distress during feeding was recorded using a VAS. This procedure was repeated for the remaining two animals. The order in which the animals were fed and the completed steps of the hierarchy were noted down.

Table 1 Stepwise hierarchy during the behavioral approach test

\begin{tabular}{ll}
\hline 1. & Child grasps food (at 5 meter distance) \\
2. & Child walks towards the animal \\
3. & Child passes three-meter line \\
4. & Child passes one-meter line \\
5. & Child walks towards the box and observes the animal \\
6. & Child walks towards the box, touches the cage and observes the animal \\
7. & Child walks towards the box and raises the wire netting \\
8. & Child walks towards the box, raises the wire netting, places the food cup in the box at a \\
9. & Certain distance from the animal \\
& Child walks towards the box, raises the wire netting, places the food cup close to the \\
\hline
\end{tabular}

\section{Procedure}

All children were tested in their classroom under supervision of two female research assistants. The assistants guided the children through the session by providing instructions, by collectively running through practice items and they ensured that children did not consult each other during testing. Children started with the FSSCR. Next, one of the assistants exemplified the usage of the VAS scales by filling in the temperature of that day on the VAS (anchors: not hot at all and very hot). After this example, the children filled out the VASs concerning the quokka, possum, and aye aye. Subsequently, children completed the FBQs and the SAISs. For the VAS, FBQ and SAIS the order of animal presentation was counterbalanced resulting in three versions. Different versions were provided for children that were seated next to each other. Next, the children were individually guided by one of the assistants to an adjacent room to carry out the BAT. After the BAT the child received information about the animal and left the school (parents were waiting in the schoolyard). The children, parents, and school were debriefed via an information letter.

\section{Missing values and statistics}

A total of seven participants omitted one item of the FSSC-R, one participant omitted eleven items. Missing items were imputed using the mean of the remaining items of that particular subscale; the participant missing eleven items was discarded from data analyses concerning the FSSC-R. For the threat attitude, one child missed al items of the quokka VAS, the data of this child were discarded from data analyses concerning the quokka VAS. For the SAIS three participants missed one item; this 
missing value was replaced by the mean of the remaining (non)threat items of that particular animal. One participant omitted four SAIS items (leaving one page blank) and three participants missed 3 items; these participants were excluded from data analyses involving the SAIS-scores.

The questionnaire and VAS data were analyzed parametrically (General Linear Model, repeated measures and Pearson correlations); the BAT order and steps were analyzed by means of non-parametric tests (Friedman Test and Wilcoxon Signed Ranks test). Bonferroni Holm corrections were made in case of multiple or pairwise comparisons. If sphericity assumptions were violated Greenhouse-Geisser corrections were made. The rejection criterion was set at $p<.05$

\section{Results}

\section{Anxiety vulnerability}

The overall level of fear as measured with the FSSC-R was 41.99 (SD = 8.25, range 2663). The scores were normally distributed, Kolmogorov-Smirnov, $D(79)=.058, p=.20$ As in previous research, girls displayed higher FSSC-R scores ( $M=45.02, S D=7.52)$ than boys $(M=39.04, S D=7.94)$, t-test, $t(77)=3.43, p=.001$ (e.g., Ollendick, 1983). No effect of age was observed, $r=.074, p=.52$. Note that age also did not significantly correlate with other main task effects, $|r| s<.21$, ps $>$.067. To control for the observed gender difference, we decided to enter gender as a factor for the remainder of the data analyses ${ }^{2}$.

\section{Threat attitude differences quokka, aye aye and possum}

None of the children correctly identified the animals. The results of the questionnaires and tests can be found in Table 2. First, we assessed if the aye aye and possum were perceived as more threatening than the quokka. A general linear model (GLM) with repeated measures was performed with the VAS scores of the animals serving as within-subjects factor and gender as factor. This analysis revealed a main effect of animal, $F(2,154)=103.19, p<.001, n \rho^{2}=.57$. Pairwise comparisons indicated that both the aye aye and the possum were perceived as more threatening than the quokka, $p s<.001, \eta \rho^{2}=.61$ and $n \rho^{2}=.68$, respectively. Though the possum received higher ratings than the aye aye, this difference just felt short of significance, $p=.061$ $\eta \rho^{2}=.044$. A similar analysis was run for the kindness item. This analysis revealed a main effect of animal, $F(2,156)=76.63, p<.001, n \rho^{2}=.50$. The quokka was rated as more kind than the aye aye and possum, $\mathrm{ps}<.001, \mathrm{n} \rho^{2}=.56$ and $n \rho^{2}=.60$, respectively. No difference was observed between the aye aye and possum, $p=.44, n \rho^{2}=.008$.

2 Note that similar results were obtained in case gender was not entered as a factor in the analyses
A similar GLM was run for the FBQ scores. This analysis revealed a main effect of animal, $F(2,156)=118.98, p<.001, n \rho^{2}=.60$. Both the aye aye and the possum were perceived as more fearful than the quokka, $p s<.001, n \rho^{2}=.66$ and $n \rho^{2}=.67$, respectively; no difference was observed between the aye aye and possum, $p=.65, n \rho^{2}=.003$.

\section{Confirmation bias: Search for additional information}

A GLM repeated measures with animal (quokka, aye aye and possum) and search for additional information (SAIS, non-threatening and threatening) as withinsubject factors and gender as factor was run. This analysis revealed a main effect of information, $F(1,75)=6.13, p=.016, n \rho^{2}=.077$, and a main effect of animal, $F(2$, $148)=6.67, p<.005, n \rho^{2}=.083$. Furthermore, an animal $x$ information interaction was found, $F(2,148)=5.48, p=.005, n \rho^{2}=.069$

The animal $x$ information interaction was analyzed further using separate GLMs for each animal. These analyses indicated that for the aye aye participants requested more threatening than neutral information, $F(1,77)=12.61, p<.001, n \rho^{2}=.14$. A similar pattern was observed for the possum, $F(1,76)=6.85, p<.05, n \rho^{2}=.083$

No such pattern was observed for the quokka, $F<1$. Note that these results cannot be explained by a ceiling effect as all scores significantly fell below the maximum score of 35 , one-sample t-tests, $t s<-11.41$, ps $<.001$. These results indicate that perceived threat coincided with a relatively enhanced search for confirming threat-related information. This pattern was not observed for the non-threatening quokka.

Table 2 Mean scores (SDs) on the questionnaires and tests concerning the animals.

\begin{tabular}{|c|c|c|c|c|}
\hline \multicolumn{2}{|c|}{ 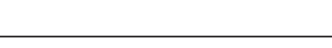 } & Quokka & Aye aye & Possum \\
\hline \multicolumn{2}{|c|}{ VAS threat attitude } & $25.34(19.02)$ & $53.58(24.44)$ & $57.99(21.42)^{*}$ \\
\hline \multicolumn{2}{|l|}{$\mathrm{FBQ}$} & $19.13(7.32)$ & $32.15(10.36)$ & $31.82(9.66)^{*}$ \\
\hline SAIS & $\begin{array}{l}\text { Non-threatening } \\
\text { Threatening }\end{array}$ & $\begin{array}{l}25.22(7.62) \\
25.44(6.69)\end{array}$ & $\begin{array}{l}22.32(8.28) \\
24.56(7.74)\end{array}$ & $\begin{array}{l}22.90(8.00)^{*} \\
24.88(7.14)\end{array}$ \\
\hline BAT & $\begin{array}{l}\text { Steps } \\
\text { VAS score } \\
\text { Order }\end{array}$ & $\begin{array}{c}8.95(.445) \\
35.95(34.44) \\
1.50(.76)\end{array}$ & $\begin{array}{c}8.61(1.77) \\
38.84(32.44) \\
2.19(.63)\end{array}$ & $\begin{array}{c}8.61(1.77)^{*} \\
37.95(32.16) \\
2.29(.82)^{*}\end{array}$ \\
\hline
\end{tabular}

VAS = visual analogue scale; $F B Q$ = fear beliefs questionnaire; SAIS = search for additional information BAT = behavioral approach test

Main effect of animal, $p<.001$

\section{Confirmation bias and fear}

Additional GLM repeated measures were run per animal to test the assumption that confirmation bias is specifically observed in case of perceived threat. In each 
analysis search for additional information (SAIS, non-threatening and threatening) served as within-subject factor, the associated FBQ score as covariate and gender was implemented as factor. The aye aye analysis revealed a SAIS $\times$ FBQ interaction, $F(1,76)=5.47, p<.05, n \rho^{2}=.067$; a similar interaction was observed for the possum, $F(1,75)=4.04, p<.05, n \rho^{2}=.051$. No such interaction was found for the quokka, $F(1$ 76) $=2.40, p=.13, n \rho^{2}=.031$

The interaction was analyzed further by using a median split on the FBQ data (separately for the aye aye and the possum). Separate GLM repeated measures were carried out for the high- and low-FBQ group (see Figure 2). The aye aye analysis revealed that the high $F B Q$ group requested more threatening than non-threatening information, $F(1,38)=8.19, p<.01, n \rho^{2}=.18$, this effect was absent in the low $F B Q$ group, $F(1,37)=2.65, p=.11, n \rho^{2}=.067$. The possum analysis revealed a similar pattern, with the high group requesting more threatening than non-threatening information, $F(1,37)=9.86, p<.005, n \rho^{2}=.21$, and no significant difference was observed in the low FBQ group, $F<1$.
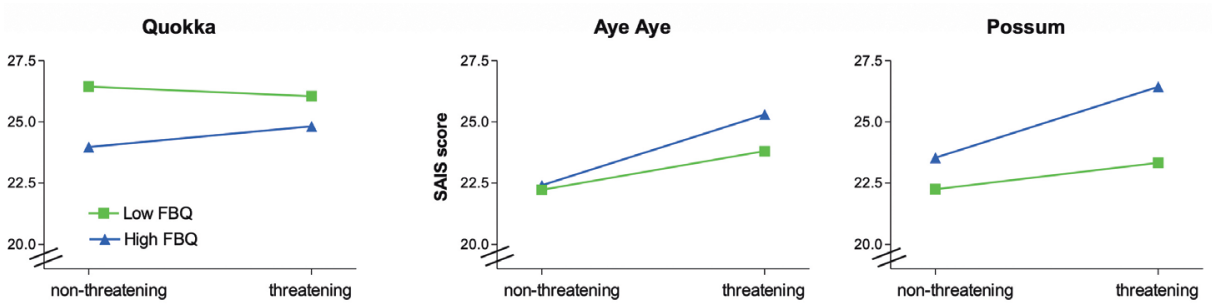

Figure 2 Information search for high- and low FBQ groups

\section{Behavioral approach test (BAT)}

The amount of reported distress (VAS) was analyzed with a GLM repeated measures with animal as within-subjects factor and gender as factor. This analysis revealed no effect, $F<1$. However, positive Pearson correlations were observed between the amount of reported distress and the accompanying FBQ scores; for the quokka $r=.50$, for the aye aye $r=.50$ and for the possum $r=.45$, ps $<.001$, indicating that higher levels of reported fear on the FBQ coincided with higher distress levels during the BAT.

For the quokka, 79 out of 80 children were able to feed the animal and the remaining child finished step 5 (i.e., child walks towards the box and observes the animal). For the aye aye, 76 children were able to feed the animal, one child finished step 5, and three children did not dare to approach the animal (0 steps completed) This same pattern was observed for the possum. Friedman's Test indicated that the three animals differed concerning the amount of steps, $\chi^{2}(2)=6.00, p<.05$. However, post-hoc tests did not reveal any significant differences, Wilcoxon Signed Ranks test, zs $>-1.73, p s>.083$

Finally, the order in which the animals were approached was analyzed. The quokka was firstly approached by 53 children, whereas the aye aye and possum were the first animal to approach by 9 and 18 children respectively. Friedman's test revealed significant differences between the three animals, $x^{2}(2)=26.99, p<.001$. Post-hoc tests indicated that the quokka was more often approached first than the aye aye and possum, zs < -4.21, ps <.001; no difference was observed between the aye aye and possum, $z=-.51, p=.61$. These results indicate that the children were more reluctant to approach the aye aye and possum than the quokka.

\section{Discussion}

The aim of the present study was to examine whether the mere perception of threat without providing additional information, results in confirmation bias in children To this end, 80 non-clinical children (age: 7-13 years) were shown a picture of an unknown neutral animal, the quokka, and two potentially dangerous-looking animals, the aye aye and an angry possum. Children rated these animals (threat attitude, VAS scores), filled out fear questionnaires concerning these animals (FBQs) and could indicate what kind of additional information, threatening or non-threatening, they would like to receive about the animals (SAIS). At the end the children were invited to feed each animal (BAT). The results indicated that, as expected, the children rated the aye aye and possum as more threatening (VAS) and fearful (FBQ) than the quokka. Concerning the search for additional information, more threatening than non-threatening information was requested for the animals that were perceived as threatening (i.e. aye aye and possum), indicative of confirmation bias; no such pattern was observed for the non-threatening quokka. As expected, this confirmation bias pattern was only observed in children that reported high levels of fear for the aye aye and possum (i.e. high FBQ scores); children with low levels of fear (i.e. low FBQ scores) did not show a discrepancy in search for non-threatening and threatening information. During the BAT children more often started with feeding the quokka than the two other animals, indicative of avoidance. Furthermore, higher fear belief scores (FBQ) coincided with more self-reported distress during the BAT. These results are in line with our expectations that just the mere perception of threat is sufficient to observe a confirmation bias and that this fear is also expressed in more avoidance.

The results agree with previous research on confirmation bias in children. That is, especially a negative view of an animal coincided with a search for additional threat information (see for indirect evidence Huijding, Muris, Lester, Field, \& Joosse, 2011 
Muris et al., 2011; Muris et al., 2009). However, our data on the quokka contradict the results of Muris et al. (2009). In their study a confirmation bias pattern was also observed for the neutral cuscus, even if no negative view was established. In our study, no discrepancy between the search of threatening and non-threatening information was detected. However, the quokka was rated as less threatening as the cuscus (FBO score, $M=22.18, S D=5.52$ ), $t(150)=2.88, p=.0046$. A logical explanation is that confirmation bias is only expressed in case fear exceeds a certain threshold, for example if the animal is rated at least as neutral (i.e., an FBQ score close to 30). Additionally, in the study of Muris et al. (2009) only one animal was presented, in the current study children received three different animal pictures. It is plausible that children compared the three pictures, resulting in a low level of perceived threat by the quokka.

The BAT data are in line with previous research on fear and avoidance. Higher fear levels coincided with more avoidance (Kivlighan, Lo Coco, \& Gullo, 2012). In our study this was most visible in the approach pattern. The least threatening animal, in this case the quokka, was more often approached first compared to the threatening aye aye and possum. An unexpected observation was the lack of a difference between the amounts of reported distress for the animals, though the distress scores did correlate with the FBQ scores. This might be explained by the approach pattern. Children more often selected the non-threatening quokka as the first animal to approach. Feeding a novel animal might elicit distress, even if the animal is rated as non-threatening. After feeding the animal successfully, distress extinction or habituation occurs and subsequent approaches are less fear-evoking, resulting in similar ratings across animals. This line of reasoning accords to the literature on habituation and extinction in anxious and non-anxious children. That is, as in our study, in case of no threat non-anxious children showed fast extinction and quickly habituated to potentially or previously harmful stimuli (Liberman, Lipp, Spence, \& March, 2006). In case of increased vulnerability or clinical anxiety the children displayed increased responding during a safe situation (Jovanovic et al., 2014; Liberman et al., 2006). Such impaired safety signal learning may be a risk factor for anxiety disorders in adulthood. An option for future studies could be to compare fear behavior and confirmation bias in anxious and non-anxious children.

One point that deserves attention is the confirmation bias patterns observed across animals. The bias was merely caused by a (relative) decrease in search for non-threatening information rather than an increase in the search for threatening information. This mainly reflects the absence of searching for alternative, nonconfirming information. Such strategy of course hinders the adjustment of a negative view into a more positive or neutral view. In the study by Muris et al. (2009) confirmation bias was mainly observed as an increased search for information in case negative or ambiguous information about the neutral cuscus was provided. However, providing positive information resulted in increased search of non-threatening information compared to no information. As such, one can argue that our quokka equaled the positive information condition of the study by Muris et al. (2009). The quokka was indeed rated as more kind than the remaining two animals. Nevertheless, this explanation does not clarify the absence of increased search for threatening information for the aye aye and cuscus. However, when taking a closer look at the level of fear and confirmation bias patterns, we do observe the expected pattern for the aye aye and possum. A high level of self-reported fear coincided with more search for threatening than non-threatening information; in case of a low level of fear no difference between the two types of information was observed. This discrepancy of these patterns was mostly visible as an increase in search for threatening information. These results do support the results of previous studies on confirmation bias in children (Muris et al.,2011; Muris et al.,2009: Remmerswaal, Huijding, Bouwmeester, Brouwer, \& Muris, 2014; Remmerswaal et al., 2010)

In the present study no additional information was provided in order to minimize memory bias effects. However, not providing information but only pictures renders the animals ambiguous. From a functional-evolutionary perspective it makes sense to check the dangerousness of novel or ambiguous animals (Öhman \& Mineka, 2001). Such 'better safe than sorry' strategy is then reflected in general high levels of search for threat-related information for all novel animals, even in case an animal is perceived as non-threatening. In case an animal also entails dangerous features, as is the case with the aye aye and possum, the focus lies on threat-related information, resulting in the ignorance of non-threat-related information.

The present study suffers from several limitations. First, in the current study we only included non-clinical children without anxiety problems. Though we observed an interaction between the perceived threat of each animal and the presence/ absence of confirmation bias, this does not imply that similar results will be obtained in a clinically anxious group. Applying the current (adjusted) experimental set-up in clinically anxious children would be a next, logical step. Based on the confirmation bias patterns observed in the high animal-related fear groups of the current study, we expect that a clinical sample will show an even more pronounced confirmation bias. This pattern might even extend to the non-threatening quokka.

Second, as no information was provided, all animals remained ambiguous, even the positively rated quokka. This has the advantage that spontaneous confirmation bias and avoidance patterns can be observed, but the drawback is that such lack of information might trigger a 'better safe than sorry' search strategy. For future studies 
we would recommend to include two additional groups that receive either positive or negative information.

Third, the current confirmation bias task incorporates threatening and nonthreatening statements, but does not comprise safety statements. The lack of safety statements hinders a valid comparison between search patterns for safe and threatening information. Additionally, the child does not have to make a choice between threatening and non-threatening statements, which might result, for some children, in a general interest for all statements. For future research, we strongly recommend adding safety statements enabling a direct comparison between search for safe, neutral and threatening information. Furthermore, we would recommend adding a second confirmation bias task in which children have to choose between predefined questions (positive, negative or neutral); answers to these questions will always be confirmative (Remmerswaal, Muris, \& Huijding, 2016). Such task provides more insight in pre-existing fear beliefs and, at the same time, confirms these beliefs (see for a similar approach, Huijding et al., 2011). Finally, it would be highly interesting to perform a follow-up memory test on the children tested. Not only to see which type of information is consolidated in memory, but also to assess the endurance of confirmation bias. Additionally, extending such follow up into a longitudinal study can help to examine the relation between confirmation bias and the development of anxiety disorders (Muris \& Field, 2013).

In spite of these shortcomings, the current study does indicate that perceived danger can coincide with confirmation bias. As such, the present data provide support for the notion that just the mere perception of danger is enough to encourage such a strategy. Additionally, we observed that threat-perception results in an initial avoidance of the more dangerous-looking animals. Further studies are necessary to explore the role of threat perception in search strategies in children.

\section{References}

Beck, A. T., \& Clark, D. A. (1997). An information processing model of anxiety: Automatic and strategic processes. Behaviour Research and Therapy, 35(1), 49-58. doi: 10.1016/S00057967(96)00069-1

De Jong. P. J., Mayer, B., \& Van Den Hout, M. (1997). Conditional reasoning and phobic fear: Evidence for a fear-confirming reasoning pattern. Behaviour Research and Therapy, 35(6), 507-516. doi: 10.1016/S0005-7967(96)00124-6

Eysenck, M.W., Derakshan, N., Santos, R., \& Calvo, M. G. (2007). Anxiety and cognitive performance: Attentional control theory. Emotion, 7(2), 336-353. doi: 10.1037/1528-3542.7.2.336

Hadwin, J. A., Frost, S., French, C. C., \& Richards, A. (1997). Cognitive processing and trait anxiety in typically developing children: Evidence for an interpretation bias. Journal of Abnormal Psychology, 106(3), 486

Huiiding, J., Muris, P., Lester, K. J., Field, A. P., \& Joosse, G. (2011). Training children to approach or avoid novel animals: Effects on self-reported attitudes and fear beliefs and informationseeking behaviors. Behaviour Research and Therapy, 49(10), 606-613. doi: 10.1016/j. brat.2011.06.005

Jovanovic, T., Nylocks, K. M., Gamwell, K. L., Smith, A., Davis, T. A., Norrholm, S. D., \& Bradley, B. (2014). Development of fear acquisition and extinction in children: Effects of age and anxiety. Neurobiology of Learning and Memory, 113, 135-142. doi: 10.1016/ nIm.2013.10.016

Kessler, R. C., Ruscio, A. M., Shear, K., \&Wittchen, H. (2009). Epidemiology of anxiety disorders In M. Stein \& T. Steckler (Eds.), Behavioral neurobiology of anxiety and its treatment. Current topics in behavioral neurosciences, vol 2. (pp. 21-35). Springer, Berlin, Heidelberg.

Kivlighan, D. M., Lo Coco, G., \& Gullo, S. (2012). Attachment anxiety and avoidance and perceptions of group climate: An actor-partner interdependence analysis. Journal of Counseling Psychology, 59(4), 518-527. doi: 10.1037/a0030173

Liberman, L. C., Lipp, O. V., Spence, S. H., \& March, S. (2006). Evidence for retarded extinction of aversive learning in anxious children. Behaviour Research and Therapy, 44(10), 1491 1502. doi: 10.1016/j.brat.2005.11.004

Merikangas, K. R., Nakamura, E. F., \& Kessler, R. C. (2009). Epidemiology of mental disorders in children and adolescents. Dialogues in Clinical Neuroscience, 11(1), 7-20.

Muris, P., \& Field, A. (2013). Information processing biases. In Essau C. A. \& Ollendick T. H. (Eds.), The Wiley-Blackwell handbook of the treatment of childhood and adolescent anxiety (pp. 141-156). Chichester: Wiley-Blackwel.

Muris, P., \& Field, A. P. (2010). The role of verbal threat information in the development of childhood fear. "Beware the Jabberwock!". Clinical Child and Family Psychology Review. 13(2), 129-150. doi: 10.1007/s10567-010-0064-1

Muris, P., Huijding, J., Mayer, B., van As, W., \& van Alem, S. (2011). Reduction of verbally learned fear in children: A comparison between positive information, imagery, and a contro condition. Journal of Behavior Therapy and Experimental Psychiatry, 42(2), 139-144. doi: 10.1016/j.jbtep.2010.11.006

Muris, P., Kindt, M., Bögels, S., Merckelbach, H., Gadet, B., \& Moulaert, V. (2000). Anxiety and threat perception abnormalities in normal children. Journal of Psychopathology and Behavioral Assessment, 22(2), 183-199. doi: 10.1023/a:1007588524525 
Muris, P., Rassin, E., Mayer, B., Smeets, G., Huijding, J., Remmerswaal, D., \& Field, A. (2009). Effects of verbal information on fear-related reasoning biases in children. Behaviour Research and Therapy, 47(3), 206-214. doi: 10.1016/j.brat.2008.12.002

Ohman, A., \& Mineka, S. (2001). Fears, phobias, and preparedness: Toward an evolved module of fear and fear learning. Psychological Review, 108(3), 483-522. doi: 10.1037/0033$295 \times .108 .3 .483$

Ollendick, T. H. (1983). Reliability and validity of the revised fear survey schedule for children (FSSC-R). Behaviour Research and Therapy, 21(6), 685-692. doi: 10.1016/0005 7967(83)90087-6

Ouimet, A. J., Gawronski, B., \& Dozois, D. J. A. (2009). Cognitive vulnerability to anxiety: A review and an integrative model. Clinical Psychology Review, 29(6), 459-470. doi: 10.1016/j. cpr.2009.05.004

Remmerswaal, D., Huijding, J., Bouwmeester, S., Brouwer, M., \& Muris, P. (2014). Cognitive bias in action: Evidence for a reciprocal relation between confirmation bias and fear in children. Journal of Behavior Therapy and Experimental Psychiatry, 45(1), 26-32. doi: 10.1016/j. jbtep.2013.07.005

Remmerswaal, D., Muris, P., \& Huijding, J. (2016). Transmission of cognitive bias and fear from parents to children: An experimental study. Journal of Clinical Child and Adolescent Psychology, 45(5), 642-654. doi: 10.1080/15374416.2014.987378

Remmerswaal, D., Muris, P., Mayer, B., \& Smeets, G. (2010). "Will a Cuscus bite you, if he shows his teeth?" Inducing a fear-related confirmation bias in children by providing verbal threat information to their mothers. Journal of Anxiety Disorders, 24(5), 540-546. doi: 10.1016/j. janxdis.2010.03.012

Smeets, G., de Jong, P. J., \& Mayer, B. (2000). If you suffer from a headache, then you have a brain tumour: Domain-specific reasoning 'bias' and hypochondriasis. Behaviour Research and Therapy, 38(8), 763-776. doi: 10.1016/S0005-7967(99)00094-7

Waters, A. M..Lipp, O. V., \& Spence, S. H. (2004). Attentional bias toward fear-related stimuli: An investigation with nonselected children and adults and children with anxiety disorders. Journal of Experimental Child Psychology, 89(4), 320-337. doi: 10.1016/j.jecp.2004.06.003 


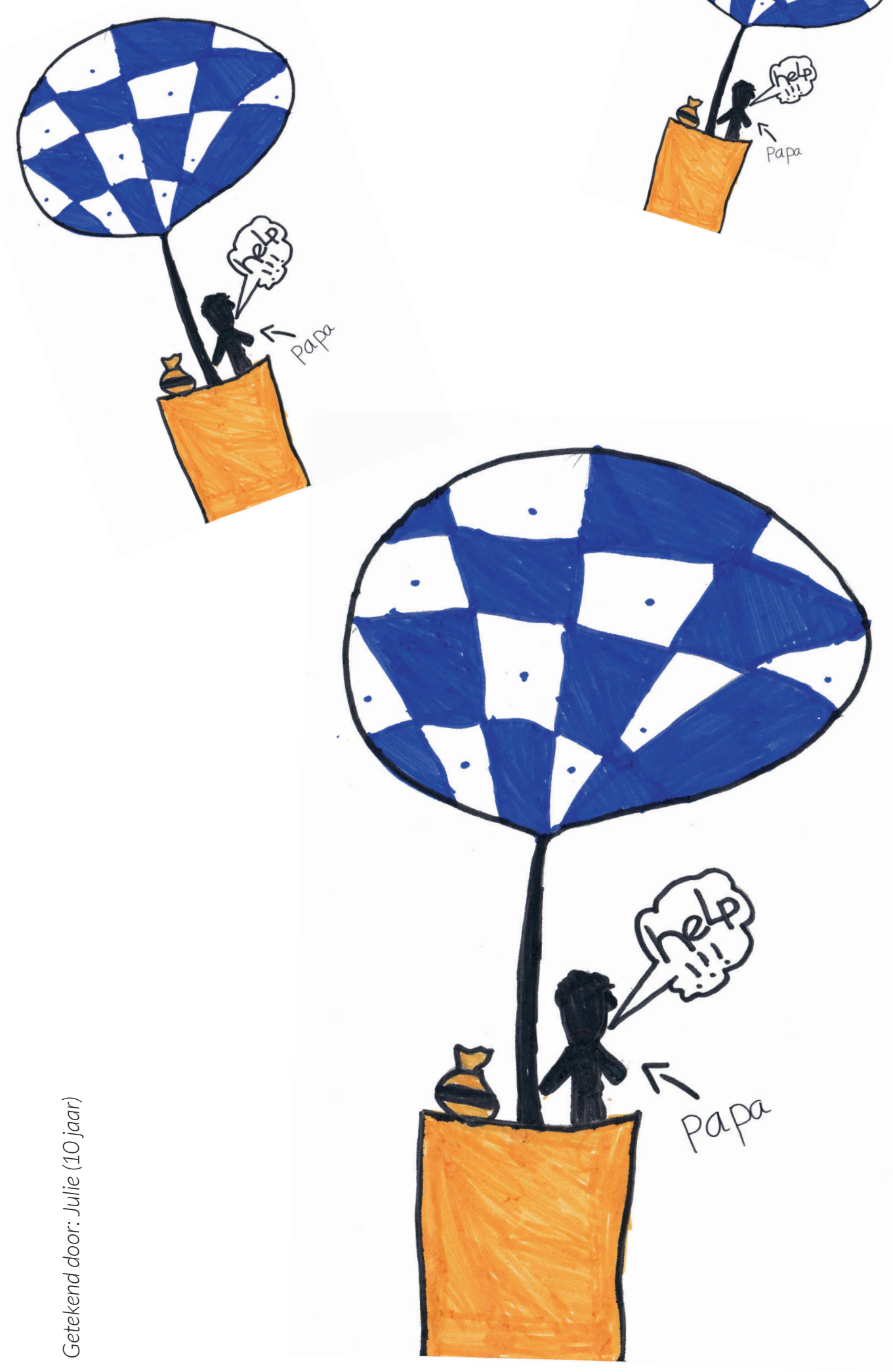

\section{Chapter 4}

Cognitive Bias as a Mediator in the Relation Between

Fear-Enhancing Parental Behaviors and Anxiety Symptoms in Children: A Cross-Sectional Study

Lorraine Fliek, Pauline Dibbets, Jeffrey Roelofs, Peter Muris 


\section{Abstract}

The present cross-sectional study explored the relations between fear-enhancing parenting behaviors (modeling and threat information transmission) and children's cognitive biases and anxiety symptoms. Participants were 258 children aged 7-12 years (132 boys and 126 girls), and their mothers $(n=199)$ and/or fathers $(n=117)$ Children and parents completed the Parental Enhancement of Anxious Cognitions questionnaire, which measures parental modeling and threat information transmission, while children also filled in a scale for assessing anxiety symptoms. In addition, children conducted a number of computerized tasks for measuring confirmation and interpretation bias. The data indicated that both biases mediated the relationship between threat information transmission (of both parents) and children's anxiety symptoms. Only interpretation bias significantly mediated the relationship between modeling (of mothers) and anxiety symptoms. These findings give partial support for the hypothesis that cognitive biases play a mediating role in the relation between fear-enhancing parental behaviors and children's anxiety symptoms.

Keywords: children's anxiety symptoms; cognitive biases; parenting; modeling; threat information transmission.

\section{Introduction}

Fear and anxiety are normal, mild, and transient phenomena in childhood, but in a minority of children these symptoms become so intense and invalidating that they qualify as an anxiety disorder (Muris, 2007). Heritability is thought to be involved in the etiology of childhood fear and anxiety problems, with behavioral-genetic studies showing that about 30\% of the variation in anxiety disorders can be ascribed to genetic influences (Eley \& Gregory, 2004). This means that environmental factors also play an important role in the development of fear and anxiety problems, and among these factors parenting behaviors are considered as particularly relevant (Murray, Creswell, \& Cooper, 2009).

In the current study, both parents were included, while previous studies have mostly included only mothers. The role of fathers has often been neglected, although there is some evidence suggesting that fathers play a unique and often different role than mothers in the development of anxiety problems in children (e.g., Bögels \& Phares, 2008; Fliek, Daemen, Roelofs, \& Muris, 2014). In the article we further focus on two types of parenting behaviors that, according to Rachman $(1977,1991)$ are involved in the acquisition of fear and anxiety symptoms within the context of the family. The first type is known as modeling or vicarious learning and refers to the phenomenon of children learning anxious behavior after watching parents acting in a fearful way when facing certain stimuli and situations. The second type is threat information transmission, which is concerned with parents installing fear and anxiety in their offspring by telling their children about the dangerousness of particular stimul and situations. There is a steadily growing body of evidence showing that parental modeling and threat information transmission can promote fear and anxiety in children (see reviews by Askew \& Field, 2008; Muris \& Field, 2010).

Early studies have typically relied on self-report questionnaires and interviews asking children about these types of learning experiences in relation to their main fear. For instance, in the studies conducted by Ollendick and King (1991) and Muris, Merckelbach, and Collaris (1997), children were first asked to identify their main object of fear, after which they had to indicate to what extent modeling and threat information transmission had played a role in the origins of that fear. It was found that substantial percentages (i.e., 50-90\%) of the children reported such learning experiences, and although their context was not explicitly examined, it is highly plausible that parents were involved.

Subsequent investigations have explored the role of modeling and threat information transmission using experimental designs. With regard to modeling, an exemplary study was conducted by Gerull and Rapee (2002) who investigated the influence of fearful 
responses of mothers to an unknown stimulus on young children's behavior. Fifteento 20-months-old toddlers were confronted with rubber toy animals (i.e., spider, snake), while their mother maintained either a negative or a positive facial expression. After a brief delay, children were again exposed to the toy animals to measure fear and avoidance reactions, this time without their mother being present. The results clearly indicated that toddlers for whom the toy animals had been previously paired with a negative facial expression of their mother showed more fear and avoidance than the toddlers for whom the toy animals had been presented with a positive facia expression of their mother (see also Dubi, Rapee, Emerton, \& Schniering, 2008).

To directly examine the effects of threat information transmission, Muris, Van Zwol, Huijding, and Mayer (2010) adopted a comparable approach. Parents of children aged 8-13 years ( $N=88$ ) were presented with either negative, positive, or ambiguous information about an unknown animal and were then given a number of open-ended vignettes describing hypothetical confrontations with the animal. Parents were instructed to tell their children what would happen in these situations. Results indicated that children's fear levels were influenced by the type of information that was provided to the parent. That is, parents who had received negative information provided more threatening narratives about the animal and hence installed higher levels of fear in their child than parents who had received positive information. In the case of ambiguous information, the transmission of fear was dependent on parents trait anxiety levels. More precisely, the higher the trait anxiety level of the parents, the more they were inclined to tell negative stories about the unknown animal on the basis of the ambiguous information, thereby producing higher fear levels in the child. Several other studies have also shown that cognitive biases can be induced in non-anxious individuals by providing them with negative information (Muris, Huijding, Mayer, \& Hameetman, 2008; Muris, Huijding, Mayer, Remmerswaal, \& Vreden, 2009a; Muris et al., 2009b; Remmerswaal, Muris, Mayer, \& Smeets, 2010).

Thus, there appears to be considerable evidence from both survey and experimental research for the idea that young children can rapidly acquire fear and anxiety via the parental behaviors of modeling and threat information transmission. However, little is known about the mechanisms involved in these ways of fear acquisition. It is well-known that threat-related cognitive biases are a robust correlate of anxiety pathology in children and adults (see reviews by Mathews, Mackintosh, \& Fulcher, 1997; Muris \& Field, 2008). However, only recently studies have begun o explore the possibility that cognitive biases are involved in the intergenerationa transfer of fear and anxiety. An investigation by Lester, Field, and CartwrightHatton (2012) found evidence indicating that the anxiety-related interpretation bias of mothers was not only concerned with self-referent situations, but also with situations that involved their children, suggesting that mothers may extend their own catastrophic cognitive style to the living environment of the children. Another study by Podină, Mogoașe, and Dobrean (2013) took this one step further and actually investigated whether cognitive biases indeed acted as mediators between maternal social anxiety and children's anxiety symptoms. Four-hundred-and-twenty-three mothers and their children completed questionnaires measuring anxiety symptoms and interpretation bias. Multiple mediation analysis demonstrated that both maternal and child interpretation biases were significant mediators in the relation between maternal social anxiety and children's anxiety symptoms. In similar research by Affrunti and Ginsburg (2012), it was also demonstrated that interpretation biases acted as the connector between parental and children's anxiety symptoms. A fina relevant investigation was recently conducted by Remmerswaal, Muris, and Huijding (2016) who examined the role of mothers in the development of a cognitive bias and subsequent fear levels in their offspring. Using an inventive experimental design, these researchers were able to show that mothers induced a negative information search bias in their children either on the basis of instruction or driven by their own anxiety, which was also associated with heightened fear levels in relation to a novel stimulus.

The above described research provides support for the idea that cognitive biases play a role in the transfer of fear and anxiety from parents to offspring. The aim of the present cross-sectional study was to further contribute to this literature. In a sample of 258 non-clinical youths aged 9 to 12 years, fear-enhancing parental variables (i.e., modeling and threat information transmission), children's cognitive biases, and children's and parents' anxiety symptoms were measured. In line with Hadwin, Garner, and Perez-Olivas (2006) who claim that cognitive biases might have their origins in parenting, we hypothesized that these biases would act as a mediator in the link between the parenting behaviors of modeling and threat information transmission and children's anxiety symptoms.

The current study adds to our existing knowledge in four ways: (1) A newly developed questionnaire was used which made it possible to simultaneously examine both modeling and threat information transmission as predictors of children's cognitive biases and subsequent anxiety symptoms. (2) The fear-enhancing parental behaviors of both parents were investigated, which can be seen as an advancement to previous studies that mainly focused on the role of mothers (e.g., Bögels \& Phares, 2008). Note that the comparison between both parents was exploratory in nature and so we did not have an explicit hypothesis. (3) Two types of cognitive biases, interpretation bias and confirmation bias, were assessed. Interpretation bias refers to the inclination to infer threat on the basis of ambiguous information, whereas confirmation bias has to do with the tendency to search for information that confirms one's anxious 
preconceptions, while ignoring information that could disconfirm threat. Most research has focused on only one type of bias, thereby neglecting the issue of whether such biases are inter-related and make independent contributions to anxiety. Although both interpretation bias and confirmation bias seem to be linked to the interpretation stage of social information processing (Crick \& Dodge, 1994), the present study explored the unique role of both biases as mediators in the relation between fearenhancing parenting behaviors and children's anxiety symptoms. (4) Because both parents also completed measures of trait anxiety and overprotection, we were also able to investigate to what extent the fear-enhancing parental behaviors of modeling and threat information transmission were associated with these two well-established parental correlates of childhood anxiety problems (Hudson \& Rapee, 2001; Last Hersen, Kazdin, Orvaschel, \& Perrin, 1991). Based on previous studies we expected that higher levels of fear-enhancing parenting behaviors would be associated with higher levels of trait anxiety and overprotection of parents.

\section{Method}

Participants

Participants were 258 non-clinical children (132 boys and 126 girls) aged between 7 and 12 years $(M=9.52, S D=1.38)$ and their parents. $A$ total of 199 mothers and 117 fathers (mean ages being 42.20 years, $S D=4.42$ and 44.36 years, $S D=4.95$, respectively, range 28-65 years) also participated in this study. All children had the Dutch nationality and the majority of them were from original Dutch descent ( 95\%). The remainder of the families represented a diversity of nationalities (i.e. German, Belgian, American, Moroccan, Irish, Hungarian, Swedish, and Iraqi). Parenta questionnaires were nearly always completed by children's biological parents; the two exceptions were one child who had adoptive parents and one child who was raised by two mothers. The latter child only answered the questions with regard to his biologica mother. About 15\% of children came from divorced families.

\section{Child measures}

The Parental Enhancement of Anxious Cognitions (PEAC) was construed for the purpose of this study. Initially, 23 items were created that referred to the fear-enhancing parenta behaviors of modeling and verbal threat information. Two steps were taken to obtain a final version of the scale that we considered as appropriate for our research. The first step involved an inspection of the initial set of PEAC items by two research experts in the field of fear acquisition (prof. Andy Field of Sussex University, Brighton, United Kingdom, and prof. Stanley Rachman of the University of British Columbia, Vancouver,
Canada) and 26 clinicians who worked with anxiety disordered children. The two experts helped us to refine and improve the items of the questionnaire, while the clinicians performed a face validity check: they were asked to classify each of the 23 PEAC items as either modeling or threat information transmission. The face validity check was satisfactory: clinicians classified almost all items correctly to either modeling or threat information transmission. The 2 threat information items that were not correctly classified by more than 2 clinicians were removed; these were 2 negatively formulated items and it appeared that they did not load consistently on the two factors. The second step was an exploratory factor analysis (with direct oblimin rotation), which was performed on the PEAC data of the children and their parents. ${ }^{3}$ For children, fathers, and mothers, the factor analysis produced the hypothesized structure with one factor representing modeling behaviors and one threat information transmission. However, 9 items (predominantly negatively formulated items) had to be removed as they did not load consistently on one of the two factors across the three informants. Thus, eventually 14 items were retained in the final version of the PEAC: 6 items pertained to modeling. while 8 items were concerned with threat information transmission (see Appendix) The child version of the PEAC asks children for each item to first rate the frequency of their fathers' and then that of their mothers' fear-enhancing behaviors, using 4-point Likert-scales $(0=$ never, 1 = sometimes, 2 = often, and $3=$ always $)$. For each factor, a total score can be computed by summing the ratings on relevant items. In the current study, Cronbach's alphas of the child version of the PEAC modeling and threat information transmission factors were .65 and .80 for the mother scales and .66 and .84 for the father scales, indicating that the measure has sufficient to good reliability.

The Revised version of the Screen for Child Anxiety Related Emotional Disorders is an extension of the original SCARED (Birmaher et al., 1997; Muris, Merckelbach, Van Brakel, \& Mayer, 1999b) and assesses symptoms of the entire spectrum of DSMIV-defined (American Psychiatric Association, 2000) anxiety disorders in children and adolescents. In the current study only the SCARED subscales of social phobia (7 items; e.g., "I don't like to be with unfamiliar people"), generalized anxiety disorder (9 items; e.g., "I worry about things working out for me"), and separation anxiety disorder (8 items; e.g., "I don't like being away from my family") were used, because these three types of anxiety were considered as most relevant for the scenarios that were employed to assess cognitive biases. Children were asked to rate the frequency with which they experienced each symptom using a three-point scale $(\mathrm{O}=$ almost never, 1 = sometimes, 2 = often) and a total anxiety score can be obtained by summing ratings on the items of the three selected anxiety scales (range: 0-48). Research

3 These data can be obtained from the first author. 
has demonstrated that the SCARED-R has good internal consistency, test-retest reliability, and validity (Muris, Dreessen, Bögels, Weckx, \& Van Melick, 2004; Muris, Merckelbach, Schmidt, \& Mayer, 1999a; Muris et al., 1999b). In the current study, the mean total anxiety score on the shortened SCARED was $16.67(S D=8.21)$ and an independent samples t-test revealed that girls $(M=18.29, S D=7.94)$ scored higher on this scale than did boys $(M=15.14, S D=8.20)[t(256)=3.13, p<.01]$. Further, the reliability of the SCARED-R total anxiety score was good, with a Cronbach's alpha of .87.

The Information Search Task (IST) was also developed for the purpose of this study to assess children's confirmation bias. The task was based on a similar paradigm as used in a previous study (Remmerswaal, Huijding, Bouwmeester, Brouwer, \& Muris, 2014). Children were presented with new, potentially threatening situations (e.g., going to a new school) about which they had to gain more information (e.g., "What would you like to know about the teachers at your new school?") by choosing between a positive (e.g., "Whether they have a nice way of teaching") and a negative (e.g., "Whether they become angry very easily") option. After making their choice, children always received a confirmative answer (e.g., positive: "Most teachers have a nice way of teaching", negative: "Most teachers become angry very easily"). In total, children were presented with 3 situations (the other two scenarios were: going to the new warehouse in the city and playing at a friend's home for the first time), for each of which they were able to seek new information 5 times. The types of information the children could collect were related to the different types of anxiety symptoms. A confirmation bias score was computed by summing the number of negative options chosen (range: 0-15). The reliability of the IST was acceptable, with a Cronbach's alpha of .72

To assess interpretation bias, we used three Ambiguous Stories (Muris, Rapee, Meesters, Schouten, \& Geers, 2003), which represented the themes of social anxiety (i.e., going to a sporting club for the first time), generalized anxiety (i.e., driving with your bike on a very busy street), and separation anxiety (i.e., staying with a friend while parents are on vacation). Children had to read the stories, which consisted of five sentences presented to them sentence by sentence on the computer screen. Following each sentence, they were asked whether they thought that the story would be "scary" or "not scary". A total interpretation bias score was calculated by summing up the number of sentences after which children indicated the story was going to be scary (range 0-15). The reliability of the Ambiguous Stories test was sufficient, with a Cronbach's alpha of. 63

\section{Parent measures}

The Y2-version of the Spielberger State-Trait Anxiety Inventory (STAI; Spielberger Gorsuch, Lushene, Vagg, \& Jacobs, 1983; Van der Ploeg, Defares, \& Spielberger, 1980) was used to assess trait anxiety in the parents. The questionnaire includes
20 items (e.g., "I feel nervous" and "I worry too much about little things") for which respondents have to indicate their answer on a four-point Likert type scale ( 1 = almost never, 2 = sometimes, 3 = often, 4 = almost always). After recoding the positively phrased items, a total score can be obtained by summing all items (range 20-80). There is clear support for the psychometric properties of the STAI (Bieling, Antony, \& Swinson, 1998; Spielberger et al., 1983). Cronbach's alphas in the present sample were .92 for the mothers and .94 for the fathers, indicating excellent reliability.

The Parental Overprotection Measure (POM; Edwards, Rapee, \& Kennedy, 2008) was used to measure overprotective parenting behaviors which are thought to restrict the child's exposure to situations that are perceived as threatening or harmful. The instrument consists of 19 items (e.g., "I do not allow my child to climb in trees" and "I protect my child from criticism") that are scored on a five-point Likert scale ( $\mathrm{O}=$ not at all, 1 = a little, 2 = somewhat, 3 = quite often, 4 = very often). A total score can be obtained by summing all items (range 0-76). The scale has been shown to possess high internal consistency, strong test-retest reliability, and good validity (Edwards et al., 2008). In the current study reliability was also good, with Cronbach's alphas of .88 for the mothers and .87 for the fathers.

A parent version of the Parental Enhancement of Anxious Cognitions (PEAC) was also completed by the parents. The scale is similar to the one completed by the children, but the 14 items are formulated from the perspective of the parent (e.g., "I warn my child explicitly that he/she should avoid dangerous situations" instead of "My mother/ father warns me explicitly that I should avoid dangerous situations"). Cronbach's alphas of the modeling and threat information transmission factors were .77 and .81 for the mother scales and .68 and .72 for the father scales, indicating that the parent version of the PEAC has sufficient to good reliability.

\section{Procedure}

Participants were recruited via four Dutch primary schools. Informed parental consent was obtained by sending parents an information letter about the study with a consent form. Children for whom parents granted permission were tested in smal groups (of approximately eight children per group) in a separate room in school. Each child used a computer to fill out the questionnaires and to conduct the cognitive bias tasks. This assessment took place under supervision of two experimenters, who guided the children through the session by providing instructions and by collectively conducting some practice items. The children received explicit instructions to call upon the experimenters in case they had any questions about the scales or tasks. The experimenters ensured that the children answered the questions and conducted the computer tasks confidentially and independently. Children first completed the 
SCARED and the PEAC, after which they carried out the IST and the Ambiguous Stories test. Children did not appear to experience great difficulties while completing the questionnaires and computer tasks. Some children had questions about how to fill out the negatively formulated items of the PEAC (most of these items were eventually removed during the factor analyses). Parents completed the questionnaires at home on their own computer using a web-link provided to them by the experimenters.

\section{Statistical analyses}

T-tests and correlations were computed to investigate possible differences and links among various child and parent scales. To investigate whether the two cognitive biases acted as mediators in the relation between modeling and threat information transmission on the one hand and anxiety symptoms of the child on the other hand we conducted a bootstrapping procedure for multiple mediators (Preacher \& Hayes, 2008) using the child-report data. We used the SPSS macro relying on a method with 1000 bootstrap resamples to test the indirect effects of modeling and threat information transmission via the potential mediating variables on child anxiety. The output provides a 95\% confidence interval of the indirect effects, controlling for the effects of the other variables. If zero is not included in the confidence interval, the effect is considered significant. This means that the effect of the independent variable (modeling or threat information) on the dependent variable (child anxiety) is mediated by the proposed mediators (confirmation bias or interpretation bias). We conducted four different analyses: one for each independent parenting variable of mothers and fathers.

\section{Results}

\section{General results}

Before discussing the main findings of the present study, a number of general results will be addressed. First, $t$-tests comparing the levels of modeling and threat information transmission between fathers and mothers revealed significant differences when these parenting behaviors were assessed from the child's perspective. As can be seen in Table 1, children indicated that their mothers more often displayed modeling $[t(248)=9.39 p=.01]$ and threat information transmission $[t(248)=9.29 p=.01]$ than their fathers. When using the parents' point-of-view, no significant differences between fathers and mothers were observed, although a trend was noted signaling somewhat higher levels of threat information transmission in fathers than in mothers $t(105)=1.93, p=.06]$. No differences were found between fathers and mothers with regard to trait anxiety or overprotective parenting [both $t(106)$ 's $<1$; see Table 1].
Second, a statistical comparison of the PEAC scores of children and parents indicated that children scored their mothers as higher on both modeling $[t(198)=5.70$ $p<.001]$ and threat information transmission $[t(198)=6.43 p<.001]$ than mothers themselves (Table 1). No such differences were observed when comparing the PEAC scores between children and fathers [both $t(115)$ 's $\leq 1.56$ p's $\geq .12$ ].

Table 1 Mean scores (standard deviations) on parent-related questionnaires as completed by parents and children separately, as well as reliability coefficients for various scales

\begin{tabular}{lllcl}
\hline Children & Mothers & $a$ & Fathers & $a$ \\
\cline { 2 - 5 } \multicolumn{1}{l}{ PEAC Modeling } & $10.77(3.14)^{\mathrm{a}}$ & .65 & $9.39(2.82)^{\mathrm{b}}$ & .66 \\
PEAC Threat info & $22.94(4.96)^{\mathrm{a}}$ & .80 & $21.14(5.44)^{\mathrm{b}}$ & .84 \\
Parents & & & & \\
PEAC Modeling & $9.40(2.69)^{\mathrm{b}}$ & .77 & $9.19(2.46)^{\mathrm{b}}$ & .68 \\
PEAC Threat info & $20.24(4.27)^{\mathrm{b}}$ & .81 & $20.97(3.54)^{\mathrm{b}}$ & .72 \\
STAl Trait anxiety & $31.90(8.12)$ & .92 & $31.86(8.88)$ & .94 \\
POM Overprotection & $24.12(10.40)$ & .88 & $25.06(10.08)$ & .87 \\
\hline
\end{tabular}

Note. N's were 199 for mothers, 117 for fathers and 258 for children. STAI = State-Trait Anxiety Inventory; POM = Parental Overprotection Measure; PEAC $=$ Parental Enhancement of Anxious Cognitions. Threat info = Threat information transmission. For each type of fear-enhancing parenting behavior, within-row and within column means not sharing similar superscripts differ at $p<.01$

\section{Correlation analysis}

Table 2 displays correlations among various child and parent measures included in this study. A number of conclusions can be drawn from this table. When looking at the correlations obtained among the child measures, it can first of all be concluded that fearenhancing parenting behaviors of fathers and mothers were positively and significantly correlated (all r's between .31 and .83, p's < .01). Thus, according to the children, mothers' and fathers' modeling and negative information transmission were moderately to strongly associated. Fear-enhancing parenting behaviors were also positively related to children's anxiety symptoms (r's between .32 and .37, $p^{\prime} s<.01$ ), implying that the more children perceived modeling and negative information transmission in fathers and mothers, the higher their levels of anxiety symptoms. Further, children's anxiety symptoms were also positively linked to cognitive bias scores ( $r$ 's $=.31$ and .49, p's .01). That is, higher levels of anxiety symptoms were accompanied by higher levels of threatening interpretations of ambiguous stories (i.e., interpretation bias) and a stronger endency to search for negative information (i.e., confirmation bias). Finally, a small but significant positive correlation was found between both types of cognitive biases $(r=.20$, $p<.01$ ), meaning that a stronger inclination towards threat interpretation was also to some extent associated with a stronger tendency to search for negative information. 
The correlations among the scales as completed by the mothers revealed the expected pattern of positive links among trait anxiety, overprotection, and the fearenhancing parental behaviors of modeling and negative information transmission. Most of these correlations were in the small to moderate range, but in particular the correlation between overprotection and threat information transmission was quite robust $(r=.60, p<.001)$. In fathers, the correlations among parental indices were less clear. Only a small correlation between trait anxiety and modeling was found $(r=.23$, $p$ $<$.05), whereas the link between overprotection and threat information transmission was again substantial $(r=.55, p<.001)$

When looking at the cross-informant correlations in Table 2, the overall conclusion is that few significant associations between child- and parent-reports and between measures of mothers and fathers were found. As for fear-enhancing parenting, significant correlations emerged for modeling of mothers and fathers as reported by the children and modeling as reported by mothers and fathers themselves ( $r$ 's being. 25 and .28, respectively, $p$ 's < .01). In addition, threat information transmission of mothers as reported by the children was positively linked to threat information transmission as reported by mothers themselves, although the magnitude of this correlation was small $(r=.15, p<.05)$. Fathers and mothers did show some similarity with regard to their level of trait anxiety and overprotective parenting ( $r$ 's being 20 and .38, p's < .05), but for the fear-enhancing behaviors of modeling and threat information transmission correlations between fathers and mothers were nonsignificant. Finally, parental indices and children's anxiety symptoms and cognitive biases were largely unrelated, except for a small positive correlation between threat information transmission of mothers and children's anxiety symptoms $(r=.17, p<.05)$.

\section{The mediating role of cognitive biases}

The results of the mediation analyses are presented in Table 3. In the first analysis, threat information transmission of mothers was the independent variable. The indirect effects of confirmation bias (bias corrected $95 \% \mathrm{Cl}=.02, .10$ ) and interpretation bias (bias corrected $95 \% \mathrm{Cl}=.01, .12$ ) were both significant. The direct effect was not significant, which implies that these cognitive biases mediated the relationship between maternal threat information transmission and child anxiety. In the second analysis, modeling of mothers was the independent variable. Only the indirect effect of interpretation bias was found to be significant (bias corrected $95 \% \mathrm{Cl}=.03, .14$ ). Here, the direct effect still accounted for a significant proportion of the variance in children's anxiety symptoms

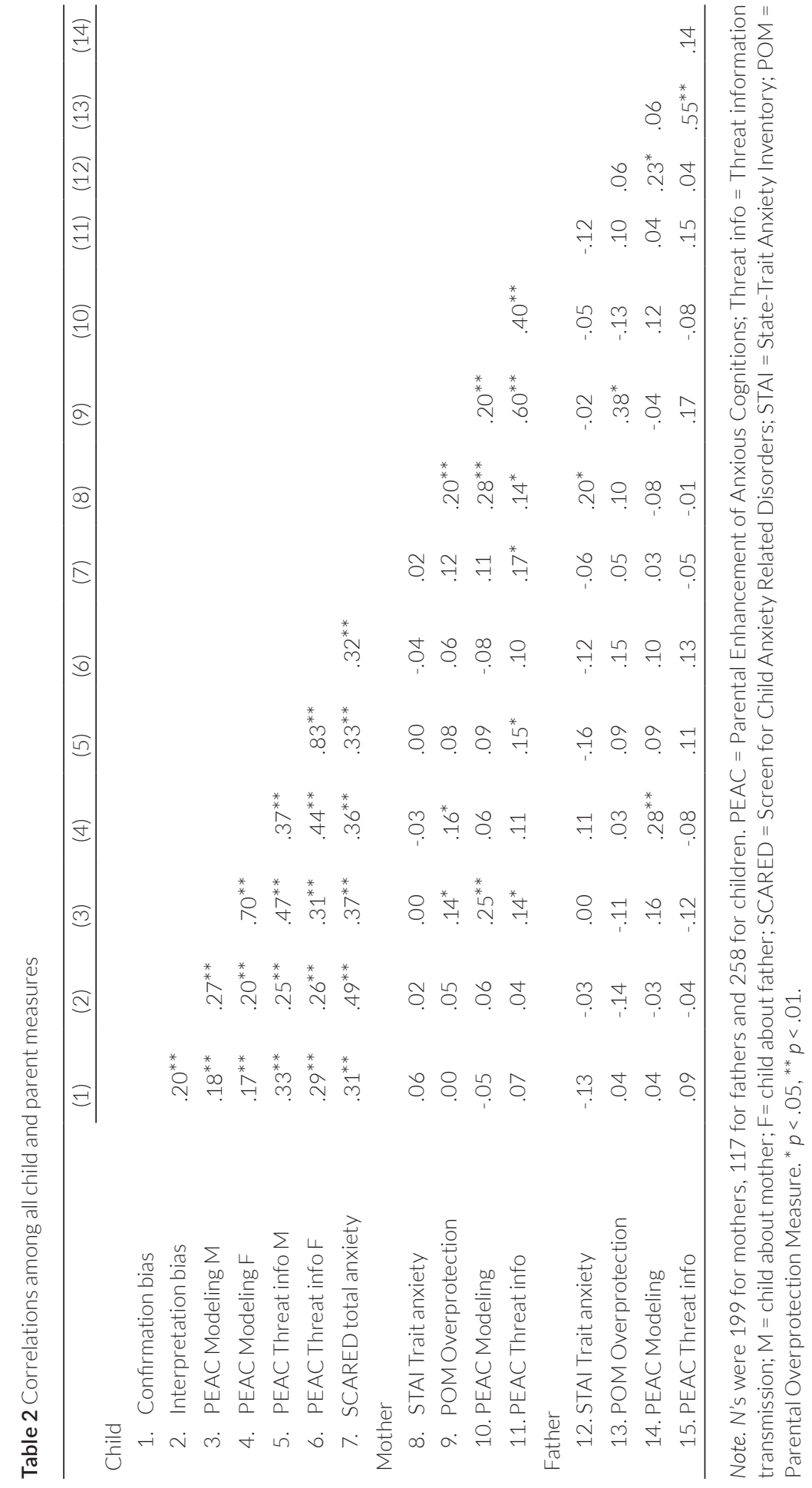


Table 3 Results of the bootstrapping analyses testing cognitive biases as mediators between childreported threat information transmission and modeling of parents and children's anxiety symptoms

\begin{tabular}{lllllll}
\hline IV & M & $\begin{array}{l}\text { Effect of } \\
\text { IV on M }\end{array}$ & $\begin{array}{l}\text { Effect of } \\
\text { Mon DV }\end{array}$ & $\begin{array}{l}\text { Direct } \\
\text { effect }\end{array}$ & $\begin{array}{l}\text { Indirect } \\
\text { effect }\end{array}$ & $\begin{array}{l}\text { Total } \\
\text { effect }\end{array}$ \\
\hline Mothers & & & & & & \\
\hline Threat information & Confirmation bias & $.31^{* * *}$ & $.17^{* *}$ & .09 & $.05^{a}$ & $.20^{* *}$ \\
& Interpretation bias & $.16^{*}$ & $.39^{* * *}$ & & $.16^{\text {a }}$ & \\
Modeling & Confirmation bias & .03 & $.17^{* *}$ & $.19^{* *}$ & .01 & $.28^{* * *}$ \\
& Interpretation bias & $.20^{* *}$ & $.39^{* * *}$ & & $.08^{\text {a }}$ & \\
\hline Fathers & & & & & & \\
\hline Threat information & Confirmation bias & $.26^{* * *}$ & $.18^{* *}$ & .06 & $.05^{\text {a }}$ & $.20^{* *}$ \\
& Interpretation bias & $.21^{* *}$ & $.42^{* * *}$ & & $.09^{\text {a }}$ & \\
Modeling & Confirmation bias & .05 & $.18^{* *}$ & $.21^{* * *}$ & .01 & $.27^{* * *}$ \\
& Interpretation bias & .11 & $.42^{* * *}$ & & .05 & \\
\hline
\end{tabular}

Note. IV = Independent Variable, $M=$ Mediator, $\mathrm{DV}$ = Dependent Variable. ${ }^{\mathrm{a}}$ Significant point estimate $(p$ $<.05) .{ }^{*} p<.05,{ }^{* *} p<.01,{ }^{* * *} p<.001$

In the third analysis, threat information transmission of fathers was the independent variable. Both the indirect effects of confirmation bias (bias corrected $95 \% \mathrm{Cl}=.02$, .09) and interpretation bias (bias corrected $95 \% \mathrm{Cl}=.03, .16$ ) were significant. As the direct effect was non-significant, it can be concluded that both cognitive biases mediated the relationship between paternal threat information transmission and child anxiety. In the final analysis, modeling of fathers was the independent variable. The indirect effects for confirmation bias (bias corrected 95\% Cl $=-.01, .04$ ) and interpretation bias (bias corrected $95 \% \mathrm{Cl}=-.01, .11$ ) were not significant, which means that there was no indication for a mediation effect.

\section{Discussion}

The aim of the present study was to examine whether cognitive biases play a role in the transfer of fear and anxiety from parents to offspring. More specifically, it was investigated whether confirmation bias and interpretation bias would act as mediators in the relation between the fear-enhancing parenting behaviors of modeling and threat information transmission and anxiety symptoms in children. The results first of all showed that child-reported modeling and threat information transmission of fathers and mothers were positively related to children's anxiety symptoms. Thus, children who indicated that their parents often acted as an anxious model or frequently communicated threat information also displayed higher levels of anxiety. Further, evidence was found indicating that both confirmation and interpretation bias mediated the relationship between threat information transmission of both mother and father and children's anxiety symptoms, which is in keeping with other studies investigating the mediational role of cognitive bias in the relation between parenting behaviors and childhood anxiety problems (Gallagher \& Cartwright-Hatton, 2008; Pereira, Barros, Mendonça, \& Muris, 2014; Perez-Olivas, Stevenson, \& Hadwin, 2008). The support for a mediating role of cognitive bias in the relation between modeling and children's anxiety symptoms was less convincing. Only interpretation bias mediated the relationship between modeling of mothers (but not of fathers) and children's anxiety symptoms. Remarkably, the direct effect of modeling on children's anxiety symptoms still accounted for a significant proportion of the variance in the models of both the mothers and the fathers. This implies that parental modeling does not solely exert its impact via children's cognitive biases, but suggests other mediators (or moderators) to be involved in the relation between maternal modeling and children's anxiety symptoms.

It is unclear why cognitive biases played a more important role in the relation between parental threat information transmission and children's anxiety symptoms than it did in the relation between parental modeling and children's anxiety symptoms. A plausible explanation has to do with the fact that cognitive biases are verbal in nature, and this might be the modus operandi of threat information transmission. That is, parents verbally communicate threat information to the child, thereby having a direct impact on the cognitions of their offspring. The mechanism involved in the relation between modeling and child anxiety seems to be quite different. Illustrative in this regard is the research on social referencing; children observe their mothers reacting with fear and anxiety to a certain stimulus or situation, and subsequently start to copy that anxious behavior when they are exposed to that stimulus or situation themselves (de Rosnay, Cooper, Tsigaras, \& Murray, 2006). This mechanism already occurs in children at a young age and seems less cognitive, but above all emotionalbehavioral in nature.

The pattern of the effects in the mediation models was more or less comparable for both parents. It may well be the case that the contributions of fathers and mothers to children's anxiety symptoms are made via the same mechanisms. However, one should also be aware of the possibility that similarities in findings for mothers and fathers might have been mainly due to the fact that these analyses only relied on the child-report data, for which the mother and father ratings on the PEAC were highly correlated. The cross-informant (i.e., child-father, child-mother) correlations in general yielded few significant findings (see review by De Los Reyes \& Kazdin 2005), and thus were less suitable for studying differential findings between both parents. It would have been interesting if we had assessed all constructs (that is, not 
only fear-enhancing parenting behaviors, but also children's cognitive biases and anxiety symptoms) from both parents' point-of-view, and this is an important venue for further research.

When looking at the PEAC data, a number of additional findings should be noted. First, according to the children, mothers displayed more modeling and threat information transmission than fathers, which is of course in keeping with the literature indicating that females (mothers) generally display higher levels of fear and anxiety and are probably more likely to engage in fear-enhancing behaviors than males (Craske, 2003). However, when looking at the parental data, no evidence was found for this idea: that is, mothers and fathers did not only report equal levels of modeling and threat information transmission, but also did not differ in terms of trait anxiety and overprotection. It is not clear why children rated their mothers as higher on fearenhancing behaviors, but one explanation could be that mothers more often act as the primary caretaker and thus spent more time with their children (Lamb, 2000). It is possible that for this reason children could think of more examples when evaluating the behaviors of their mothers and as such provided higher ratings of modeling and threa information transmission. Second, the child-parent and mother-father correlations for the PEAC scales were rather low or non-significant. Again, this is in line with previous findings and indicates that informant discrepancies not only occur when assessing childhood symptoms but also when measuring contextual, etiological factors, such as fear-enhancing parental behaviors. Third, when looking at the relations between the PEAC scales and two well-known parental correlates of childhood anxiety symptoms, namely parental trait anxiety and overprotective parenting (Hudson \& Rapee, 2001 Last et al., 1991), the mother data clearly showed the predicted pattern of findings. That is, positive and significant correlations emerged among modeling, threat information transmission, trait anxiety, and overprotection. The father data only revealed significant correlations between trait anxiety and modeling, and between overprotection and threat information transmission. Obviously, these results provide some support for the validity of the PEAC scales. The fact that the most robust correlation (for both mothers and fathers) was found between overprotection and threat information transmission makes sense, and seems to point out that parents especially try to shield their offspring against potential danger by providing them with threatening information.

The two types of cognitive biases, interpretation bias and confirmation bias, were only moderately correlated. The modest overlap between both biases was also confirmed in the mediation analyses, which showed that interpretation bias and confirmation bias each made their own unique contributions as mediators in the relation between parental fear-enhancing behaviors and children's anxiety symptoms.
Since interpretation and confirmation bias are both thought to occur during the more conceptual stages of information processing (Crick \& Dodge, 1994; Muris \& Field 2008), we had expected to find a higher correlation between these biases. So far, few other studies have explored the relations among (children's) cognitive biases and the unique links of these biases to anxiety disorders symptoms. One exception is an investigation by Dalgleish et al. (Dalgleish et al., 2003) who also documented small, mostly non-significant correlations among various types of biases in a sample of youth with mixed internalizing disorders. These authors argued that this may have been primarily due to the fact that these biases are measured with different experimental tasks, thereby introducing quite a large amount of non-shared variance which leads to fairly low inter-correlations among various biases. Obviously, this argument is also true for the two biases that were investigated in the present study.

The assessment of multiple cognitive biases was certainly a strong point of this study as was the inclusion of both mothers and fathers. However, the present investigation also suffers from a number of limitations. To begin with, this was a cross-sectional study, which means that no conclusions about the directionality of the relationships can be drawn. Obviously, a longitudinal set-up is needed, a requirement which will be met as we are planning a follow-up assessment of this sample. A further shortcoming has already been mentioned and is concerned with the fact that we did not take all the assessments in every informant. Moreover, it would have been preferable if we had not only relied on rating scales for measuring modeling and threat information transmission, but had also employed some kind of interview or observational method to assess these fear-enhancing parental behaviors. More specifically, children could either be asked open-ended questions to learn more about how their parents discourage various behaviors or how threatening their parents view the world (e.g., new places, unfamiliar people, risky situations), or child-paren interactions could be observed in challenging situations. Apart from the fact that such a multi-method approach is preferable, this would also give us the opportunity to study the validity of the PEAC more thoroughly. Furthermore, the reliability coefficients of the modeling subscale of the PEAC, in particular for the child and father data, were on the low side. The most plausible explanation might be that the modeling scale consists of only a limited set of items that are quite heterogeneous in terms of content. That is, modeling items refer to parents' concealed fear reactions, facial expression, body language, and panic symptoms, which may not all be equally well observed and scored, especially by children. Another shortcoming of the study has to do with the fixed sequence in which the questionnaires were administered, which may have introduced some unintended order effects. For example, responding to SCARED social anxiety items may have primed children's responses on the bias tasks, which were partly 
geared to assess children's responses to scenarios depicting social situations. Finally, children's PEAC scores for mothers and fathers were strongly correlated, which may be the result of the method of scoring each item simultaneously for both parents (left on the screen: father, right on the screen: mother). For future studies, it would be better to present the father and mother versions of this questionnaire serially instead of parallel.

This cross-sectional study is the first to explore relations between parenta modeling and verbal threat information and child anxiety symptoms, while taking into account the role of two types of cognitive biases: confirmation bias and interpretation bias. Some evidence was provided for a mediating role of cognitive biases in the relation between threat information transmission and child anxiety. This suggests that intervention programs targeting anxiety problems of children via the parents should target the threat information transmission pathway if one intends to produce cognitive change, whereas a focus on the modeling pathway is required to produce behavioral change. Future research should explore this possibility in anxious children of various ages.

\section{References}

Affrunti, N. W., \& Ginsburg, G. S. (2012). Exploring parental predictors of child anxiety: The mediating role of child interpretation bias. Child and Youth Care Forum, 41(6), 517-527. doi: 10.1007/s10566-012-9186-6

American Psychiatric Association. (2000). Diagnostic and statistical manual of mental disorders. (4th ed., text rev.). Washington, DC

Askew, C., \& Field, A. P. (2008). The vicarious learning pathway to fear 40 years on. Clinical Psychology Review, 28(7). 1249-1265. doi: 10.1016/j.cpr.2008.05.003

Bieling. P. J., Antony, M. M., \& Swinson, R. P. (1998). The State-Trait Anxiety Inventory, Trait version: structure and content re-examined. Behaviour Research and Therapy, 36(7-8), 777-788.

Birmaher, B., Khetarpal, S., Brent, D., Cully, M., Balach, L., Kaufman, J., \& Neer, S. M. (1997) The Screen for Child Anxiety Related Emotional Disorders (SCARED): Scale construction and psychometric characteristics. Journal of the American Academy of Child and Adolescent Psychiatry, 36(4), 545-553. doi: 10.1097/00004583-199704000-00018

Bögels, S. M., \& Phares, V. (2008). Fathers' role in the etiology, prevention and treatment of child anxiety: A review and new model. Clinical Psychology Review, 28(4), 539-558. dol: 10.1016/j.cpr.2007.07.011

Craske, M. G. (2003). Origins of phobias and anxiety disorders: Why more women than men Oxford: Elsevier.

Crick, N. R., \& Dodge, K. A. (1994). A review and reformulation of social information-processing mechanisms in children's social adjustment. Psychological Bulletin, 115(1), 74-101. doi: 10.1037/0033-2909.115.1.74

Dalgleish, T., Taghavi, R., Neshat-Doost, H., Moradi, A., Canterbury, R., \& Yule, W. (2003) Patterns of processing bias for emotional information across clinical disorders: A comparison of attention, memory, and prospective cognition in children and adolescents with depression, generalized anxiety, and posttraumatic stress disorder. Journal of Clinica Child and Adolescent Psychology, 32(1), 10-21. doi: 10.1207/s15374424jccp3201_02

De Los Reyes, A., \& Kazdin, A. E. (2005). Informant discrepancies in the assessment of childhood psychopathology: A critical review, theoretical framework, and recommendations for further study. Psychological Bulletin, 131(4). 483. doi: 10.1037/0033-2909.131.4.483

de Rosnay, M., Cooper, P. J., Tsigaras, N., \& Murray, L. (2006). Transmission of social anxiety from mother to infant: An experimental study using a social referencing paradigm. Behaviour Research and Therapy, 44(8), 1165-1175. doi: 10.1016/j.brat.2005.09.003

Dubi, K., Rapee, R., Emerton, J., \& Schniering, C. (2008). Maternal modeling and the acquisition of fear and avoidance in toddlers: Influence of stimulus preparedness and child temperament. Journal of Abnormal Child Psychology, 36(4), 499-512. doi: 10.1007/ s10802-007-9195-3

Edwards, S. L., Rapee, R. M., \& Kennedy, S. J. (2008). Psychometric properties of a parent-report measure of overprotection of preschool-aged children. Unpublished manuscript.

Eley, T. C., \& Gregory, A. M. (2004). Behavioral genetics. In T. M. Morris \& J. S. March (Eds.) Anxiety disorders in children and adolescents (pp. 71-97). New York: Guilford Press.

Fliek, L., Daemen, E., Roelofs, J., \& Muris, P. (2014). Rough-and-tumble play and other parenta factors as correlates of anxiety symptoms in preschool children. Journal of Child and Family Studies, 24(9), 2795-2804. doi: 10.1007/s10826-014-0083-5 
Gallagher, B., \& Cartwright-Hatton, S. (2008). The relationship between parenting factors and trait anxiety: Mediating role of cognitive errors and metacognition. Journal of Anxiety Disorders, 22(4), 722-733. doi: 10.1016/j.janxdis.2007.07.006

Gerull, F. C., \& Rapee, R. M. (2002). Mother knows best: Effects of maternal modelling on the acquisition of fear and avoidance behaviour in toddlers. Behaviour Research and Therapy 40(3), 279-287. doi: 10.1016/S0005-7967(01)00013-4

Hadwin, J. A., Garner, M., \& Perez-Olivas, G. (2006). The development of information processing biases in childhood anxiety: A review and exploration of its origins in parenting. Clinical Psychology Review, 26(7), 876-894. doi: 10.1016/j.cpr.2005.09.004

Hudson, J. L., \& Rapee, R. M. (2001). Parent-child interactions and anxiety disorders: An observational study. Behaviour Research and Therapy, 39(12), 1411-1427. doi: 10.1016/ S0005-7967(00)00107-8

Lamb, M. E. (2000). The history of research on father involvement: An overview. Marriage and Family Review, 29(2-3), 23-42. doi: 10.1300/J002v29n02_03

Last, C. G., Hersen, M., Kazdin, A., Orvaschel, H., \& Perrin, S. (1991). Anxiety disorders in children and their families. Archives of General Psychiatry, 48(10), 928-934. doi: 10.1001/ archpsyc.1991.01810340060008

Lester, K. J., Field, A. P., \& Cartwright-Hatton, S. (2012). Maternal anxiety and cognitive biases towards threat in their own and their child's environment. Journal of Family Psychology 26(5). 756-766. doi: 10.1037/a0029711

Mathews, A., Mackintosh, B., \& Fulcher, E. P. (1997). Cognitive biases in anxiety and attention to threat. Trends in Cognitive Sciences, 1(9), 340-345. doi: 10.1016/S1364-6613(97)01092-9 Muris, P. (2007). Normal and abnormal fear and anxiety inchildrenandadolescents. Oxford, UK: Elsevier.

Muris, P., Dreessen, L., Bögels, S. M., Weckx, M., \& Van Melick, M. (2004). A questionnaire fo screening a broad range of DSM-defined anxiety disorder symptoms in clinically referred children and adolescents. Journal of Child Psychology and Psychiatry, 45(4). 813-820. doi: 10.1111/j.1469-7610.2004.00274.x

Muris, P., \& Field, A. P. (2008). Distorted cognition and pathological anxiety in children and adolescents. Cognition and Emotion, 22(3), 395-421. doi: 10.1080/02699930701843450

Muris, P., \& Field, A. P. (2010). The role of verbal threat information in the development of childhood fear. "Beware the Jabberwock!". Clinical Child and Family Psychology Review, 13(2), 129-150. doi: 10.1007/s10567-010-0064-1

Muris, P., Huijding, J., Mayer, B., \& Hameetman, M. (2008). A space odyssey: experimental manipulation of threat perception and anxiety-related interpretation bias in children. Child Psychiatry and Human Development, 39(4), 469-480. doi: 10.1007/s10578-008-0103-z

Muris, P., Huijding, J., Mayer, B., Remmerswaal, D., \& Vreden, S. (2009a). Ground control to Major Tom: Experimental manipulation of anxiety-related interpretation bias by means of the "space odyssey" paradigm and effects on avoidance tendencies in children. Journal of Anxiety Disorders, 23(3), 333-340. doi: 10.1016/j.janxdis.2009.01.004

Muris, P., Merckelbach, H., \& Collaris, R. (1997). Common childhood fears and their origins. Behaviour Research and Therapy, 35(10), 929-937. doi: 10.1016/S0005-7967(97)00050-8

Muris, P., Merckelbach, H., Schmidt, H., \& Mayer, B. (1999a). The revised version of the Screen for Child Anxiety Related Emotional Disorders (SCARED-R): Factor structure in normal children. Personality and Individual Differences, 26(1), 99-112. doi: 10.1016/S01918869(98)00130-5

Muris, P., Merckelbach, H., Van Brakel, A., \& Mayer, B. (1999b). The revised version of the Screen for Child Anxiety Related Emotional Disorders (SCARED-R): Further evidence for its reliability and validity. Anxiety Stress and Coping, 12(4), 411-425. doi: 10.1080/10615809908249319
Muris, P., Rapee, R. Meesters, C., Schouten, E., \& Geers, M. (2003). Threat perception abnormalities in children: The role of anxiety disorders symptoms, chronic anxiety, and state anxiety. Journal of Anxiety Disorders, 17(3), 271-287. doi: 10.1016/S08876185(02)00199-8

Muris, P., Rassin, E., Mayer, B., Smeets, G., Huijding, J., Remmerswaal, D., \& Field, A. (2009b). Effects of verbal information on fear-related reasoning biases in children. Behaviour Research and Therapy, 47(3), 206-214. doi: 10.1016/j.brat.2008.12.002

Muris, P., van Zwol, L., Huijding, J., \& Mayer, B. (2010). Mom told me scary things about this animal: Parents installing fear beliefs in their children via the verbal information pathway. Behaviour Research and Therapy, 48(4), 341-346. doi: 10.1016/j.brat.2009.12.001

Murray, L., Creswell, C., \& Cooper, P. J. (2009). The development of anxiety disorders in childhood: An integrative review. Psychological Medicine, 39(9), 1413-1423. doi: 10.1017/ s0033291709005157

Ollendick, T. H., \& King, N. J. (1991). Origins of childhood fears: An evaluation of Rachman's theory of fear acquisition. Behaviour Research and Therapy, 29(2), 117-123. doi: 10.1016/0005-7967(91)90039-6

Pereira, A. I., Barros, L., Mendonça, D., \& Muris, P. (2014). The relationships among parental anxiety, parenting, and children's anxiety: The mediating effects of children's cognitive vulnerabilities. Journal of Child and Family Studies, 23(2), 399-409. doi: 10.1007/s10826-013-9767-5

Perez-Olivas, G., Stevenson, J., \& Hadwin, J. A. (2008). Do anxiety-related attentional biases mediate the link between maternal over involvement and separation anxiety in children? Cognition and Emotion, 22(3). 509-521. doi: 10.1080/02699930801886656

Podină, I. R., Mogoașe, C., \& Dobrean, A. (2013). Intergenerational transmission of anxiety: Evidence for the mediating role of the negative interpretation bias. Journal of Cognitive and Behavioral Psychotherapies, 13(2), 309-320.

Preacher, K. J., \& Hayes, A. F. (2008). Asymptotic and resampling strategies for assessing and comparing indirect effects in multiple mediator models. Behavior Research Methods, 40(3), 879-891. doi: 10.3758/BRM.40.3.879

Rachman, S. (1977). The conditioning theory of fearacquisition: A critical examination. Behaviour Research and Therapy, 15(5), 375-387. doi: 10.1016/0005-7967(77)90041-9

Rachman, S. (1991). Neo-conditioning and the classical theory of fear acquisition. Clinica Psychology Review, 11(2), 155-173. doi: 10.1016/0272-7358(91)90093-A

Remmerswaal, D., Huijding, J., Bouwmeester, S., Brouwer, M., \& Muris, P. (2014). Cognitive bias in action: Evidence for a reciprocal relation between confirmation bias and fear in children. Journal of Behavior Therapy and Experimental Psychiatry, 45(1), 26-32. doi: 10.1016/. jbtep.2013.07.005

Remmerswaal, D., Muris, P.. \& Huijding, J. (2016). Transmission of cognitive bias and fear from parents to children: An experimental study. Journal of Clinical Child and Adolescent Psychology, 45(5), 642-654. doi: 10.1080/15374416.2014.987378

Remmerswaal, D., Muris, P., Mayer, B., \& Smeets, G. (2010). "Will a Cuscus bite you, if he shows his teeth?" Inducing a fear-related confirmation bias in children by providing verbal threa information to their mothers. Journal of Anxiety Disorders, 24(5), 540-546. doi: 10.1016/]. janxdis.2010.03.012

Spielberger, C. D., Gorsuch, R. L., Lushene, R., Vagg, P. R., \& Jacobs, G. A. (1983). Manual for the State-Trait Anxiety Inventory (Form Y). Palo Alto, CA: Consulting Psychologists Press.

Van der Ploeg, H. M., Defares, P. B., \& Spielberger, C. D. (1980). Handleiding bij de zelfbeoordelingsvragenlijst, ZBV:een Nederlandse vertaling van de Spielberger State-Trait Anxiety Inventory. Lisse, The Netherlands: Swets \& Zeitlinger. 


\section{Appendix}

Parental Enhancement of Anxious Cognitions (PEAC)

\begin{tabular}{|c|c|c|c|c|c|c|c|}
\hline \multicolumn{4}{|c|}{ FATHER } & \multicolumn{4}{|c|}{ MOTHER } \\
\hline 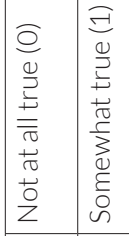 & 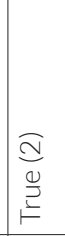 & 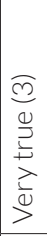 & & 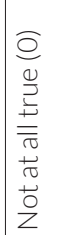 & 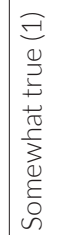 & 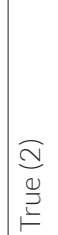 & 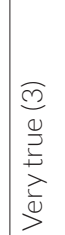 \\
\hline & & & $\begin{array}{l}\text { 1. This parent warns me about potential dangers, to } \\
\text { prevent accidents from happening. }\end{array}$ & & & & \\
\hline & & & $\begin{array}{l}\text { 2. When I am anxious to do something, this parent } \\
\text { cannot conceal his/her worries. }\end{array}$ & & & & \\
\hline & & & $\begin{array}{l}\text { 3. This parent explicitly warns me that I should be } \\
\text { careful when I leave home. }\end{array}$ & & & & \\
\hline & & & $\begin{array}{l}\text { 4. This parent warns me that I should never talk to } \\
\text { strangers because of bad things that might happen. }\end{array}$ & & & & \\
\hline & & & $\begin{array}{l}\text { 5. When this parent is scared, his/her body language } \\
\text { reveals his/her fear (e.g., fidgeting hands, sweating, } \\
\text { trembling, touching neck or face). }\end{array}$ & & & & \\
\hline & & & $\begin{array}{l}\text { 6. This parent shows when he/she is in panic in my } \\
\text { presence. }\end{array}$ & & & & \\
\hline & & & $\begin{array}{l}\text { 7. When this parent is scared, he/she has a fearful } \\
\text { expression on his/her face in my presence. }\end{array}$ & & & & \\
\hline & & & $\begin{array}{l}\text { 8. This parent shows me that he/she is afraid to do } \\
\text { certain things. }\end{array}$ & & & & \\
\hline & & & $\begin{array}{l}\text { 9. This parent warns me explicitly that I should avoid } \\
\text { dangerous situations. }\end{array}$ & & & & \\
\hline & & & $\begin{array}{l}\text { 10. This parent tells me that the world is not always } \\
\text { a safe place. }\end{array}$ & & & & \\
\hline & & & $\begin{array}{l}\text { 11. Even if this parent tries to hide his/her fear, I can } \\
\text { still see that he/she is anxious. }\end{array}$ & & & & \\
\hline & & & $\begin{array}{l}\text { 12. When I do something new or go to a new place, } \\
\text { this parent warns me about the things that could go } \\
\text { wrong. }\end{array}$ & & & & \\
\hline & & & $\begin{array}{l}\text { 13. This parent points out to me that an accident can } \\
\text { always happen. }\end{array}$ & & & & \\
\hline & & & $\begin{array}{l}\text { 14. This parent warns me explicitly not to go along } \\
\text { with unfamiliar people. }\end{array}$ & & & & \\
\hline
\end{tabular}

Note. Threat information transmission: items 1, 3, 4, 9, 10, 12, 13, 14; Modeling: items 2, 5, 6, 7, 8, 11. 


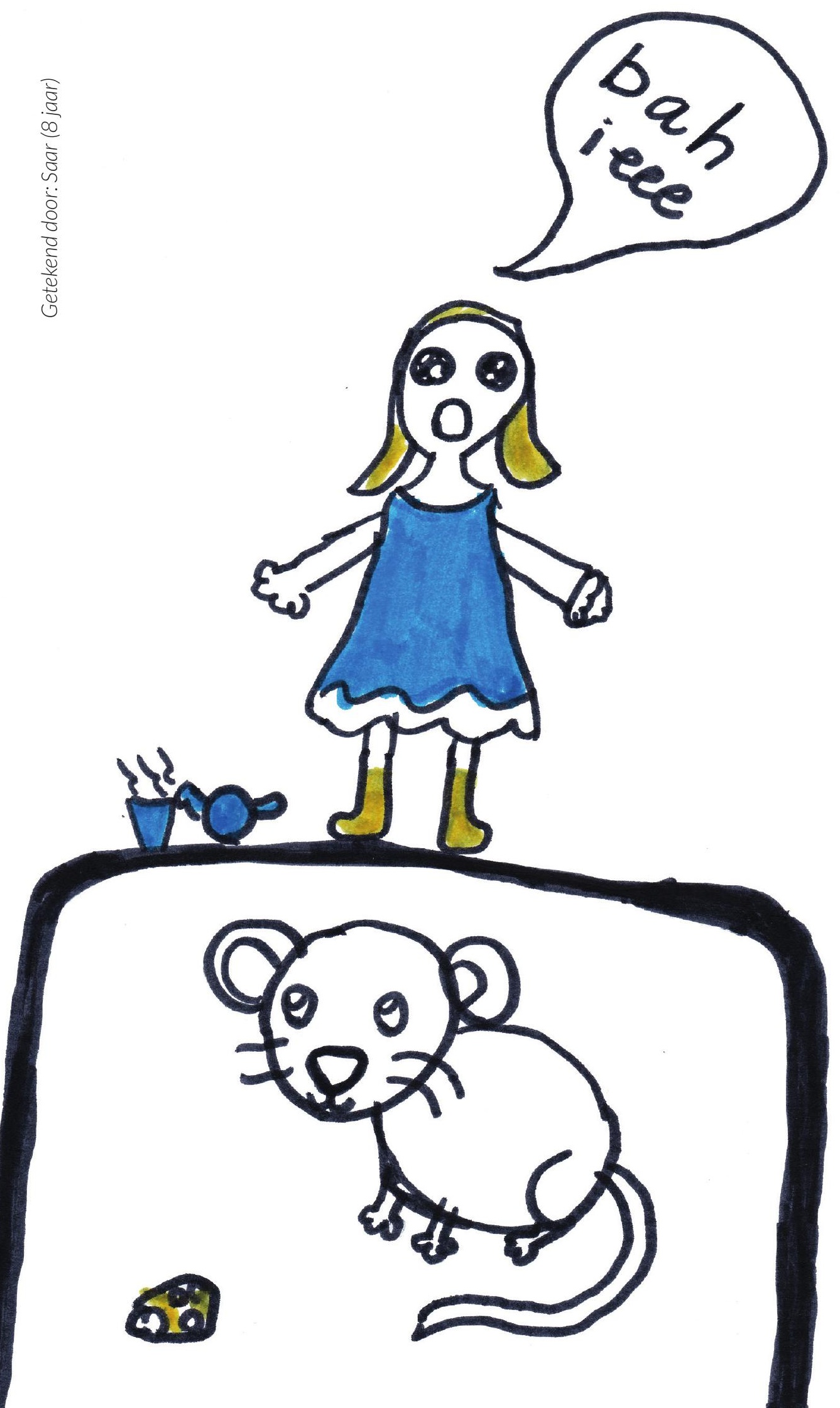

\section{Chapter 5}

A Longitudinal Study on the Relations Among Fear-

Enhancing Parenting, Cognitive Biases,and Anxiety Symptoms in Non-Clinical Children 


\section{Abstract}

This longitudinal study explored the relations between fear-enhancing parenting behaviors (modeling and threat information transmission) and children's cognitive biases and anxiety symptoms on three subsequent time points over a one-year period. Participants were 216 children aged 7-12 years (114 boys and 102 girls), and their mothers $(n=199)$ and/or fathers $(n=117)$. On each time point, children and parents completed the Parental Enhancement of Anxious Cognitions scale, which measures parental modeling and threat information transmission. Furthermore, children filled in a measure of anxiety disorder symptoms. In addition, confirmation bias and interpretation bias were measured by means of a number of computerized tasks. The results yielded support for a circular model in which cognitive biases enhanced anxiety symptoms, which in turn promoted cognitive biases on each of the three ime points. However, no evidence was found for longitudinal effects of cognitive biases on anxiety or vice versa. In contrast to what we expected, cognitive biase and anxiety appeared to promote parental modeling and threat information rather than the other way around. These findings extend research on the relations between parenting behaviors, cognitive biases, and childhood anxiety symptoms, and suggest valuable leads for assessment and intervention.

Keywords: children's anxiety symptoms; cognitive biases; parenting; modeling; threat information transmission.

\section{Introduction}

Epidemiological studies show that anxiety disorders are among the most common mental disorders in childhood (e.g., Costello, Mustillo, Erkanli, Keeler, \& Angold, 2003; Ford, Goodman, \& Meltzer, 2003; Polanczyk, Salum, Sugaya, Caye, \& Rohde, 2015). Given their high prevalence rates, research on the etiology and maintenance of anxiety disorders in children and adolescents is important and it is good to see that in previous decades considerable advancements have been made in our understanding of the factors involved in the pathogenesis of this type of psychopathology (see reviews by Muris \& Broeren, 2009; Rapee, Schniering, \& Hudson, 2009). According to Beck's (1976) cognitive theory, information processing biases play an important role, and there is indeed evidence showing that these biases are involved in the maintenance and exacerbation of anxiety problems (Harvey, Watkins, Mansell, \& Shafran, 2004). It is also known that anxiety-related cognitive biases not only occur in adults but are also present in children (Hadwin \& Field, 2010; Muris \& Field, 2008).

Anxiety-related cognitive biases are concerned with overactive schemas involving the themes of threat and danger (Harvey et al., 2004), which manifest themselves as cognitive distortions that occur during subsequent stages of information processing (e.g., Daleiden \& Vasey, 1997). In the early stages, where information about the internal or external world is automatically perceived and encoded, anxious individuals display a typical tendency to shift their attention towards threatening stimuli (i.e., attentional bias). During later stages, information is consciously interpreted and transformed into action tendencies and actual behavior. Two types of cognitive biases in these later stages have our special interest in the present investigation. The first one is interpretation bias, which can be defined as the tendency to interpret ambiguous stimuli and situations as threatening (Muris \& Field, 2013). The most widely used method for assessing this type of bias is the ambiguous vignette paradigm, which makes use of a series of short descriptions of everyday situations that may occur in daily life. Children are asked to score the perceived level of threat or indicate how they would respond in such situations. From both types of responses one can reliably infer whether children interpret the ambiguous scenarios as dangerous, a tendency that has been demonstrated to be present in high-anxious non-referred children (e.g., Bell-Dolan, 1995; Bögels \& Zigterman, 2000; Muris, Luermans, Merckelbach, \& Mayer, 2000) as well as in children with anxiety disorders (e.g., Cannon \& Weems, 2010; Waters, Wharton, Zimmer-Gembeck, \& Craske, 2008). The second cognitive distortion is confirmation bias, which refers to the selective search for information that concurs with the view that one holds, while ignoring information that might disconfirm this view (Muris \& Field, 2013). A paradigm that is often employed to 
investigate confirmation bias is a task in which children are given the opportunity to select additional, negative or positive information about a novel (potentially) threatening stimulus (often an unknown animal) or situation. It has been shown that anxious children display a stronger tendency to search for negative information and less frequently tend to choose positive information, indicating the presence of a confirmation bias (Dibbets, Fliek, \& Meesters, 2015; Dibbets \& Meesters, 2017; Muris et al., 2009; Remmerswaal, Huijding, Bouwmeester, Brouwer, \& Muris, 2014).

Like other psychopathological phenomena, the origins of anxiety-related cognitive biases are assumed to be due to genetic and environmental factors, which also interact with each other (Hadwin \& Field, 2010). There is evidence showing that cognitive biases occurring during the early stages of information processing (i.e., attentional biases) are more clearly associated with genetic factors such as an inherited liability in the serotonintransporter gene (Pérez-Edgar et al., 2010; Thomason et al., 2010). Meanwhile, the contribution of heritability to anxiety-related distortions that take place during the ater stages of processing (such as interpretation bias and confirmation bias) has been shown to be quite modest (Zavos, Rijsdijk, Gregory, \& Eley, 2010). For these biases, it seems more plausible to investigate the role of environmental factors, of which familial influences such as parenting can be considered as especially relevant. Murray, Creswell, and Cooper (2009) have outlined a cognitive-behavioral model in which parents distorted cognitions (e.g., threat interpretation bias) and in its wake expectations of the child (about how well it can control or cope with [potentially] dangerous situations) fuel fear-enhancing parenting behaviors such as modeling (i.e., a parent showing fear and anxiety reactions in the presence of the child; Askew \& Field, 2008) and verbal threat information transmission (i.e., a parent verbally expressing to the child that a stimulus or situation might be dangerous; Muris \& Field, 2010), which ultimately will install anxious information processing biases in the child (see also Creswell, Cooper, \& Murray, 2010).

The support for a scenario in which parenting behaviors promote cognitive biase and subsequent anxiety symptoms in children has been mainly circumstantial (Hadwin, Garner, \& Perez-Olivas, 2006). That is, research so far demonstrated that: (1) anxious parents have anxious children (e.g., Last, Hersen, Kazdin, Orvaschel, \& Perrin, 1991); (2) anxious parents display threat-related cognitive biases that tend to generalize to their child's environment (Lester, Field, \& Cartwright-Hatton, 2012) and that may also install similar cognitive biases in offspring (Creswell, O'Connor, \& Brewin, 2006); and (3) the parenting behaviors of modeling and verbal threat information transmission are involved in the transfer of anxiety and threat-related biases from parents to children (Fisak \& Grills-Taquechel, 2007; Wood, McLeod, Sigman, Hwang, \& Chu, 2003).

Attempts to investigate the relations among parenting, cognitive bias, and anxiety in children in one and the same study are relatively sparse. One exception is an investigation by Barrett, Rapee, Dadds, and Ryan (1996) who assessed interpretation bias in anxious youths aged 7-14 years and explored how family processes influenced children's interpretations of ambiguity. Clinically referred children with anxiety disorders $(n=152)$, children with externalizing problems (i.e., oppositional-defiant disorder; $n=27)$, and non-clinical control children without any problems $(n=26)$ and their parents were asked separately to interpret and provide action plans for a series of ambiguous scenarios. Following this initial assessment, children and parents were asked to discuss a number of these scenarios together, after which children were invited to provide a final response for each of the scenarios. The results indicated that the anxious and aggressive children were both more likely to interpret the ambiguous scenarios in a threatening way as compared to the non-clinical control group, with anxious children more often choosing avoidant action plans and oppositional-defiant children more frequently selecting aggressive solutions. Most importantly, the family discussions strengthened this pattern of results, showing significant increases in anxious children's avoidant action plans and oppositional-defiant children's aggressive action plans. Although these findings are relevant for multiple types of psychopathology, they clearly demonstrate that in the case of anxiety problems, a threat-related cognitive style may develop within the context of anxiety-enhancing family processes.

A recent study by Sicouri et al. (2017) used a similar procedure to explore the relations between parent-child discussions, cognitive bias, and anxiety in children with asthma. Eighty-nine parent-child dyads were included across four groups: children with asthma and anxiety $(n=29)$, children with anxiety only $(n=21)$, children with asthma only ( $n=15)$, and healthy control children $(n=24)$, all aged between 8 and 13 years. Interpretation bias was measured using two types of scenarios related to general threat and asthma threat. It was found that children with anxiety displayed an interpretation bias in response to the general threat scenarios, whereas children with asthma exhibited an interpretation bias in response to the asthma threat scenarios. Most interestingly, following parent-child discussions, changes in avoidance reactions were noted, and these mainly occurred in the anxious children in response to asthma threat scenarios.

Another study was conducted by Remmerswaal, Muris, and Huijding (2016) who explored the role of parents in the development of a cognitive bias and subsequent fear levels in non-clinical children aged between 8 and 13 years who were confronted with a novel animal. More precisely, in two experiments (N's being 122 and 49), it was examined whether instructed (experiment 1) or spontaneous (experiment 2) verbal feedback of mothers induced a negative information search strategy (i.e., confirmation bias) in their offspring. The results convincingly demonstrated that the verbal feedback of the mothers (either provided on instruction or given spontaneously 
- based on their own cognitive distortion) had a significant impact on children's cognitive bias. More precisely, when mothers verbally encouraged their offspring to search for threat-related information about the animal, children indeed displayed a stronger confirmation bias, which subsequently also resulted in increased fear for the unknown animal. Again, this can be taken as supportive evidence for the role of parenting variables in the intergenerational transmission of cognitive biases from mothers to children (Remmerswaal et al., 2016).

In further research by Van Niekerk et al. (2018), anxiety-related interpretation biases were measured in 7- to 14-year-old children of whom the parents were diagnosed with panic disorder (PD; $n=44$ ), social anxiety disorder (SAD; $n=27$ ), comorbid PD and SAD $(n=7)$, or of whom parents did not suffer from an anxiety disorder at all $(n=84)$. A set of ambiguous scenarios with a panic or social threat content was used, which had to be interpreted by the children under two conditions: first without priming and one week later with priming (i.e., viewing a video of an adult elling what it is like to have a specific anxiety disorder). The results indicated that in general children's own level of anxiety symptoms was predictive of interpretation bias scores. Parental anxiety diagnosis also played a significant role: more precisely, it was found that children of parents with PD, but not the offspring of parents with SAD, displayed a stronger tendency to interpret ambiguous scenarios in a more negative way as compared to children of parents without anxiety disorders. Priming appeared not to have a significant impact on children's interpretation of the scenarios. A similar study by Schneider, Unnewehr, Florin, and Margraf (2002), which was conducted more than 15 years earlier, compared 29 children of parents with PD, 21 children of parents with animal phobias, and 30 children of parents without a mental disorder (all children were between 8 and 15 years old). Findings revealed that children of parents with PD, but not those of parents with animal phobia or healthy control parents, showed an increase in anxious interpretations, although in this study the effect could only be demonstrated when children had been primed with a panic-relevant model. Although the priming procedure used in both studies (Schneider et al., 2002; Van Niekerk et al., 2018) certainly bears resemblance to the modeling and verbal threat transmission phenomena that have been described earlier, it should be borne in mind that the use of a video model makes these investigations less relevant if one wants to gain insight in the family processes underlying the transfer of cognitive biases and anxiety from parents to children. Nevertheless, the findings do confirm that there are significant links between parental anxiety (especially in case symptoms are clearly noticeable as in PD) and children's cognitive biases and anxiety symptoms.

While the studies by Barrett et al. (1996), Schneider et al. (2002), Remmerswaal et al. (2016), Sicouri et al. (2017), and Van Niekerk et al. (2018) were all to some extent experimental in nature, Fliek, Dibbets, Roelofs, and Muris (2017) relied on a different research approach. They conducted a cross-sectional survey to examine the relations between parenting, cognitive bias, and anxiety symptoms in a sample of 258 children aged 7 to 12 years. Interestingly, the fear-promoting parenting behaviors of modeling and threat information transmission were both measured by means of a specifically construed scale in fathers as well as mothers. Further, children's cognitive distortions of interpretation bias and confirmation bias and DSM-defined anxiety disorder symptoms were also assessed. The results indicated that both types of cognitive biases mediated the relationship between threat information transmission (of both parents) and children's anxiety symptoms, while only interpretation bias significantly mediated the relationship between modeling (of mothers) and children's anxiety symptoms.

The data of the Fliek et al. (2017) study were collected as part of a longitudinal study on the relations between cognitive biases, anxiety disorder symptoms, and family factors that might influence the relation between these variables. Follow-up assessments have now been conducted in this sample of children on two further time points (i.e., after 6 and 12 months) and these data will be included in the present study, so that it becomes possible to investigate the relations among fear-enhancing parenting, cognitive bias, and anxiety symptoms in children longitudinally. Thus, the fear-enhancing parental variables of modeling and verbal threat information transmission, the two types of cognitive biases: interpretation bias and confirmation bias, and anxiety symptoms were measured in 258 children aged 7 to 12 years on three occasions. The data were used to test the following hypotheses: First of all, with regard to the relations between cognitive biases and children's anxiety symptoms on a cross-sectional level, we predicted to find support for a bidirectional (circular) model (Remmerswaal et al.. 2014) in which cognitive biases promote anxiety symptoms, and anxiety symptoms in turn enhance cognitive biases. Second, we expected that children's cognitive biases and anxiety symptoms would be stable over time. A third hypothesis concerned longitudinal effects, and implied that cognitive biases would enhance children's anxiety symptoms on subsequent time points, which of course would substantiate the idea that these distortions are involved in the maintenance and exacerbation of anxiety problems (Beck, 1976; Harvey et al., 2004), but also that anxiety problems would promote cognitive distortions over time, which is in keeping with the abovementioned bi-directional model. As a fourth hypothesis, we predicted that detrimental parenting behaviors would lead to more cognitive distortions and higher anxiety levels, both on a cross-sectional and on a longitudinal level. Fifth and finally, based on the most current theoretical notions and the findings of previous studies (Barrett et al., 1996; Fliek et al., 2017; Hadwin et al., 2006; Remmerswaal 
et al., 2016), we expected to find support for a longitudinal mediational model in which the cognitive distortions of interpretation bias and confirmation bias mediate the relation between the parenting behaviors of modeling and threat information transmission on the one hand, and children's anxiety symptoms on the other hand.

With regard to the cross-sectional and longitudinal model testing, it is important to note the current data were also used to test a number of (plausible) alternative models, since it should not only be proven that a hypothesized model fits the data well, but also that it fits better than alternative models. For instance, we examined the fit of models in which both biases were correlated versus models in which one bias affected the other, and a model in which anxiety symptoms and both cognitive biases were all correlated to each other versus models with bias affecting anxiety or vice versa. Further, in our exploration of parental influences, we also tested a model in which anxiety symptoms and cognitive biases promoted detrimental parenting, as there is some evidence in the literature that when children are highly anxious, their parents become more overprotective (and thus likely show modeling and threat information transmission; Rapee, 2009).

\section{Method}

\section{Participants}

At the beginning of the study, the sample consisted of 258 non-clinical children (132 boys and 126 girls) aged between 7 and 12 years $(M=9.52, S D=1.38)$. All children had the Dutch nationality and the majority of them were Caucasian (> 95\%). The remainder of the families originated from diverse ethnic backgrounds (e.g., North African, Arabic, Asian). Questionnairezs about parental behaviors nearly always referred to children's biological parents; the two exceptions being one child who had adoptive parents and one child who was raised by his mother and her female partner. The latter child only answered the questions with regard to the biological mother. About 15\% of the children came from divorced families. For the ultimate analysis, we only used those cases for which we had complete child data on each of the three time points. More precisely, on the second time point, four children dropped out, whereas on the third time point, another 38 children dropped out, and as a result the final sample of participants consisted of 216 children (114 boys and 102 girls). Independent-samples $t$-tests revealed that children who dropped out $(M=10.99$, $S D=1.07)$ were significantly older than children who did not drop out $(M=9.69$, $S D=1.14 ; t(256)=6.76, p<.001)$, whereas they did not differ significantly with regard to anxiety, both types of cognitive biases (all t(256)'s $<1, p^{\prime} s>$.05), and gender $\left(\chi^{2}(1)=1.12, p>.05\right)$ as measured at baseline. ${ }^{4}$

Parents were also asked to fill out the questionnaire measuring modeling and threat information transmission. A total of 199 mothers and 117 fathers (mean ages being 42.20 years, $S D=4.42$ and 44.36 years, $S D=4.95$, respectively, range $28-65$ years) did so on the first time point of this study. On the second time point, 18\% of mothers and $14 \%$ of fathers dropped out. On the third time point, another $6 \%$ of mothers as well as $6 \%$ of fathers dropped out. Independent-samples t-tests revealed no significant differences between parents who dropped out and parents who did not drop out for any of the child and parent variables that were assessed in this study (all $t(d f)$ 's $\leq 1.98$, p's > .05), where df varied from 79 to 174 depending on the variable for which dropouts were compared to non-dropouts, and depending on the different sample sizes for mothers and fathers. For the statistical analyses of the parent data, we only used those cases for which we had obtained data on all three time points ( $N=147$ ). For 43 children only the mother completed all three assessments. For 3 children only the father completed the three assessments. For a total of 44 children, the three assessments were completed alternately by either the mother or the father. For the remaining 57 children, both parents completed all three assessments and their scores were averaged for the final data analysis. As compensation for their participation, families, for whom children and parents had completed questionnaires on all three assessment points, received a set of cinema vouchers (which each had a value of 7.50 Euro)

\section{Measures}

The Parental Enhancement of Anxious Cognitions (PEAC) was used to assess parental modeling and threat information transmission behaviors. The scale was construed for the purpose of this research project (see Fliek et al., 2017). The PEAC asks children to rate the frequency of parents' fear-enhancing behaviors, using a 4-point Likert scale $(0=$ never, 1 = sometimes, 2 = often, and 3 = always $)$. The questionnaire consists of 14 items: 6 items are concerned with modeling behaviors of parents (e.g., "This parent shows me that he/she is afraid to do certain things"), while 8 items have to do with threat information transmission (e.g., "This parent warns me explicitly that should avoid dangerous situations"). Each item is answered twice, once for the mother

The finding that the drop-outs were significantly older probably has to do with the fact that the older children were in transition from primary to secondary school at the time of the second follow-up assessment. It was no longer possible to test these children 'live' at school, but they were asked to complete the measurements via the internet. Note that we adjusted for age (and gender) in the statistical analyses, so it is unlikely that this had a significant impact on the obtained results. 
and once for the father. For each parent, PEAC modeling and threat information transmission scores are computed by summing the ratings on relevant items. In the current study, Cronbach's alphas of the modeling scale for mothers and fathers varied between .65 and .84 on various assessment points, while alphas of the threat information scale ranged between .80 and .92. These values indicate that the PEAC scales have sufficient to good reliability in terms of internal consistency.

The Parent version of the PEAC (PEAC-P) is similar to the questionnaire that is completed by the children, but the 14 items are formulated from the perspective of the parent (e.g., "I warn my child explicitly that he/she should avoid dangerous situations" instead of "This parent warns me explicitly that I should avoid dangerous situations"). Cronbach's alphas of the PEAC-P modeling scale for mothers and fathers varied between .63 and .78, while alphas of the threat information scale ranged between .73 and .83 . These values indicate that the internal consistency of the PEAC-P is similar to that of the child version.

The Revised version of the Screen for Child Anxiety Related Emotional Disorders (SCARED-R; Muris, Merckelbach, Van Brakel, \& Mayer, 1999b) is an extension of the original SCARED (Birmaher et al., 1997). The scale assesses symptoms of the entire spectrum of DSM-IV-defined anxiety disorders (American Psychiatric Association 1994, 2000). In the current study only the SCARED-R subscales of social phobia (7) items; e.g., "I don't like to be with unfamiliar people"), generalized anxiety disorder (9 items; e.g., "I worry about things working out for me"), and separation anxiety disorder (8 items; e.g., "I don't like being away from my family") were used, because these three types of anxiety were considered as most relevant in relation to the scenarios that were employed to assess cognitive biases (see below). Children were asked to rate the frequency with which they experienced each symptom using a three-point scale 0 = almost never, 1 = sometimes, 2 = often) and a total anxiety score was obtained by summing ratings on the items of the three selected anxiety scales (range: 0-48). Research has demonstrated that the SCARED-R has good internal consistency, testretest reliability, and validity (Muris, Dreessen, Bögels, Weckx, \& Van Melick, 2004 Muris, Merckelbach, Schmidt, \& Mayer, 1999a; Muris et al., 1999b). In the present study, the internal consistency of the SCARED-R total anxiety score was excellent with Cronbach's alphas of $.87, .88$ and .90 on the three successive time points.

The Information Search Task (IST) was based on the paradigm used by Remmerswaal et al. (2014) and adjusted for the purpose of the current study to assess children's confirmation bias. The adjustments to the IST entailed that the stories described real-life situations that reflected social, separation, and general anxiety themes instead of stories involving a novel animal, which were employed by Remmerswaal et al. (Remmerswaal et al., 2014). Children were presented with new, potentially threatening situations (e.g., going to a new school) about which they had to gain additional information (e.g., "What would you like to know about the teachers at your new school?") by choosing between a positive (e.g., "Whether they have a nice way of teaching") and a negative (e.g., "Whether they become angry very easily") option. Following their choice, children always received a confirming response (e.g., positive: "Most teachers have a nice way of teaching", negative: "Most teachers become angry very easily"). In total, children were presented with three situations (one per anxiety theme) on each time point, for each of which they were given five opportunities to gain extra information. A confirmation bias score was computed for each time point by summing the number of negative options chosen (range: 0-15). The reliability in terms of internal consistency of the IST proved to be satisfactory in this study, with Cronbach's alphas of .75, .81, and .80 on the three time points.

Ambiguous Stories (Bögels \& Zigterman, 2000; Muris, Rapee, Meesters, Schouten, $\&$ Geers, 2003) were used to assess interpretation bias. These stories represented the themes of social anxiety (e.g., going to a sporting club for the first time), generalized anxiety (e.g., driving with your bike on a very busy street), and separation anxiety (e.g., staying with a friend while parents are on vacation). Children had to read the stories, which consisted of five sentences presented to them sentence by sentence on the computer screen. An example of a story relating to the theme of generalized anxiety would be: "You ride on the bike slowly because you are carrying a large bag with purchases. You ride on a street without a bikeway. It is a very busy street. The cars that pass you by drive very fast. You hear a big truck approaching from behind" (see Bögels \& Zigterman, 2000; Muris et al., 2003). Following each sentence, children were asked whether they thought that the story would ultimately be "scary" or "not scary". On each time point, children were presented with three different stories (again one for each of the three anxiety themes). A total interpretation bias score was calculated for each time point by summing the number of sentences after which children indicated that the story was going to be scary (range 0-15). The reliability in terms of internal consistency of the Ambiguous Stories test was good, with Cronbach's alphas of .79, 81 , and .81 on the three consecutive time points.

\section{Procedure}

Participants were recruited via four primary schools in the Southern part of The Netherlands. Informed parental consent was obtained by sending parents an information letter about the study along with a consent form. Children for whom parents granted permission were tested in small groups (of approximately eight children per group) in a separate room at school. Each child used a computer to fill out the questionnaires (PEAC and SCARED-R) and to conduct the cognitive bias 
tasks. This assessment took place under supervision of two experimenters, who guided the children through the session by providing instructions and by collectively conducting some practice items. Children received explicit instructions to call upon the experimenters in case they had any questions about the scales or tasks. The experimenters remained always present during the assessments to ensure that the children worked independently and completed all questionnaire and test items. Children first completed the SCARED and the PEAC, after which they carried out the ST and the Ambiguous Stories test. Parents completed the questionnaire at home on their own computer using a web-link provided to them by the experimenters. Followup assessments were conducted on two time points, 6 and 12 months after the initia assessment session. Children who were in the last grade of primary school when the study started, had already left school at the time that the 12 month follow-up assessment took place. These children received an e-mail that included an internet link which enabled them to carry out the final assessment at home.

\section{Statistical analyses}

Descriptive statistics and correlations were computed to inspect cross-sectiona and longitudinal links among all variables that were measured in the study. Further the presence of differences among the four participating schools with respect to the mean scores of various variables on the three time points was checked by repeated measures analyses of variance (ANOVAs), with school as between-subject factor and time as within-subject factor. Data were further analyzed by means of structura equations modeling using LISREL 8.80 (Joreskog \& Sorbom, 1989, 1993). For al children the child-reported PEAC data of the mother and father were averaged, and this procedure seemed justified as scores for both parents were substantially correlated (i.e., r's were respectively .70 for modeling and .83 for threat information transmission on time point $1, .60$ and .80 on time point 2, and .57 and .78 on time point 3 , all p's <.001). Further, preliminary regression analyses showed that childreported mother and father PEAC scores displayed similar relations with children's cognitive biases and anxiety symptoms. Confirmation and interpretation bias were analyzed separately in the model, since they were not particularly strongly correlated ( $r=.20$ on time point $1, r=.28$ on time point 2 , and $r=.36$ on time point 3 , all $p$ 's < .01) Moreover, it can be assumed that there is a logical temporal order for both biases, with interpretation bias being the starting point of conscious threat perception and confirmation bias constituting a cognitive response occurring once threat has been perceived. Age and sex were included as exogenous variables in all models as previous research has indicated that these may have an effect on childhood anxiety symptoms (and possibly related psychological constructs): that is, anxiety symptoms tend to decline as children become older and girls generally display higher levels of anxiety symptoms than boys (e.g., Craske, 2003; Lewinsohn, Gotlib, Lewinsohn, Seeley, \& Allen, 1998; Westenberg, Siebelink, Warmenhoven, \& Treffers, 1999).

A four-step procedure was followed for the LISREL analyses. First, we conducted a series of analyses to explore the direction of the relations between child anxiety, confirmation bias, and interpretation bias on each of the three time points. To this end we tested a number of theoretically plausible models: First, we tested a mode with arrows pointing from both (correlated) biases to anxiety (model 1; see Table 3 of the results section for a graphical overview of all the models). We also tested a model with arrows pointing in the opposite direction (model 2), which essentially assumes that both (correlated) biases are the result of anxiety. Another plausible model that was tested was a circular model, since we know from previous research that cognitive bias and anxiety influence each other reciprocally (Remmerswaal et al., 2014). In this circular model (model 3) interpretation bias was placed before confirmation bias, since - as noted above - interpretation and perception of threat is likely to occur before one can search for confirming or disconfirming information. Another model resembled model 1 , by assuming that anxiety is the result of both biases, but here interpretation bias preceded confirmation bias (model 4). In a similar vein, a further model was tested as a variant of model 2 , with both biases being the result of anxiety and interpretation bias preceding confirmation bias (model 5). A final model hypothesized that anxiety, interpretation bias, and confirmation bias were al inter-correlated with no clear-cut directions among these three variables (mode 6). All models were tested twice, once without and once with equality constraints. Testing without equality constraints means that every causal path at every time point has its own regression weight, whereas in the analyses with equality constraints it was assumed that the path coefficients were stable over the three time points for any given causal path, such as from interpretation bias to anxiety (thereby reducing the number of path coefficients and making the model more parsimonious). In each of these models a residual correlation was included between the three repeated measures of the same variable (e.g., between anxiety at time 1, 2 and 3).

As a second step, the best fitting model was tested longitudinally by adding timelagged paths between the three variables across the three time points, for instance between cognitive biases on one time point $(t)$ and anxiety symptoms on a subsequent time point $(t+1)$ and between anxiety symptoms on $t$ and biases on $t+1$. Third, the parenting variables (PEAC modeling and threat information transmission) were added in order to test the cross-sectional relations between the parenting variables on the one hand and anxiety and both biases on the other hand. Fourth, again the best fitting 
model was tested longitudinally by adding time-lagged paths between parenting and child variables. Further details of all models will be given in the Results section.

Model fit was assessed by means of the following goodness-of-fit indices: the Chi Square test, the root mean square of approximation (RMSEA), the normed fit index (NFI), the non-normed fit index (NNFI), and the comparative fit index (CFI). Apart from the first measure, all measures combine goodness of fit (Chi Square) with mode parsimony (degrees of freedom). For the RMSEA, lower values are indicative of a better fit and values of 0.05 and 0.08 can be considered as respectively good and reasonable (Browne \& Cudeck, 1993). The NFI, NNFI, and CFI range between 0 (poor) and 1 (excellent), and for these indices values thus need to be large, with 0.90 being the cut-off for defining a good fit.

\section{Results}

\section{Mean differences and correlations among parenting, biases, and anxiety}

Table 1 displays the mean scores and standard deviations for various child-completed measures as obtained on the three time points as well as the cross-sectional and longitudinal correlations among these variables. Apart from the finding that longitudinal associations between different variables were in general weaker than cross-sectional relations, a number of conclusions can be drawn from this table. To begin with, test-retest correlations varied between .56 and .70 ( $p$ 's < .01) for anxiety symptoms, .42 and .61 ( $p$ 's $<.01$ ) for confirmation bias, .42 and .50 ( $p$ 's < .01) for interpretation bias, .41 and .50 ( $p$ 's $<.01$ ) for parental modeling, and .44 and .55 ( $p$ 's < .01) for parental threat information transmission. Repeated measures ANOVAs showed that there was no effect of school for any of the variables (all p's > .05). A significant time effect was found with regard to anxiety scores $\left[F(2,430)=10.28, p<.001, n \rho^{2}=.05\right]$. Post-hoc tests showed that children's anxiety scores significantly decreased from time point 1 to time point $2(p=.01)$, with no significant change being observed from time 2 to time $3(p=11)$. A repeated measures ANOVA for confirmation bias also revealed a significant time effect $[F(2,430)=32.91, p$ $\left.<.001, n \rho^{2}=.13\right]$. Post-hoc tests revealed a significant decrease from time 1 to time 2 ( $p<$ .001), while there was a significant increase from time 2 to time $3(p<.001)$. The repeated measures ANOVAs with interpretation bias, parental modeling, and threat information transmission as dependent variables did not show significant time effects (all p's > .05). Further, it was found that children's anxiety symptoms were significantly correlated with cognitive biases and parenting variables on all three time points (r's between 30 and .51 , p's <.01). Finally, although cognitive biases were as expected positively associated with modeling and threat information transmission, these correlations were modest and sometimes even non-significant (r's between .10, $p$ > .05 and .29, $p^{\prime}$ s <.01). 


\section{Correlations of the parent-report data}

In Table 2, an overview is given of the correlations between the PEAC scales as completed by the parents and both biases and anxiety as reported by the child. In general, these cross-informant correlations were weak and in most cases nonsignificant. The one exception was the correlation between parent-reported modeling and child-reported anxiety symptoms on time $2(r=.20, p=.02)$. Given these findings, we decided to discard the parent data and merely focused on the child-report data in the remainder of the analyses.

In passing, it should be noted that the parent-child correlations for the PEAC scales were also very low. For modeling, these correlations were .16 ( $p=.06)$ on time 1,.06 ( $p=.49$ ) on time 2 , and .21 ( $p=.01$ ) on time 3. For threat information transmission, the correlations between parents and children were .16 ( $p=.05), .16(p=.05)$, and $07(p=.42)$ on the three subsequent time points.

Table 2 Correlations among the parent-reported PEAC scales and the child-reported anxiety and cognitive biases scores

\begin{tabular}{lcc}
\hline & PEAC Modeling Parent & PEAC Threat Parent \\
\cline { 2 - 3 } Time 1 & .04 & .13 \\
SCARED-R Anxiety & -.02 & .14 \\
IST C-bias & .04 & .02 \\
Amb Stories I-bias & & \\
Time 2 & $.20^{*}$ & .10 \\
SCARED-R Anxiety & .04 & .08 \\
IST C-bias & .00 & -.03 \\
Amb Stories I-bias & & \\
Time 3 & .06 & -.02 \\
SCARED-RAnxiety & -.05 & .04 \\
IST C-bias & -.05 & -.11 \\
Amb Stories I-bias & & \\
\hline
\end{tabular}

Note. $N=147$. SCARED-R = Screen for Child Anxiety Related Disorders-Revised, IST = Information Search Task, C-bias $=$ Confirmation Bias, Amb Stories = Ambiguous Stories, I-bias = Interpretation Bias, PEAC $=$ Parental Enhancement of Anxious Cognitions, Threat $=$ Threat Information Transmission,

$* p<.05$

\section{Cross-sectional models of the relations among cognitive biases and anxiety}

As can be seen in Table 3, the results indicated that models 3 and 5 provided the best fit for the cross-sectional relations among interpretation bias, confirmation bias, and anxiety. In the circular model (model 3), anxiety promoted interpretation bias, which had an enhancing effect on confirmation bias, which in turn again increased the level of anxiety. In model 5 , both biases were the result of anxiety, with interpretation bias preceding confirmation bias. All models were subsequently re-run with equality constraints, that is, under the assumption that the path coefficient from $X$ to $Y$ is the same on all three time points for any given pair of variables $X, Y$ (thereby reducing the number of path coefficients from 18 to 6 for the effects of age and gender on anxiety and biases in all models, from 9 to 3 for the paths among anxiety and both biases in models 3, 4, and 5, and from 6 to 2 for those paths in models 1 and 2). Likelihood Ratio (LR) testing of each constrained model against its unconstrained counterpart confirmed the validity of the equality constraints (see Table 3, the LR test uses the difference in Chi Square between both models as chi square test statistic, and the difference in degrees of freedom as the $\mathrm{df}$ for the LR test). Examination of the fit measures showed that models 3 and 5 again provided the best fit for the data. Because the circular model with bidirectional relations from bias to anxiety and vice versa (model 3) makes theoretically more sense (e.g., Remmerswaal et al., 2014) than a model in which biases are only by-products of anxiety (model 5), we chose model 3 with equality constraints as the starting point for further analyses.

Longitudinal model of the relations among cognitive biases and anxiety

The following four extensions of model 3 with longitudinal paths were tested against model 3 with LR tests: (a) Time-lagged paths from both biases to anxiety; (b) Time-lagged paths from anxiety to both biases; (c) A combination of time-lagged paths from both biases to anxiety as well as time-lagged paths from anxiety to both biases; and (d) The same time-lagged paths as cross-sectional paths, that is, from anxiety to interpretation bias, from interpretation bias to confirmation bias, and from confirmation bias to anxiety. None of these four model extensions with time-lagged paths provided a better fit than model 3 with cross-sectional paths between the three constructs and residual correlations between the repeated measurements of a given constructs (i.e., anxiety, interpretation bias, confirmation bias). In all cases, the change in Chi Square was very close to the change in degrees of freedom and thus non-significant. Given the already very good fit of model 3 (see Table 3), this did not come as a complete surprise. Figure 1 shows the longitudinal version of model 3 including children's anxiety and cognitive biases variables as measured on the three consecutive time points. 
Table 3 The six tested structural models of the cross-sectional relations among interpretation bias, confirmation bias, and anxiety symptoms on the three consecutive time points. The upper rows show the results of the analyses conducted without equalityconstra analyses with equality constraints.

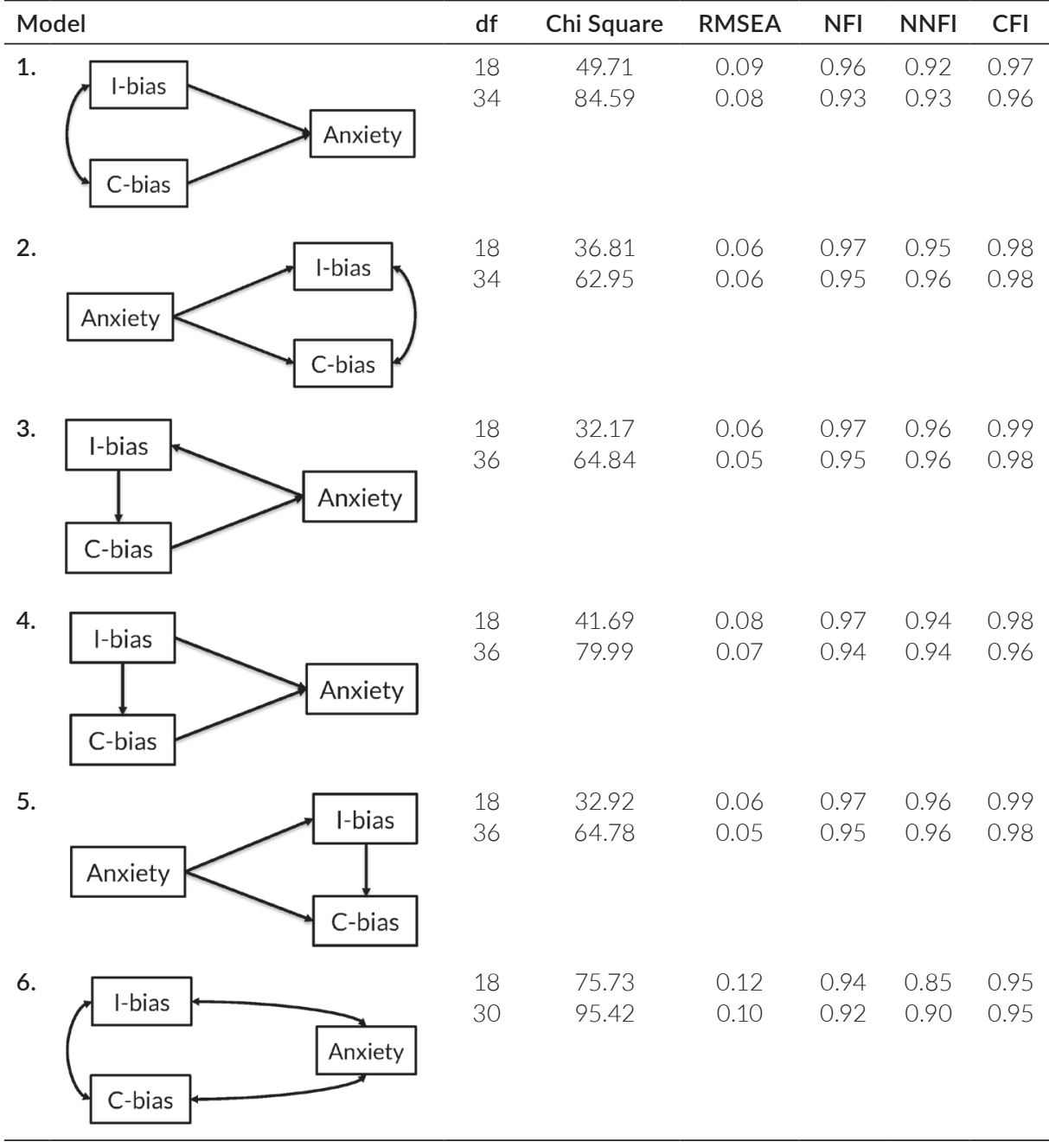

Note. $\mathrm{N}=216 . \mathrm{C}$-bias $=$ confirmation bias, $\mathrm{I}$-bias $=$ interpretation bias, $\mathrm{df}=$ degrees of freedom, RMSEA = Root Mean Square of Approximation, NFI = Normed Fit Index, NNFI = Non-normed Fit Index, $\mathrm{CFI}=$ Comparative Fit Index. One-way arrows reflect hypothesized to causal relations, while two-way arrows indicate correlation instead of effect. In all models, age and gender were included as exogenous variables having an effect on all psychological variables, and residual covariances were included between the repeated measures of a given psychological variable.

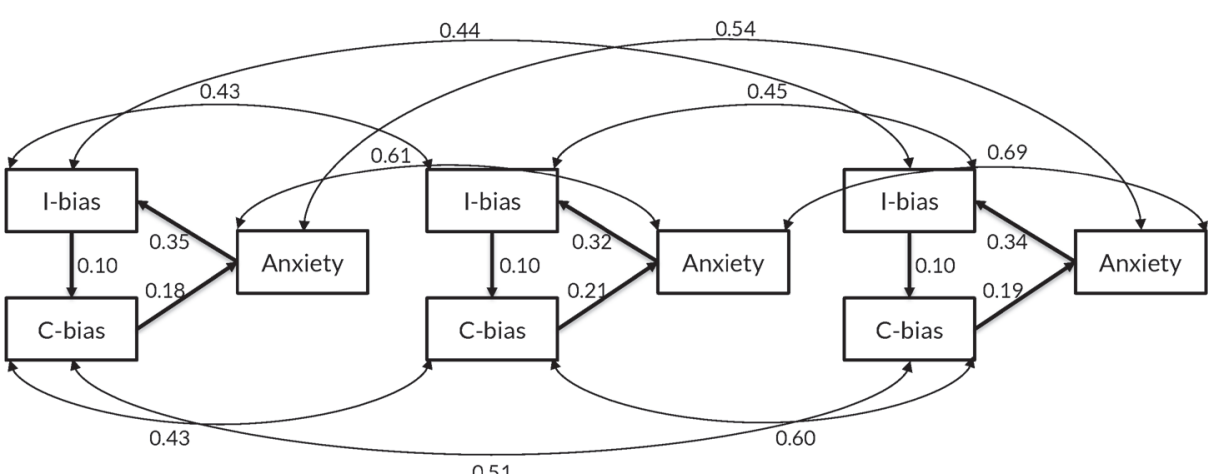

Figure 1 The best fitting model with circular relations among cognitive biases and anxiety on each of the three time points including residual correlations between the three repeated measurements of the same variable. Standardized path coefficients and residual correlations are shown. C-bias = confirmation bias. I-bias = interpretation bias Equality constraints apply to unstandardized path coefficients. Standardized Coefficients are not exactly equal across time points due to changes in variance of anxiety, C-bias, and . variables with an effect on all psychological variables in the model.

\section{Final model with parenting variables}

The effects of the parenting variables of modeling and threat information transmission were first explored cross-sectionally by adding relations between parenting variables to the best fitting, theoretically most meaningful model (i.e., model 3) on each of the three time points. Three variants were tested: (a) A model in which parenting variables had an effect on anxiety and both cognitive biases; (b) A reversed model in which anxiety and cognitive biases had an impact on both parenting variables; and (c) A third and final model with bidirectional relations between parenting variables on the one hand and anxiety and cognitive biases on the other hand. In all three models we also assumed a cross-sectional correlation between modeling and threat information transmission as well as longitudina correlations between the repeated measures of any given variable (e.g., between modeling at $t$ and $t+1$ ), and again we imposed equality constraints on all three paths for a given pair of variables (e.g., on the paths from modeling to anxiety at $\mathrm{t} 1, \mathrm{t} 2$, and $\mathrm{t} 3$ ).

Model $\mathrm{C}$ with bidirectional relations between parenting and anxiety/cognitive biases gave warnings and did not converge (probably due to unidentifiability). Mode $B$ with paths from anxiety and cognitive biases towards parenting variables had better fit $\left(\chi^{2}=169.76, \mathrm{df}=98, \mathrm{RMSEA}=0.05, \mathrm{NFI}=0.93, \mathrm{NNFI}=0.96, \mathrm{CFI}=0.97\right.$ than model A with paths from parenting variables to anxiety and cognitive biases $\left(\chi^{2}=199.00, \mathrm{df}=98, \mathrm{RMSEA}=0.06, \mathrm{NFI}=0.92, \mathrm{NNFI}=0.94, \mathrm{CFI}=0.96\right)$.

Extending model $\mathrm{B}$ with time-lagged paths from child to parenting variables or vice versa (e.g., from threat information transmission at $t$ to anxiety at $t+1$ ) did not 
improve the model fit and revealed no significant time-lagged effects. The best fina model is therefore the model depicted in Figure 2, with equality constraints and thus stability over time of all path coefficients.

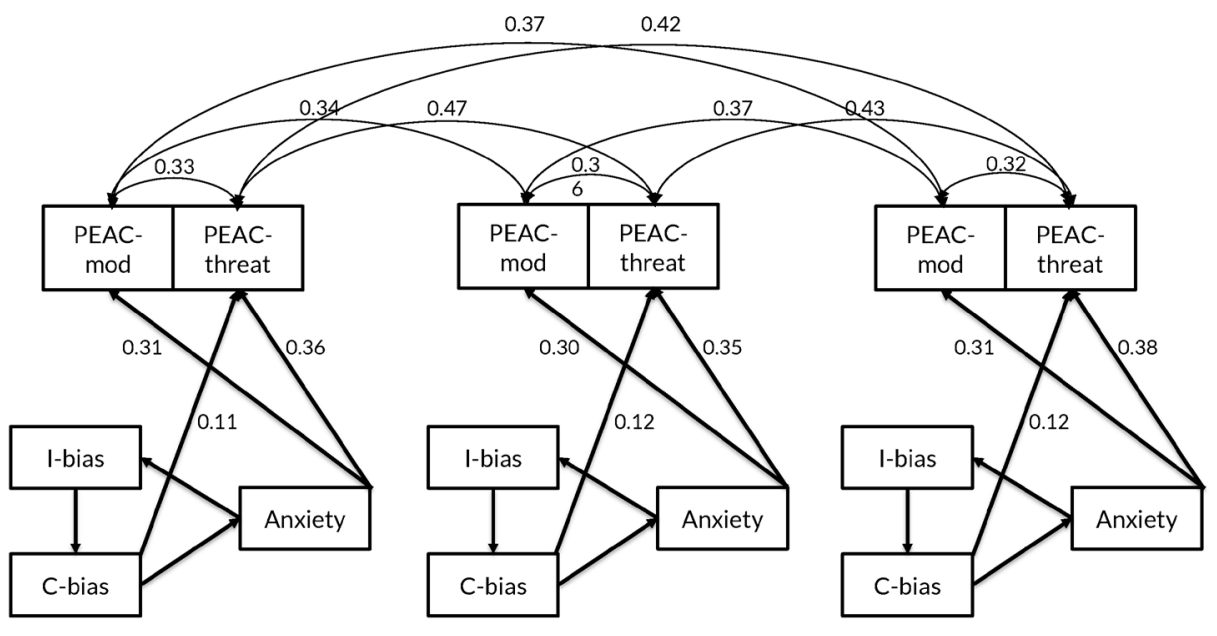

Figure 2 The best fitting model with circular relations among cognitive biases and anxiety on each of the three time points as well as paths from biases and anxiety towards both PEAC subscales. Standardized path coefficients are shown as well as residual correlations between the three repeated measures of the same PEAC variable and between modeling and threat information transfer at the same time point. C-bias $=$ confirmation bias, $\mathbf{I}$-bias $=$ interpretation bias, mod $=$ modeling, threat $=$ threat information transmission. Equality constraints hold for the unstandardized path coefficients, but not for the residua variances, and thereby not exactly for the standardized path coefficients. Age and gender are not displayed in the figure, although they were entered as exogenous variables with an effect on all psychological variables in the model. For clarity reasons, non-significant paths as well as the residuat correlatical

\section{Mediation model}

Note that we did not formally test a model in which cognitive biases acted as mediators in the relation between parental variables and children's anxiety symptoms. We considered testing such a model as no longer appropriate, because we obtained no convincing evidence for a unidirectional relation between cognitive biases and anxiety (see Table 3 ).

\section{Discussion}

The aim of the current study was to investigate associations among fear-enhancing parenting behaviors (modeling and threat information transmission), cognitive biases (interpretation bias and confirmation bias), and anxiety symptoms in non-clinica children, using a longitudinal study design consisting of three time points. Structura equation modeling by means of LISREL was employed to first test various models assuming only cross-sectional relations, and varying the direction of the paths among child anxiety, interpretation bias, and confirmation bias. Next, the best fitting theoretically most plausible model was extended with longitudinal (cross-lagged) paths between anxiety and both biases. Finally, the parenting variables were added to the model. The key findings of the study can be catalogued as follows. First, we found support for a circular model in which cognitive biases promoted anxiety symptoms, which in turn enhanced cognitive biases. Second, no evidence was obtained for longitudinal effects indicating that cognitive biases increased anxiety levels or that anxiety strengthened cognitive biases over time. Third, the effects regarding fearenhancing parenting were not completely as anticipated: the data suggested that cognitive biases and anxiety promoted modeling and negative information transmission rather than the other way around. Based on a previous cross-sectional analysis of these data (collected on time point 1; Fliek et al., 2017) and current theoretica hotions (e.g., Hadwin et al., 2006), we also expected to find support for a longitudinal mediational model in which cognitive biases would act as connector (mediator) between fear-enhancing parenting behaviors and children's anxiety symptoms. However, the present findings indicated that there appeared to be reciprocal relations between cognitive biases and child anxiety and that child anxiety had an impact on parenting variables rather than the other way around. For these reasons, we considered tests of the hypothesized meditational model as no longer justifiable.

The analyses showed that children's anxiety symptoms were significantly and positively associated with interpretation and confirmation bias on each of three assessment occasions. This is well in line with previous studies showing that anxious children display a stronger tendency to interpret ambiguous situations in a threatening way (e.g., Bell-Dolan, 1995; Bögels \& Zigterman, 2000; Muris et al., 2000) and are more inclined to search for information that confirms threat (e.g., Dibbets et al., 2015; Dibbets \& Meesters, 2017; Muris et al., 2009; Remmerswaal et al., 2014). LISREL analyses modeling the direction of the relations among anxiety and both biases revealed acceptable fits for most models. However, there were two models that stood out and displayed the best goodness-of-fit values across various fit indices. In one model, there was a unidirectional link from anxiety symptoms to both types of cognitive biases, whereas the other model was circular in nature with a bidirectional relation between anxiety and biases. Although there is certainly evidence showing that anxiety can precede the occurrence of cognitive biases, a wide range of studies have also demonstrated a reversed scenario in which these biases come first and contribute to the development of anxiety symptoms (see reviews by Van Bockstaele et al., 2014; Wilson, MacLeod, Mathews, \& Rutherford, 2006). A recent investigation by Remmerswaal et al. (2014) demonstrated that in children such a bidirectional 
relation between cognitive biases and anxiety is also applicable, and for this reason we consider the circular, bidirectional model as theoretically more plausible than the model in which biases are just a by-product of anxiety.

An additional remark concerns the relation between cognitive biases and anxiety. The best fitting models had in common that there was a temporal order for both cognitive biases in which interpretation bias preceded confirmation bias. This sequence makes sense because interpretation bias describes the process of transforming a neutral or even an apparently positive event into a dangerous one and as such is typically considered to be the starting point of conscious threat perception (Muris \& Field, 2008). In contrast, confirmation bias only occurs after threat has been perceived: the individual perceives the danger and subsequently searches for further information that confirms this threat (Muris et al., 2009).

In contrast to the support for relations between anxiety and cognitive biases, no cross-lagged, longitudinal relations were found. That is, no indications were found showing that (a) anxiety symptoms increased cognitive biases on subsequent time points, or that (b) cognitive biases enhanced anxiety symptoms over time. These results are in keeping with Muris, Jacques, and Mayer (2004) who also failed to document prospective links between interpretation bias and children's anxiety symptoms, but are obviously in contrast with Dodd, Hudson, Morris, and Wise (2012) who did show that threat interpretation predicted anxiety symptoms at a 12-month follow-up, and Creswell and O'Connor (2011) who noted that anxiety symptoms predicted change in interpretation bias over time. Given these inconsistent findings, one might conclude that the contribution of cognitive biases occurring during the later stages of information processing, such as interpretation bias and confirmation bias, do not play a prominent role in the development of childhood anxiety symptoms. However, as the research so far has been mainly focused on young people in primary and middle childhood, it is still possible that this conclusion is only appropriate for early developmental stages and that the contribution of these cognitive biases to anxiety pathology becomes more important during adolescence and adulthood (e.g., Creswell, Murray, \& Cooper, 2014). Obviously, replication of the present study in a sample of older youth is necessary to further investigate this possibility. Furthermore. it would be interesting to explore the link between cognitive biases and anxiety in young people who face a stressful life event or in at-risk children and adolescents of parents with anxiety disorders. As described in the introduction, previous research has shown that especially the offspring of parents with PD are more likely to show an interpretation bias (Schneider et al., 2002; Van Niekerk et al., 2018), and it would be particularly relevant to explore whether parental modeling and threat information transmission are involved in the familial transmission of this cognitive susceptibility.
Our analyses also showed substantial stability for both the cognitive biases and anxiety symptoms across the three assessment points. This means that the interindividual variation in anxiety symptoms and associated cognitive biases did not show substantial changes during the year that the children were followed. The most important practical implication of this finding is that there seems to be a reliably identifiable subgroup of children with continuing high levels of anxiety symptoms that also show the typical concomitant cognitive features of this type of psychopathology (see also Bosquet \& Egeland, 2006; Ialongo, Edelsohn, Werthamer-Larsson, Crockett, \& Kellam, 1995). It seems likely that these children are prone to develop a full-blown anxiety disorder when confronted with stress and adversity (Muris, 2007). They probably constitute a suitable target population for prevention and early intervention efforts (Rapee et al., 2009).

With regard to the parental variables of modeling and threat information transmission, our main prediction was that these parenting behaviors would enhance children's anxiety symptoms and cognitive biases. The results first of all indicated that a model in which the parenting variables of modeling and threat information transmission had an enhancing effect on children's anxiety symptoms and associated biases fitted the data rather well. However, the structural equations modeling analyses also revealed that a model in which anxiety symptoms and cognitive biases promoted fear-enhancing parental behaviors even had a slightly better fit. In view of these findings, a model with bidirectional relations between fear-enhancing parenting behaviors and children's anxiety symptoms/cognitive biases seemed most plausible, but unfortunately that model appeared to be unidentifiable. Altogether, these results warrant the conclusion that a scenario in which anxiety symptoms and cognitive biases in children elicit anxious parenting is at least as likely as one in which fear-enhancing parenting elicits cognitive biases and anxiety. In the literature, severa scholars have noted that fear-enhancing parental behaviors such as modeling and threat information transmission may intensify cognitive biases and anxiety symptoms in young people (e.g., Fisak \& Grills-Taquechel, 2007), but at the same time it is also possible that fear and anxiety symptomatology in children will evoke this type of parental behaviors in an attempt to help youngsters to face potentially threatening stimili and situations (Rapee, 2009). Meanwhile, it should be kept in mind that the above described findings regarding the role of parenting were mainly based on the analysis of children's self-report data. It is possible that high-anxious children more easily perceive fear-promoting behaviors in their parents, which could also reflect some type of cognitive bias.

The present study also yielded a number of additional findings that need to be briefly discussed. First of all, for some variables, a significant gender effect was documented. In keeping with the literature, girls displayed higher levels of anxiety 
symptoms and interpretation bias than boys (e.g., Craske, 2003; Lewinsohn et al., 1998). Second, age was negatively related to anxiety symptoms and cognitive biases (Broeren, Muris, Diamantopoulou, \& Baker, 2013; Duchesne, Vitaro, Larose, \& Tremblay, 2008; Westenberg et al., 1999) Thus, with increasing age, children reported lower levels of anxiety symptoms and indicated decreased tendencies to interpret ambiguous situation as threatening (interpretation bias) and to search for information that confirms threat (confirmation bias). Given that there are no reasons to assume that the relations between anxiety, cognitive biases, and parenting are different for boys and girls, and the fact that we only included young people of middle childhood with a limited age range, we did not explore moderation effects of gender and age but rather controlled for these demographic variables in our analyses.

A strong point of this study was that we tested cross-sectional as well as timelagged relations between anxiety symptoms, cognitive biases, and parenting variables, eventually selecting the model that was the best compromise between goodness of fit (not lacking any relevant and significant paths or correlations) and parsimony (imposing sensible equality constraints). However, the present investigation also suffers from a number of limitations. To begin with, the study focused on a limited set of variables (modeling, threat information transmission, cognitive biases) that might be relevant within the etiology of childhood anxiety problems, thereby neglecting other factors (e.g., temperament, conditioning, overprotective parenting, and insecure attachment, or even protective factors) that are involved in the development of this type of psychopathology (Vasey \& Dadds, 2001). Second, although we did include parent rating scales and children's self-report measures, most constructs were only assessed using one informant (i.e., either child or parent). The measure that was administered to children and parents (PEAC questionnaire) did not yield fully converging results, and this highlights the importance of including multiple informants for all variables (De Los Reyes \& Kazdin, 2005). Third, although an attempt was made to include both parents in the study, the participation rate was clearly higher for mothers than for fathers. As we used averaged parent scores if both parents had participated, or the scores of the one available parent else, it should be borne in mind that mothers were overrepresented in the present data set. Fourth, parenting was only assessed via a rating scale; it would have been better if we had employed some kind of interview or observational method to assess the fear-enhancing parental behaviors of modeling and threat information transmission. Apart from the fact that such a multi-method approach is preferable, this would also give us the opportunity to study the validity of the PEAC more thoroughly. Fifth, the study was carried out with a sample of non-clinical young people in middle childhood, a developmental stage with fairly little socio-emotional turmoil. It would be interesting to conduct a similar study in clinically referred youth or children/adolescents who face a significant life event. Sixth, children's PEAC scores for mothers and fathers were strongly correlated, which may be the result of the method of scoring each item simultaneously for both parents (father ratings had to be provided on the left side of the screen, while mothers were given on the right side). For future studies, it would be better to present the father and mother versions of this questionnaire serially instead of employing this type of paralle assessment. Finally, the task for measuring interpretation bias included only three vignettes (i.e., one vignette per anxiety type: i.e., social anxiety, generalized anxiety, and separation anxiety) on each time point, and so one could question the validity of this task. However, it is important to note that this bias was not assessed by only three items as each vignette actually contained 5 items. This means that the interpretation bias scores, and this was also true for confirmation bias scores, were based on a total of 15 items, a number which was considered as more than sufficient for measuring these anxiety-related constructs. Moreover, for practical reasons, the administration of more vignettes was not desirable because this would have substantially increased the overall testing time for the children.

In spite of these limitations, this study yields important information on the cross-sectional and prospective relations between parenting, cognitive biases, and childhood anxiety. While the longitudinal analysis provided no support for the idea that cognitive biases are important for the etiology of childhood anxiety disorders, the data at least showed that these biases were solid correlates of anxiety and may fuel symptoms on each time point separately. This means that cognitive biases may indeed be a feasible target for interventions that aim to decrease anxiety levels in children, an idea that is of course already widespread in cognitive behavior therapy (CBT; Kendall, 1993). Besides regular cognitive restructuring, an alternative option would be to apply bias modification approaches (e.g., Amir, Beard, Burns, \& Bomyea, 2009; Reuland $\&$ Teachman, 2014) to undermine the cognitive biases to ultimately decrease the anxiety level. With regard to parenting, implications for therapy are less clear-cut: it seems common sense that parents should try not to increase their offspring's anxiety symptoms by continuously modeling fear reactions or by constant communication of threat information. In the meantime, we should not overrate the importance of these parenting behaviors for the maintenance of children's anxiety symptoms as they may ust as likely be a reaction of the parents to an already anxious child. In support of this line of reasoning is the treatment literature which generally shows that adding parental components to CBT for anxious children does not necessarily imply that the intervention will be more effective (Bodden et al., 2008). Taken together, this research challenges a number of common assumptions on the etiology of childhood anxiety that are certainly a topic of further inquiry. 


\section{References}

American Psychiatric Association. (1994). Diagnostic and statistical manual of mental disorders. (4th ed.). Washington, DC

American Psychiatric Association. (2000). Diagnostic and statistical manual of mental disorders. (4th ed., text rev.). Washington, DC

Amir, N., Beard, C., Burns, M., \& Bomyea, J. (2009). Attention modification program in individuals with generalized anxiety disorder. Journal of Abnormal Psychology, 118(1), 28-33. doi: 10.1037/a0012589

Askew, C., \& Field, A. P. (2008). The vicarious learning pathway to fear 40 years on. Clinical Psychology Review, 28(7), 1249-1265. doi: 10.1016/j.cpr.2008.05.003

Barrett, P. M., Rapee, R. M., Dadds, M. M., \& Ryan, S. M. (1996). Family enhancement of cognitive style in anxious and aggressive children. Journal of Abnormal Child Psychology 24(2), 187-203. doi: 10.1007/BF01441484

Beck, A. T. (1976). Cognitive therapy and the emotional disorders. New York: International Universities Press.

Bell-Dolan, D. J. (1995). Social cue interpretation of anxious children. Journal of Clinical Child Psychology, 24(1), 2-10. doi: 10.1207/s15374424jccp2401_1

Birmaher, B., Khetarpal, S., Brent, D., Cully, M., Balach, L., Kaufman, J., \& Neer, S. M. (1997) The Screen for Child Anxiety Related Emotional Disorders (SCARED): Scale construction and psychometric characteristics. Journal of the American Academy of Child and Adolescent Psychiatry, 36(4), 545-553. doi: 10.1097/00004583-199704000-00018

Bodden, D. H. M., Bögels, S. M., Nauta, M. H., De Haan, E., Ringrose, J., Appelboom, C., . Appelboom-Geerts, K. C. M. M. J. (2008). Child versus family cognitive-behavioral therapy in clinically anxious youth: An efficacy and partial effectiveness study. Journal of the American Academy of Child and Adolescent Psychiatry, 47(12), 1384-1394. doi: 10.1097/ CHI.Ob013e318189148e

Bögels, S. M., \& Zigterman, D. (2000). Dysfunctional cognitions in children with social phobia, separation anxiety disorder, and generalized anxiety disorder. Journal of Abnormal Child Psychology, 28(2), 205-211. doi: 10.1023/a:1005179032470

Bosquet, M., \& Egeland, B. (2006). The development and maintenance of anxiety symptoms from infancy through adolescence in a longitudinal sample. Development and Psychopathology, 18(2), 517-550. doi: 10.1017/s0954579406060275

Broeren, S., Muris, P., Diamantopoulou, S., \& Baker, J. R. (2013). The course of childhood anxiety symptoms: Developmental trajectories and child-related factors in normal children. Journal of Abnormal Child Psychology, 41(1), 81-95. doi: 10.1007/s10802-012-9669-9

Browne, M. W., \& Cudeck, R. (1993). Alternative ways of assessing model fit. In K. A. Bollen \& J. S. Long (Eds.). Testing structural equation models (pp. 136-162). Newbury Park, CA:Sage.

Cannon, M. F., \& Weems, C. F. (2010). Cognitive biases in childhood anxiety disorders: Do interpretive and judgment biases distinguish anxious youth from their non-anxious peers? Journal of Anxiety Disorders, 24(7), 751-758. doi: 10.1016/j.janxdis.2010.05.008

Costello, E., Mustillo, S., Erkanli, A., Keeler, G., \& Angold, A. (2003). Prevalence and development of psychiatric disorders in childhood and adolescence. Archives of General Psychiatry, 60(8), 837-844. doi: 10.1001/archpsyc.60.8.837

Craske, M. G. (2003). Origins of phobias and anxiety disorders: Why more women than men Oxford: Elsevier.
Creswell, C. Cooper, P. \& Murray, L. (2010). Intergenerational transmission of anxious information processing biases. In J. A. Hadwin \& A. P. Field (Eds.), Information processin biases and anxiety. A developmental perspective (pp. 279-296): Chichester, UK: Wiley.

Creswell, C., Murray, L., \& Cooper, P. (2014). Interpretation and expectation in childhood anxiety disorders: Age effects and social specificity. Journal of Abnormal Child Psychology, 42(3), 453-465. doi: 10.1007/s10802-013-9795-z

Creswell, C., \& O'Connor, T. G. (2011). Interpretation bias and anxiety in childhood: Stability, specificity and longitudinal associations. Behavioural and Cognitive Psychotherapy, 39(2) 191-204. doi: 10.1017/s1352465810000494

Creswell, C.. O'Connor, T. G. \& Brewin, C. R. (2006). A longitudinal investigation of maternat and child 'anxious cognitions'. Cognitive Therapy and Research, 30(2), 135-147. doi: 10.1007/ s10608-006-9021-1

Daleiden, E. L., \& Vasey, M. W. (1997). An information-processing perspective on childhood anxiety. Clinical Psychology Review, 17(4), 407-429. doi: 10.1016/S0272-7358(97)00010-X

De Los Reyes, A., \& Kazdin, A. E. (2005). Informant discrepancies in the assessment of childhood psychopathology: A critical review, theoretical framework, and recommendations for further study. Psychological Bulletin, 131(4), 483. doi: 10.1037/0033-2909.131.4.483

Dibbets, P., Fliek, L., \& Meesters, C. (2015). Fear-related confirmation bias in children: A comparison between neutral-and dangerous-looking animals. Child Psychiatry and Human Development, 46(3), 418-425. doi: 10.1007/s10578-014-0481-3

Dibbets, P., \& Meesters, C. (2017). The influence of stimulus valence on confirmation bias in children. Journal of Behavior Therapy and Experimental Psychiatry, 54, 88-92. doi: 10.1016/j. jbtep.2016.07.007

Dodd, H. F., Hudson, J. L., Morris, T. M., \& Wise, C. K. (2012). Interpretation bias in preschoo children at risk for anxiety: A prospective study. Journal of Abnormal Psychology, 121(1), 28-38. doi: 10.1037/a0024589

Duchesne, S., Vitaro, F., Larose, S., \& Tremblay, R. E. (2008). Trajectories of anxiety during elementary-school years and the prediction of high school noncompletion. Journal of Youth and Adolescence, 37(9), 1134-1146. doi: 10.1007/s10964-007-9224-0

Fisak, B., \& Grills-Taquechel, A. E. (2007). Parental modeling, reinforcement, and information transfer: Risk factors in the development of child anxiety? Clinical Child and Family Psychology Review, 10(3), 213-231. doi: 10.1007/s10567-007-0020-x

Fliek, L., Dibbets, P., Roelofs, J., \& Muris, P. (2017). Cognitive bias as a mediator in the relation between fear-enhancing parental behaviors and anxiety symptoms in children: A crosssectional study. Child Psychiatry and Human Development, 48(1), 82-93. doi: 10.1007/ s10578-016-0655-2

Ford, T., Goodman, R., \& Meltzer, H. (2003). The British child and adolescent mental health survey 1999: The prevalence of DSM-IV disorders. Journal of the American Academy of Child and Adolescent Psychiatry, 42(10), 1203-1211. doi: 10.1097/00004583-200310000-00011

Hadwin, J. A., \& Field, A. P. (2010). Information processing biases and anxiety: A developmental perspective. Chichester: Wiley-Blackwell.

Hadwin, J. A., Garner, M., \& Perez-Olivas, G. (2006). The development of information processing biases in childhood anxiety: A review and exploration of its origins in parenting. Clinical Psychology Review, 26(7), 876-894. doi: 10.1016/j.cpr.2005.09.004

Harvey, A. G., Watkins, E., Mansell, W., \& Shafran, R. (2004) Cognitive behavioural processes across psychological disorders: A transdiagnostic approach to research and treatment. Oxford: Oxford University Press 
Ialongo, N., Edelsohn, G., Werthamer-Larsson, L., Crockett, L., \& Kellam, S. (1995). The significance of self-reported anxious symptoms in first grade children: Prediction to anxious symptoms and adaptive functioning in fifth grade. Journal of Child Psychology and Psychiatry, 36(3), 427-437. doi: 10.1111/j.1469-7610.1995.tb01300.x

Joreskog, K., \& Sorbom, D. (1989). LISREL 7: User's Reference Guide. Mooresville, IN: Scientific Software.

Joreskog, K., \& Sorbom, D. (1993). LISREL 8: Manual, Mooresville, IN: Scientific Software.

Kendall, P. C. (1993). Cognitive-behavioral therapies with youth: Guiding theory, current status, and emerging developments. Journal of Consulting and Clinical Psychology, 61(2), 235-247. doi: 10.1037/0022-006x.61.2.235

Last, C. G., Hersen, M., Kazdin, A., Orvaschel, H., \& Perrin, S. (1991). Anxiety disorders in children and their families. Archives of General Psychiatry, 48(10), 928-934. doi: 10.1001 archpsyc.1991.01810340060008

Lester, K. J., Field, A. P., \& Cartwright-Hatton, S. (2012). Maternal anxiety and cognitive biases towards threat in their own and their child's environment. Journal of Family Psychology, 26(5), 756-766. doi: 10.1037/a0029711

Lewinsohn, P. M., Gotlib, I. H., Lewinsohn, M., Seeley, J. R., \& Allen, N. B. (1998). Gender differences in anxiety disorders and anxiety symptoms in adolescents. Journal of Abnormal Psychology, 107(1), 109-117. doi: 10.1037/0021-843x.107.1.109

Muris, P. (2007). Normal and abnormalfear and anxiety in children and adolescents. Oxford, UK: Elsevier.

Muris, P., \& Broeren, S. (2009). Twenty-five years of research on childhood anxiety disorders: Publication trends between 1982 and 2006 and a selective review of the literature. Journa of Child and Family Studies, 18(4), 388-395. doi: 10.1007/s10826-008-9242-x

Muris, P., Dreessen, L., Bögels, S. M., Weckx, M., \& Van Melick, M. (2004). A questionnaire for screening a broad range of DSM-defined anxiety disorder symptoms in clinically referred children and adolescents. Journal of Child Psychology and Psychiatry, 45(4), 813-820. doi: 10.1111/j.1469-7610.2004.00274x

Muris, P., \& Field, A. (2013). Information processing biases. In Essau C. A. \& Ollendick T. H. (Eds.), The Wiley-Blackwell handbook of the treatment of childhood and adolescent anxiety (pp. 141-156). Chichester: Wiley-Blackwel.

Muris, P., \& Field, A. P. (2008). Distorted cognition and pathological anxiety in children and adolescents. Cognition and Emotion, 22(3), 395-421. doi: 10.1080/02699930701843450

Muris, P., \& Field, A. P. (2010). The role of verbal threat information in the development of childhood fear. "Beware the Jabberwock!". Clinical Child and Family Psychology Review, 13(2), 129-150. doi: 10.1007/s10567-010-0064-1

Muris, P., Jacques, P., \& Mayer, B. (2004). The stability of threat perception abnormalities and anxiety disorder symptoms in non-clinical children. Child Psychiatry and Human Development, 34(3), 251-265. doi: 10.1023/B:CHUD.0000015000.13845.9d

Muris, P., Luermans, J., Merckelbach, H., \& Mayer, B. (2000). "Danger is lurking everywhere”. The relation between anxiety and threat perception abnormalities in normal children Journal of Behavior Therapy and Experimental Psychiatry, 31(2), 123-136. doi: 10.1016/ S0005-7916(00)00016-1

Muris, P., Merckelbach, H., Schmidt, H., \& Mayer, B. (1999a). The revised version of the Screen for Child Anxiety Related Emotional Disorders (SCARED-R): Factor structure in normal children. Personality and Individual Differences, 26(1), 99-112. doi: 10.1016/S0191 8869(98)00130-5
Muris, P., Merckelbach, H., Van Brakel, A., \& Mayer, B. (1999b). The revised version of the Screen for Child Anxiety Related Emotional Disorders (SCARED-R): Further evidence for its reliability and validity. Anxiety Stress and Coping, 12(4), 411-425. do 10.1080/10615809908249319

Muris, P., Rapee, R., Meesters, C. Schouten, E., \& Geers, M. (2003). Threat perception abnormalities in children: The role of anxiety disorders symptoms, chronic anxiety, and state anxiety. Journal of Anxiety Disorders, 17(3), 271-287. doi: 10.1016/S08876185(02)00199-8

Muris, P., Rassin, E., Mayer, B., Smeets, G., Huijding, J., Remmerswaal, D., \& Field, A. (2009) Effects of verbal information on fear-related reasoning biases in children. Behaviour Research and Therapy, 47(3), 206-214. doi: 10.1016/j.brat.2008.12.002

Murray, L., Creswell, C., \& Cooper, P. J. (2009). The development of anxiety disorders in childhood: An integrative review. Psychological Medicine, 39(9), 1413-1423. doi: 10.1017/ s003329170900515

Pérez-Edgar, K. Bar-Haim, Y. McDermott, J. M. Gorodetsky, E.,Hodgkinson, C. A. Goldman, D.... Fox, N. A (2010). Variations in the serotonin-transporter gene are associated with attention bias patterns to positive and negative emotion faces. Biological Psychology, 83(3), 269-271. doi: 10.1016/j.biopsycho.2009.08.009

Polanczyk, G.V.. Salum, G. A.. Sugaya, L. S.. Caye, A.. \& Rohde, L.A. (2015). Annual Research Review: A meta-analysis of the worldwide prevalence of mental disorders in children and adolescents. Journal of Child Psychology and Psychiatry, 56(3), 345-365. doi: 10.1111/jcpp.12381

Rapee, R. M. (2009). Early adolescents' perceptions of their mother's anxious parenting as a predictor of anxiety symptoms 12 months later. Journal of Abnormal Child Psychology, 37(8), 1103-1112. doi: 10.1007/s10802-009-9340-2

Rapee, R. M., Schniering, C. A., \& Hudson, J. L. (2009). Anxiety disorders during childhood and adolescence: Origins and treatment. Annual Review of Clinical Psychology, 5, 311-341. doi: 10.1146/annurev.clinpsy.032408.153628

Remmerswaal, D., Huijding, J., Bouwmeester, S., Brouwer, M., \& Muris, P. (2014). Cognitive bias in action: Evidence for a reciprocal relation between confirmation bias and fear in children. Journal of Behavior Therapy and Experimental Psychiatry, 45(1), 26-32. doi: 10.1016/j. jbtep.2013.07.005

Remmerswaal, D., Muris, P., \& Huijding, J. (2016). Transmission of cognitive bias and fear from parents to children: An experimental study. Journal of Clinical Child and Adolescent Psychology, 45(5), 642-654. doi: 10.1080/15374416.2014.987378

Reuland, M. M., \& Teachman, B. A. (2014). Interpretation bias modification for youth and their parents: A novel treatment for early adolescent social anxiety. Journal of Anxiety Disorders, 28(8), 851-864. doi: 10.1016/j.janxdis.2014.09.011

Schneider, S., Unnewehr, S., Florin, I., \& Margraf, J. (2002). Priming panic interpretations in children of patients with panic disorder. Journal of Anxiety Disorders, 16(6), 605-624. doi: 10.1016/S0887-6185(02)00126-3

Sicouri, G., Sharpe, L., Hudson, J. L., Dudeney, J., Jaffe, A., Selvadurai, H., ... Hunt, C. (2017). Threat interpretation and parental influences for children with asthma and anxiety. Behaviour Research and Therapy, 89, 14-23. doi: 10.1016/j.brat.2016.11.004

Thomason, M. E., Henry, M. L., Hamilton, J. P., Joormann, J., Pine, D. S., Ernst, M.... . Britton, J. C. (2010). Neural and behavioral responses to threatening emotion faces in children as a function of the short allele of the serotonin transporter gene. Biological Psychology, 85(1), 38-44. doi: 10.1016/j.biopsycho.2010.04.009 
Van Bockstaele, B., Verschuere, B., Tibboel, H., De Houwer, J., Crombez, G., \& Koster, E. H. W. (2014). A review of current evidence for the causal impact of attentional bias on fear and anxiety. Psychological Bulletin, 140(3), 682-721. doi: 10.1037/a0034834

Van Niekerk, R. E., Klein, A. M., Allart-van Dam, E., Rinck, M., Souren, P. M., Hutschemaekers, G. J. M., \& Becker, E. S. (2018). Biases in interpretation as a vulnerability factor for children of parents with an anxiety disorder. Journal of the American Academy of Child and Adolescent Psychiatry, 57(7), 462-470. doi: 10.1016/j.jaac.2018.04.009

Vasey, M. W., \& Dadds, M. R. (2001). An introduction to the developmental psychopathology of Anxiety. In M. W. Vasey \& M. R. Dadds (Eds.), The developmental psychopathology of anxiety (pp. 3-26). New York: Oxford University Press.

Waters, A. M., Wharton, T. A., Zimmer-Gembeck, M. J., \& Craske, M. G. (2008). Threat-based cognitive biases in anxious children: Comparison with non-anxious children before and after cognitive behavioural treatment. Behaviour Research and Therapy, 46(3), 358-374. doi: 10.1016/j.brat.2008.01.002

Westenberg, P. M., Siebelink, B. M., Warmenhoven, N. J. C., \& Treffers, P. D. A. (1999). Separation anxiety and overanxious disorders: Relations to age and level of psychosocial maturity. Journal of the American Academy of Child \& Adolescent Psychiatry, 38(8), 10001007. doi: 10.1097/00004583-199908000-00016

Wilson, E. J., MacLeod, C., Mathews, A., \& Rutherford, E. M. (2006). The causal role of interpretive bias in anxiety reactivity. Journal of Abnormal Psychology, 115(1), 103-111. doi: 10.1037/0021-843x.115.1.103

Wood, J. J., McLeod, B. D., Sigman, M., Hwang, W. C., \& Chu, B. C. (2003). Parenting and childhood anxiety: Theory, empirical findings, and future directions. Journal of Child Psychology and Psychiatry, 44(1), 134-151. doi: 10.1111/1469-7610.00106

Zavos, H. M., Rijsdijk, F. V., Gregory, A. M., \& Eley, T. C. (2010). Genetic influences on the cognitive biases associated with anxiety and depression symptoms in adolescents. Journa of Affective Disorders, 124(1), 45-53. doi: 10.1016/j.jad.2009.10.030 


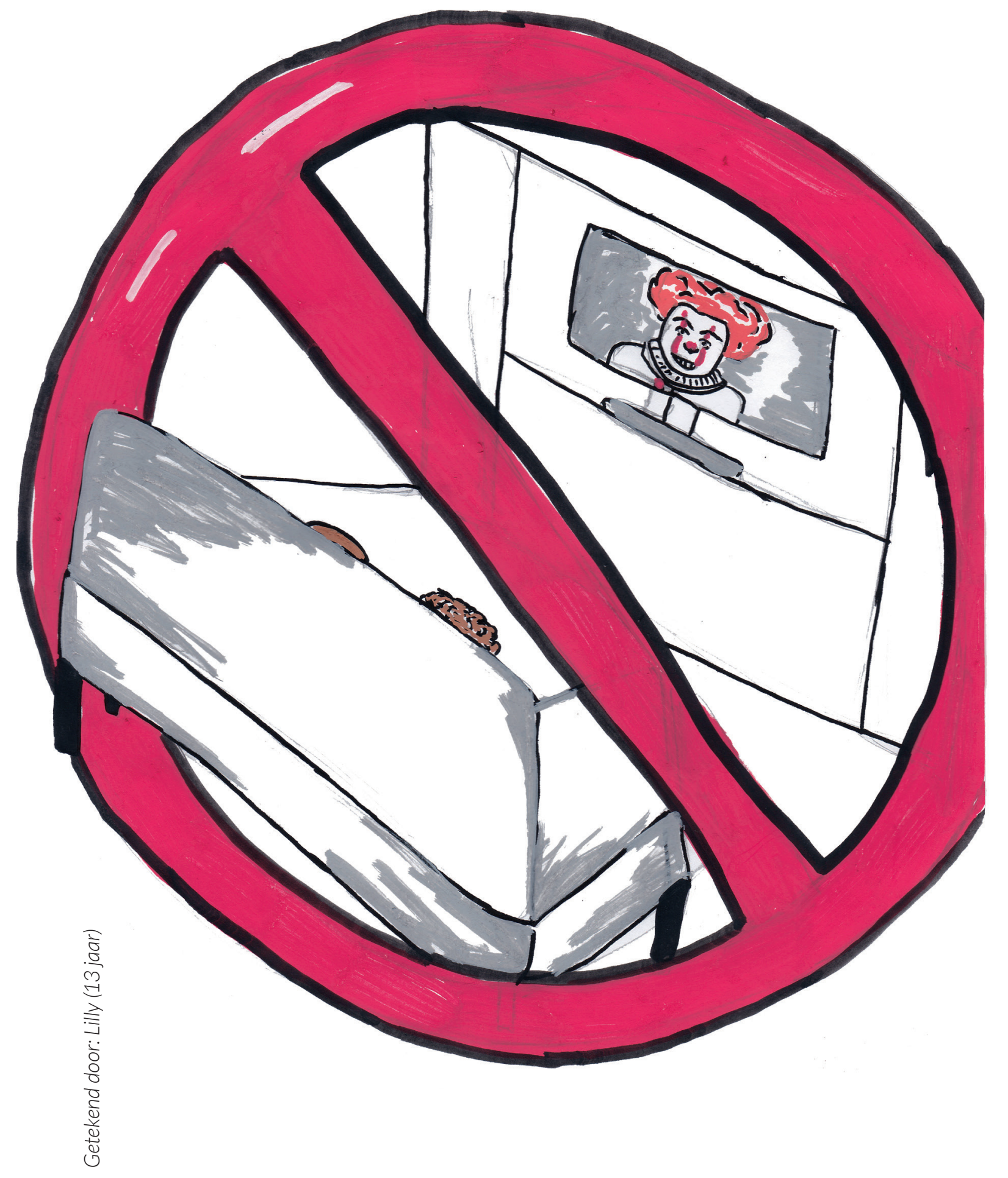

\section{ChAPTER 6}

Summary and General Discussion 
Childhood anxiety is associated with marked social, emotional, behavioral, and cognitive problems, which can have detrimental consequences later in life (Kessler et al., 2005). Research has shown that many anxiety disorders in adults are rooted in childhood (Muris, 2007), and therefore research on the developmental antecedents of these problems is highly relevant. The overall aim of this dissertation was to examine some of these developmental antecedents by investigating the relation between threat-related cognitive biases and childhood anxiety within a family context. Starting point was a theoretical model in which detrimental parenting (modeling and threat information transmission) installs cognitive biases, which in turn fuel fear and anxiety in children.

The results of the studies included in this dissertation have confirmed the notion that parenting behaviors as well as threat-related cognitive biases are involved in childhood anxiety. The findings enhance our understanding about risk- and protective factors in the origin and maintenance of childhood anxiety. In this chapter, I will firs present a summary and overview of the main findings of the separate studies. Then, will discuss the (clinical) implications of the findings. Finally, I will address the strengths and limitations of the studies and provide some suggestions for future research.

\section{Rough-and-tumble play as a protective factor in the devel- opment of childhood anxiety}

In our study on R\&T play (Chapter 2), parents of non-clinical children (aged 2 to 6 years) were asked to complete measures of childhood anxiety symptoms and parenta trait anxiety and overprotection, as well as a self-developed index of parental R\&T play and care activities. The results showed that fathers more often exhibit R\&T play with their children than mothers, while mothers exhibit more caring behaviors than fathers. This is in line with our expectations and findings of earlier studies (Bögels \& Phares, 2008: Lindsey \& Mize, 2001: Paquette, Carbonneau, Dubeau, Bigras, \& Tremblay, 2003). Another hypothesis was that R\&T play would be negatively associated with children's anxiety symptoms, because this parental variable is thought to act as a protective factor for the development of anxiety disorders, by making the child more resistant to challenging encounters (Bögels \& Phares, 2008). This hypothesis was not supported by our data. That is, no statistically significant negative correlation between R\&T play and child anxiety was found. One reason for the absence of this expected link could be that our operationalization of R\&T play was too 'narrow'. More precisely, our R\&T play measure did not include social elements such as teasing or more extreme parental behaviors such as the promotion of risk taking, which have been shown relevant in previous research (Gaumon \& Paquette, 2013; Majdandžić,
Möller, Vente, Bögels, \& van den Boom, 2014; Paquette \& Dumont, 2013). Despite the fact that we did not find a direct relation between R\&T play and child anxiety, we did find a significant interaction effect of R\&T play and paternal trait anxiety on children's anxiety symptoms, indicating that low trait anxious fathers who reported to engage more frequently in R\&T play, had more anxious children. A possible explanation for this finding could be that the R\&T play of low anxious fathers is too rough, thereby unwillingly promoting the anxiety levels of their offspring.

\section{Threat-related confirmation bias and anxiety}

A threat-related confirmation bias can be defined as the inclination to search for information that is congruent to someone's fear and anxiety, while ignoring information that is incongruent to someone's fear and anxiety. Someone with such a bias would become more afraid because he or she is constantly looking for feedback that confirms fear and anxiety, while ignoring information that could disconfirm these emotional states. In Chapter 3, the relation between childhood anxiety and confirmation bias was investigated using an experimental procedure during which fear in 7- to 13-year-old children was elicited by showing pictures of two dangerously looking animals (i.e., aye aye and possum) and creating a contrast with one neutral (non-threatening) anima (i.e., quokka). Questionnaires were used to assess levels of perceived fear and threat for each of the animals, while confirmation bias was measured using the Search for Additional Information Scale (SAIS), during which children had the opportunity to request additional threatening or non-threatening information about the animals. It was found that children who experienced more fear and threat in relation to dangerously looking animals, displayed a stronger inclination to search for more threatening and less non-threatening information about these animals, indicating the presence of confirmation bias. This pattern of information search was not found in case of the nonthreatening animal. Altogether, these results confirmed our expectations and were well in line with previous research on confirmation bias in children (Muris, Huijding, Mayer, van As, \& van Alem, 2011; Muris et al., 2009).

\section{Cognitive biases as a mediator between detrimental parenting and childhood anxiety}

Another important aim of this dissertation concerned the test of our theoretical model and was related to the question whether children's cognitive biases mediate the relation between detrimental parenting behaviors and childhood anxiety. More precisely, in Chapters 4 and 5 it was hypothesized that children's cognitive biases 
would act as a connector in the link between parental modeling and threat information transmission on the one hand, and children's anxiety symptoms on the other hand.

Chapter 4 is concerned with a cross-sectional study, which was conducted to investigate the relation between parental threat information transmission and modeling, two types of cognitive biases (interpretation bias and confirmation bias), and childhood anxiety. Parents as well as their children (aged 7 to 12 years) participated in this study. They both completed the Parental Enhancement of Anxious Cognitions (PEAC) questionnaire for measuring parental modeling and threat information transmission. Furthermore, children also filled in a scale for measuring anxiety symptoms and they performed a number of computerized tasks to assess confirmation and interpretation bias. Parents completed measures of trait anxiety and overprotection. The results indicated that both interpretation and confirmation bias mediated the link between parental threat information transmission and children's anxiety levels, which is in accordance with earlier studies investigating the mediationa role of cognitive bias in the relation between detrimental parenting behaviors and childhood anxiety problems (Gallagher \& Cartwright-Hatton, 2008; Pereira, Barros, Mendonça, \& Muris, 2014; Perez-Olivas, Stevenson, \& Hadwin, 2008). Only interpretation bias (not confirmation bias) mediated the link between modeling (of mothers only) and children's anxiety symptoms. The finding that the mediation effect in the case of modeling was less convincing than that for threat information transmission may well have to do with the operationalization of our measurement of cognitive biases, which was more verbal in nature. This could be the reason that these biases are more clearly related to threat information transmission, which also refers to a verbal process. The mechanism operating during parental modeling is less verbal and might relate to a more implicit process such as social referencing (de Rosnay, Cooper, Tsigaras, \& Murray, 2006). The results of the study presented in Chapter 4 further revealed significant correlations between parental trait anxiety and overprotection on the one hand, and parental modeling and threat information transmission on the other hand, which can be taken as tentative support for the validity of the PEAC scales.

Chapter 5 describes the follow-up study of the children and parents who were included in the cross-sectional study presented in Chapter 4. On three time points during a 1-year period, children and parents completed the same set of measures to assess detrimental parenting, cognitive biases, and anxiety symptoms. We only focused on the results of the child-report data, because cross-informant correlation were very weak and in most cases non-significant. The results of this longitudina study yielded somewhat different results than those obtained in the cross-sectiona investigation. First of all, it was found that cognitive biases and anxiety influenced each other bi-directionally. More precisely, on each of the three time points, most support was found for a model in which interpretation bias enhanced confirmation bias, which subsequently promoted anxiety, which in turn had an enhancing effect on interpretation bias. These findings are in accordance with earlier findings also highlighting the bi-directional relationship between cognitive bias and anxiety (e.g., Remmerswaal, Huijding, Bouwmeester, Brouwer, \& Muris, 2014). Further unexpectedly, it was found that cognitive biases and anxiety had an influence on detrimental parenting instead of a scenario in which detrimental parenting had an impact on cognitive biases and anxiety, which seems to indicate that it is more likely that anxious children elicit detrimental parenting behaviors than the other way around. While such an effect has been noted elsewhere in the research literature (e.g., Brunk \& Henggeler, 1984), the result may also have to do with the method of the study (i.e., using only child self-report) and simply reflect another type of cognitive bias in children, that is an attention bias for negative parenting behaviors. Most interestingly, the study presented in Chapter 5 yielded no evidence for longitudinal associations between cognitive biases and anxiety. Thus, there were no indications that cognitive biases increased anxiety levels or that anxiety levels enhanced cognitive biases over time. The same was true with regard to the parenting variables of threat information transmission and modeling, for which no longitudinal associations with anxiety or cognitive biases were found. Given these results, it was no longer justifiable to test the aforementioned mediational model in which cognitive biases act as the connecto between parenting and childhood anxiety (see Barrett, Rapee, Dadds, \& Ryan, 1996; Remmerswaal, Muris, \& Huijding, 2016; Sicouri et al., 2017).

Parenting factors in the development and maintenance of childhood anxiety

The relation between parenting and children's anxiety symptoms is often assumed to be unidirectional: for example, overprotection, modeling, threat information transmission, or anxious rearing have an enhancing effect on children's anxiety symptoms, whereas R\&T play has a protective impact on this type of emotional symptoms. In Chapter 4, evidence was found for the relation between parental modeling and threat information on the one hand, and children's anxiety symptoms on the other hand. However, as in most other investigations in this research field, this evidence was merely correlational in nature. On the basis of our longitudinal study in which we analyzed our results by means of structural equations modeling (using LISREL), we came to a totally different conclusion, namely that cognitive biases and anxiety symptoms had an enhancing influence on detrimental parenting. This seems to indicate that anxious children elicit detrimental parenting. 
This point has also been made in a review by Fisak and Grills-Taquechel (2007), who noted that when examining family prevalence rates, one can perform top-down studies that investigate anxiety in children of parents with an anxiety disorder, and bottom-up studies, which examine anxiety in the parents of children with an anxiety disorder. Both designs have shown that anxiety symptoms and disorders run in families, and on the basis of these results it is often assumed that the transmission of anxiety goes from parent to child. However, it cannot be ruled out that the transfer occurs the other way around or may even be bi-directional (Fisak \& Grills-Taquechel, 2007).

There is increasing evidence that the latter scenarios are indeed more valid. That is, observational, experimental, and survey studies have shown that parents of anxious children are more intrusively involved, more negative, and less emotionally warm than parents of nonclinical children (Hudson, Doyle, \& Gar, 2009; Hudson \& Rapee, 2001 Siqueland, Kendall, \& Steinberg, 1996). In one of these studies an experimental and observational procedure was applied (Hudson et al., 2009). Forty-five children with an anxiety disorder were compared to 46 nonclinical children. Mothers and children (aged 7 to 14 years) were observed during a speech preparation task. Each mother had to interact with a child from the same diagnostic group as their child and with a child from the other diagnostic group. Results indicated that mothers of clinically anxious children were more negative during interactions with clinically anxious children than with nonclinical children (Hudson et al., 2009). This implies that the anxiety level of the child may elicit negative parenting. Several other experimental studies have also shown that by manipulating children's behaviors, parental responses can be affected (e.g., Brunk \& Henggeler, 1984; Osofsky \& O'Connell, 1972). It is therefore importan to stress the reciprocal relation between parenting and child anxiety rather than a direct causal effect of parental behavior on child anxiety (Gouze, Hopkins, Bryant, \& Lavigne, 2017)

\section{The importance of including both parents in research}

Several studies in this dissertation (Chapter 2, 4, and 5) have stressed the importance of investigating the (different) roles of mothers and fathers. In Chapter 2 , it was found that mothers showed more caring behavior, while fathers showed more R\&T play behavior towards their children. In Chapter 4, the results were analyzed separately or mothers and fathers. It was found that from the children's point of view, mothers displayed more modeling and threat information transmission than fathers. However, in the tested mediation models, no evidence was found indicating that mothers and fathers play a different role. In Chapter 5 it was decided to average the child-reported mother- and father data, since they were strongly correlated. However, one should be aware that this strong correlation might have been mainly due to the fact that children rated mother- and father parenting behaviors on one and the same questionnaire.

Previous studies often had the problem that only mothers were included. This is because mothers are often seen as the primary caregiver of the child and are more easily accessible for participation in research. However, it has been argued that fathers do play a unique role in the development and maintenance of anxiety problems in children (see review by Bögels \& Phares, 2008). From an evolutionary perspective, one can argue that fathers are specialized in confronting their offspring with the external environment by having encounters with potentially dangerous animals and unfamiliar people, while mothers provide their children with comfort and food and typically take care of the internal protection of their offspring (Bögels \& Perotti, 2011) It has been argued that these differential roles of mothers and fathers are reflected in their parenting behavior, with mothers showing more caring and nurturing behaviors and fathers showing more challenging and risk-taking behaviors (Bögels \& Perotti, 2011). Therefore, it is important to hold this differential role of parents in mind with regard to studies involving parenting behaviors.

\section{Clinical implications}

The findings of this thesis could have clinical implications for the treatment as well as the prevention of childhood anxiety. When we consider the clinical implications of the present findings, two questions can be raised: (1) Is it useful to involve parents in the treatment of children with anxiety problems? And (2) Is cognitive bias modification training a useful alternative for treating children with this type of internalizing problems?

Related to the first question we can look at studies involving parents in the therapy of children with anxiety disorders. The results concerning the inclusion of parents in the treatment of anxious youths are mixed (see review by Barmish \& Kendall, 2005). However, a number of parenting factors seem to be potential candidates contributing to the maintenance of anxiety and as such could be regarded as useful targets for treatment. A recent systematic review on the relation between parenting behavior and child anxiety included several studies that were based on questionnaires, observations, and experimental designs (Emerson, Ogielda, \& Rowse, 2018). It was shown that several parental factors, including modeling, parental expectations, and (anxious) rearing behaviors, were of influence on children's anxious cognitions. We can also conclude from our cross-sectional study that parental modeling and threat information transmission might be relevant factors related to childhood anxiety. 
However, this conclusion does not hold for the longitudinal study included in this dissertation, in which we found no evidence for the claim that parental behaviors enhanced anxiety symptoms in children. Instead, the data indicated a reverse relation with the parenting behaviors of modeling and threat information being an epiphenomenon of children's anxiety.

Next to the involvement of detrimental parental behavior in childhood anxiety, it has furthermore been shown that when parents provide positive information about a stimulus or situation to the child, fear and avoidance behavior of children can be successfully reduced (Kelly, Barker, Field, Wilson, \& Reynolds, 2010; Muris et al., 2011; Remmerswaal, Muris, Mayer, \& Smeets, 2010). Therefore, this type of parenting behavior could be employed to diminish anxiety or maybe even prevent the development of childhood anxiety.

The second important question 'Do these cognitive biases offer a lead that can be exploited during therapy?' is related to our findings regarding cognitive biases and childhood anxiety. The most frequently used treatment to reduce anxiety is cognitive behavioral therapy (CBT), which includes techniques such as cognitive restructuring, exposure-based behavioral interventions, and relaxation training (Heimberg, 2002). CBT has shown to be effective in reducing anxiety in youth (see meta-analysis by Scaini, Belotti, Ogliari, \& Battaglia, 2016), although there is still a substantial minority of people who does not respond to this type of intervention. Furthermore, there are studies showing that this treatment fails to show clinically significant responses (see review by Kendall, Settipani, \& Cummings, 2012).

According to cognitive theories, biases in information processing and cognitive control deficits play an important role in the etiology and maintenance of anxiety disorders (e.g., Mathews \& MacLeod, 2005). Therefore, cognitive bias modification (CBM) training could offer a possible solution in this regard. Computerized training programs have been developed that aim to correct the typical errors in information processing that are often noted in people with anxiety disorders. In the case of interpretation bias, participants are trained to interpret stories in a positive way by prompting the anxious individual to complete a word fragment in a positive way. For confirmation bias, participants can be trained to search for positive instead of negative information by providing them with feedback regarding their choices.

A study that documented a significant reduction in childhood anxiety following CBM training was conducted by Reuland and Teachman (2014). In this study, the researchers investigated the effects of interpretation bias modification in 18 socially anxious children aged 10-15 years using a between-subjects design. In the firs treatment condition, cognitive biases of the children were corrected. In the second condition, an attempt was made to modify the cognitive biases of the parents. In the third condition, the cognitive biases of both the child and the parents were targeted. The results indicated a decrease in anxiety symptoms, although there were no significant differences across the three conditions.

A further study showing the efficacy of CBM training in children relied on a nonclinical sample of 4310 - and 11-year-old children who were selected for high socia anxiety (Vassilopoulos, Banerjee, \& Prantzalou, 2009). Half of the children were trained over a two-week period including three sessions prompting them to choose benign over negative interpretations of potentially threatening social scenarios. The other half of the children were included in a test-retest control group. It was found that after training, children in the experimental condition showed lower levels of interpretation bias and social anxiety symptoms in comparison to the control group (Vassilopoulos et al., 2009).

Another study that used a highly similar paradigm showed less positive outcomes of this type of training (Orchard, Apetroaia, Clarke, \& Creswell, 2017). In this study, 56 children (7 to 12 years old) with a diagnosis of social anxiety disorder were included. Half of the children performed 3 sessions of cognitive bias modification training targeting interpretation bias, while the other half did not receive the training. Participants were instructed to choose between a threatening and a non-threatening ending for a set of 15 ambiguous scenarios and after each scenario they were provided with feedback to train them towards choosing the non-threatening response. Results showed that there were no effects of the training on interpretation bias and social anxiety (Orchard et al., 2017).

In general, studies conducted so far on the employment of CBM for treating anxiety have yielded mixed results. Several meta-analyses (mostly including adult participants) have shown that CBM programs produced significant but rather weak changes in information-processing styles and anxiety symptoms (Cristea, Kok, \& Cuijpers, 2015; Eldar et al., 2012; Hakamata et al., 2010; Hallion \& Ruscio, 2011; Heeren, Mogoașe, Philippot, \& McNally, 2015; Mogoaşe, David, \& Koster, 2014). Effect sizes of these studies investigating the impact of CBM on a reduction in anxiety are in fact small ( $\mathrm{g}=0.13$; Hallion \& Ruscio, 2011). In comparison, the effect sizes found in studies involving CBT for anxiety problems are considerably larger ( $g=0.73$ Hofmann \& Smits, 2008). In addition, indications of publication bias have been found in the CBM research field (Liu, Li, Han, \& Liu, 2017).

Despite the fact that studies have shown inconsistent results, several characteristics of CBM have been identified that appear to produce more successfu outcomes. The first feature is that this intervention should include multiple sessions Hallion \& Ruscio, 2011: Lisk, Pile, Haller, Kumari, \& Lau, 2018). A second characteristic of a good program is based on the idea that cognitive biases are likely to be mutually 
reinforcing (Hirsch, Clark, \& Mathews, 2006). Thus, the training should target various types of biases to create a combined effect (de Hullu, Sportel, Nauta, \& de Jong 2017; Sportel, de Hullu, de Jong, \& Nauta, 2013). A third important element is that the training should be ecologically valid by providing the participants with real-life situations they can identify with (Hallion \& Ruscio, 2011). Furthermore, it has been suggested that CBM would be more suitable for some anxiety disorders than for others. For example, people with social anxiety disorder display the lowest rates of treatment utilization of the anxiety disorders. The vast majority never seek treatment for their social anxiety and those who eventually do so make an initial appointment only after several years with the disorder (Grant et al., 2005; Olfson et al., 2000). For CBM programs, the threshold to seek help would probably be lower as compared to CBT and therefore such an intervention seems to be an interesting alternative for people with this type of anxiety problem. Furthermore, CBM could also be a good solution for less severe cases of anxiety problems in general and could serve as a preventive method.

\section{Strengths and limitations of the current research project and} future directions

The studies in this dissertation are characterized by a number of strengths. First, both mothers and fathers are included in the studies. This is important because both mothers and fathers have different roles in the upbringing of children, which should also be taken into account in future research on the role parenting variables in childhood anxiety. Second, the inclusion of two different biases is also a strong point, as most of the previous studies often took only one cognitive bias into account. This provides the opportunity to look at the differential influence of both confirmation bias and interpretation bias on childhood anxiety. Third, all paradigms used in the studies were designed in such a way that they had high ecological validity. Thus, the paradigms reflected typical daily situations feared by anxious children. Fourth, a newly developed questionnaire, the Parental Enhancement of Anxious Cognitions (PEAC) was developed, which made it possible to simultaneously examine both parental modeling and threat information transmission within the context of childhood anxiety.

Despite these strengths, the results of this dissertation should be interpreted in the light of a number of limitations, which also form a starting point for recommendations for future research. The first issue has to do with the format of the PEAC. Children's scores of their mothers' and fathers' rearing practices on this scale appeared to be strongly correlated, which may have been the result of the method of scoring each item simultaneously for both parents. For future studies, it would be advisable to present the father and mother versions of this questionnaire serially instead of parallel.
A second limitation has to do with the (dis)agreement between parents and children. We have particularly looked at this in Chapter 4 and 5 and found out that the correlations between child- and parent-reported data was all rather low (all r's $<$.28). This is a common problem in childhood psychopathology literature when using cross-informant data (see the review by De Los Reyes \& Kazdin, 2005). However parents as well as children both provide useful information from their own viewpoint which seems to be important for our understanding of the origins children's anxiety problems.

A third limitation pertains to the strong reliance on self-report measures. Especially for the key constructs of modeling and threat information transmission, it would have been important if we had not only employed self-report rating scales, but also had included some kind of interview or observational method to assess these fear-enhancing parental behaviors. For example, children could have either been asked open-ended questions to learn more about their parents' actual behaviors or how threatening their parents view the world (in relation to new places, unfamilia people, or risky situations), or child-parent interactions could be observed in challenging situations. Especially in the light of the low parent-child agreement on the questionnaires, this approach would have given insight on the relative validity of various questionnaire data.

A fourth limitation has to do with the design of the studies. A drawback of the design in Chapter 4 is the cross-sectional nature of the study, which precludes interpretations in terms of cause-effect relations. The longitudinal approach of Chapter 5 was an improvement in this regard. However, even when conducting ongitudinal studies, it remains possible that both biases and anxiety are caused by a third factor (such as neuroticism). Therefore, the most powerful way to test causation is to manipulate cognitive variables and observe the impact on emotional experience. This can only be achieved by means of an experimental design. Such an experimenta design would also be useful to not only test the effect of parenting behavior on anxiety of children, but also the other way around. By manipulating the behavior of children, we could investigate the effect on parental behavior. Such an approach would give us more insight in the relation between parenting and childhood anxiety.

A final limitation has to do with the fact that all studies have been executed in nonclinical samples, making it difficult to generalize the results to a clinical population. It would be interesting to investigate the relations between parenting, cognitive biases, and childhood anxiety in clinical samples in future research.

Some additional considerations might be taken into account in future research. First of all, while parents can be considered as an important source of threat information for their children, other sources may be important as well. Media and 
peers have also been shown to have a significant influence that is independent from parental information (e.g., Remmerswaal \& Muris, 2011), and should therefore also be considered in future studies. Another important consideration has to do with the age range of the children and the developmental perspective. It is likely that severa cognitive, social, and emotional capacities first have to be developed before certain cognitive biases can emerge. Few researchers have explored information processing biases within a developmental framework and therefore future studies should use a wider age range and compare different age groups to gain more insight into agerelated changes with regard to cognitive biases and the influence of parents (Hadwin \& Field, 2010)

\section{Concluding remarks}

Altogether, the results indicate that familial learning experiences and cognitive biases are implicated in children's anxiety symptoms. The following conclusions can be drawn from the studies included in this dissertation: (1) Mothers and fathers appear to play different roles in the upbringing of their offspring and as such may also have a differential impact on their children's anxiety level. With regard to R\&T play, we found that fathers showed more of this behavior than mothers. In contrast, mothers showed more caring behaviors than fathers. With regard to modeling and threat information transmission, the rates at which parents exhibit these behaviors also differ. According to children, mothers show more of these detrimental parenting behaviors than fathers do. Although the rates at which parents exhibit modeling and threat information transmission differ, the mechanisms appear to be highly similar for both mothers and fathers: that is, modeling and threat information transmission have the same relation to children's anxiety and cognitive biases for both mothers and fathers. Another important conclusion is that (2) childhood anxiety and cognitive biases influence each other bi-directionally. In this circular relation, interpretation bias has an effect on confirmation bias, which in turn has an effect on childhood anxiety, which influences interpretation bias again. Next to the fact that anxiety and bias influence each other in a bi-directional way, this conclusion also seems to hold for the relation between childhood anxiety and detrimental parenting behaviors (3). In our cross-sectional study, evidence was found suggesting that detrimental parenting styles (modeling and threat information transmission) have an influence on anxiety. In our longitudinal study we found this relationship to be rather the other way around: anxiety in children evokes detrimental parenting. Finally, (4) the support for our theoretical model in which cognitive biases act as mediators in the relation between detrimental parenting and childhood anxiety, was weak. While we did find partia support for our model in the cross-sectional study presented in Chapter 4, we did not find any proof of evidence when using a methodologically superior longitudinal study design (Chapter 5). It thus remains important to further study the effects of cognitive biases on anxiety within a familial context, both for the formation of better theories as well as for improving intervention strategies for anxious youth in the clinical setting. 


\section{References}

Barmish, A. J., \& Kendall, P. C. (2005). Should parents be co-clients in cognitive-behaviora therapy for anxious youth? Journal of Clinical Child and Adolescent Psychology, 34(3), 569581. doi: 10.1207/s15374424jccp3403_12

Barrett, P. M., Rapee, R. M., Dadds, M. M., \& Ryan, S. M. (1996). Family enhancement of cognitive style in anxious and aggressive children. Journal of Abnormal Child Psychology 24(2), 187-203. doi: 10.1007/BF01441484

Bögels, S. M., \& Perotti, E. C. (2011). Does father know best? A formal model of the paterna influence on childhood social anxiety. Journal of Child and Family Studies, 20(2), 171-181. doi: 10.1007/s10826-010-9441-0

Bögels, S. M., \& Phares, V. (2008). Fathers' role in the etiology, prevention and treatment of child anxiety: A review and new model. Clinical Psychology Review, 28(4), 539-558. doi: 10.1016/j.cpr.2007.07.011

Brunk, M. A., \& Henggeler, S. W. (1984). Child influences on adult controls: An experimental investigation. Developmental Psychology, 20(6), 1074-1081. doi: 10.1037/0012 1649.20.6.1074

Cristea, I. A., Kok, R. N., \& Cuijpers, P. (2015). Efficacy of cognitive bias modification interventions in anxiety and depression: Meta-analysis. The British Journal of Psychiatry, 206(1), 7-16. doi: DOI: 10.1192/bjp.bp.114.146761

de Hullu, E., Sportel, B. E., Nauta, M. H., \& de Jong, P. J. (2017). Cognitive bias modification and CBT as early interventions for adolescent social and test anxiety: Two-year follow-up of a randomized controlled trial. Journal of Behavior Therapy and Experimental Psychiatry, 55, 81-89. doi: 10.1016/j.jbtep.2016.11.011

De Los Reyes, A., \& Kazdin, A. E. (2005). Informant discrepancies in the assessment of childhood psychopathology: A critical review, theoretical framework, and recommendations for further study. Psychological Bulletin, 131(4), 483. doi: 10.1037/0033-2909.131.4.483

de Rosnay, M., Cooper, P. J., Tsigaras, N., \& Murray, L. (2006). Transmission of social anxiety from mother to infant: An experimental study using a social referencing paradigm. Behaviour Research and Therapy, 44(8), 1165-1175. doi: 10.1016/j.brat.2005.09.003

Eldar, S., Apter, A., Lotan, D., Edgar, K. P., Naim, R., Fox, N. A., .. Bar-Haim, Y. (2012). Attention bias modification treatment for pediatric anxiety disorders: A randomized controlled trial. American Journal of Psychiatry, 169(2), 213-230. doi: 10.1176/appi.ajp.2011.11060886

Emerson, L. M.., Ogielda, C., \& Rowse, G. (2018). A systematic review of the role of parents in the development of anxious cognitions in children. Journal of Anxiety Disorders, 62, 15-25. doi: 10.1016/j.janxdis.2018.11.002

Fisak, B., \& Grills-Taquechel, A. E. (2007). Parental modeling, reinforcement, and information transfer: Risk factors in the development of child anxiety? Clinical Child and Family Psychology Review, 10(3), 213-231. doi: 10.1007/s10567-007-0020-x

Gallagher, B., \& Cartwright-Hatton, S. (2008). The relationship between parenting factors and trait anxiety: Mediating role of cognitive errors and metacognition. Journal of Anxiety Disorders, 22(4), 722-733. doi: 10.1016/j.janxdis.2007.07.006

Gaumon, S., \& Paquette, D. (2013). The father-child activation relationship and internalising disorders at preschool age. Early Child Development and Care, 183(3-4), 447-463. doi: 10.1080/03004430.2012.711593
Gouze, K. R., Hopkins, J., Bryant, F. B., \& Lavigne, J. V. (2017). Parenting and Anxiety: Bidirectional Relations in Young Children. Journal of Abnormal Child Psychology, 45(6), 1169 1180. doi: 10.1007/s10802-016-0223-z

Grant, B. F., Hasin, D. S., Blanco, C., Stinson, F. S., Chou, S. P., Goldstein, R. B., ... Huang, B. (2005). The epidemiology of social anxiety disorder in the United States: Results from the National Epidemiologic Survey on Alcohol and Related Conditions. The Journal of Clinical Psychiatry, 66(11), 1351-1361. doi: 10.4088/JCP.v66n1102

Hadwin, J. A., \& Field, A. P. (2010). Information processing biases and anxiety: A developmental perspective. Chichester: Wiley-Blackwell.

Hakamata, Y., Lissek, S., Bar-Haim, Y., Britton, J. C. Fox, N. A. Leibenluft, E., ... Pine, D. S. (2010). Attention bias modification treatment: A meta-analysis toward the establishment of novel treatment for anxiety. Biological Psychiatry, 68(11), 982-990. doi: 10.1016/j. biopsych.2010.07.021

Hallion, L. S., \& Ruscio, A. M. (2011). A meta-analysis of the effect of cognitive bias modification on anxiety and depression. Psychological bulletin, 137(6), 940-958. doi: 10.1037/a0024355

Heeren, A. Mogoase, C. Philippot, P. \& McNally, R. J. (2015). Attention bias modification for social anxiety: A systematic review and meta-analysis. Clinical Psychology Review, 40, 76-90 doi: 10.1016/j.cpr.2015.06.001

Heimberg, R. G. (2002). Cognitive-behavioral therapy for social anxiety disorder: Current status and future directions. Biological Psychiatry, 51(1), 101-108. doi: 10.1016/S00063223(01)01183-0

Hirsch, C. R., Clark, D. M., \& Mathews, A. (2006). Imagery and Interpretations in Social Phobia; Support for the Combined Cognitive Biases Hypothesis. Behavior Therapy, 37(3), 223-236 doi: 10.1016/j.beth.2006.02.001

Hofmann, S. G., \& Smits, J. A. J. (2008). Cognitive-behavioral therapy for adult anxiety disorders: A meta-analysis of randomized placebo-controlled trials. The Journal of Clinical Psychiatry, 69(4), 621-632. doi: 10.4088/JCP.v69n0415

Hudson, J. L., Doyle, A. M., \& Gar, N. (2009). Child and maternal influence on parenting behavior in clinically anxious children. Journal of Clinical Child \& Adolescent Psychology, 38(2). 256-262. doi: 10.1080/15374410802698438

Hudson, J. L., \& Rapee, R. M. (2001). Parent-child interactions and anxiety disorders: An observational study. Behaviour Research and Therapy, 39(12), 1411-1427. doi: 10.1016 S0005-7967(00)00107-8

Kelly, V. L., Barker, H. Field, A. P., Wilson, C. \& Reynolds, S. (2010). Can Rachman's indirect pathways be used to un-learn fear? A prospective paradigm to test whether children's fears can be reduced using positive information and modelling a non-anxious response. Behaviour Research and Therapy, 48(2), 164-170. doi: 10.1016/j.brat.2009.10.002

Kendall, P. C., Settipani, C. A., \& Cummings, C. M. (2012). No need to worry: The promising future of child anxiety research. Journal of Clinical Child and Adolescent Psychology, 41(1), 103-115. doi: 10.1080/15374416.2012.632352

Kessler, R. C., Berglund, P., Demler, O., Jin, R., Merikangas, K. R., \& Walters, E. E. (2005). Lifetime prevalence and age-of-onset distributions of DSM-IV disorders in the National Comorbidity Survey Replication. Archives of General Psychiatry, 62(6), 593-602. doi: 10.1001/archpsyc.62.6.593

Lindsey, E. W., \& Mize, J. (2001). Contextual differences in parent-child play: Implications for children's gender role development. Sex Roles, 44(3-4), 155-176. do: 10.1023/a:1010950919451 
Lisk, S. C., Pile, V., Haller, S. P. W., Kumari, V., \& Lau, J. Y. (2018). Multisession cognitive bias modification targeting multiple biases in adolescents with elevated social anxiety. Cognitive Therapy and Research, 42(5), 581-597. doi: 10.1007/s10608-018-9912-y

Liu, H., Li, X., Han, B., \& Liu, X. (2017). Effects of cognitive bias modification on social anxiety: A meta-analysis. PLoS One, 12(4), e0175107. doi: 10.1371/journal.pone.0175107

Majdandžić, M., Möller, E. L., Vente, W., Bögels, S. M., \& van den Boom, D. C. (2014). Fathers challenging parenting behavior prevents social anxiety development in their 4-year-old children: A longitudinal observational study. Journal of Abnormal Child Psychology, 42(2), 301-310. doi: 10.1007/s10802-013-9774-4

Mathews, A., \& MacLeod, C. (2005). Cognitive Vulnerability to Emotional Disorders. Annua Review of Clinical Psychology, 1, 167-195. doi: 10.1146/annurev.clinpsy.1.102803.143916

Mogoaşe, C., David, D., \& Koster, E. H. W. (2014). Clinical efficacy of attentional bias modification procedures: An updated meta-analysis. Journal of Clinical Psychology, 70(12), 1133-1157. doi: doi:10.1002/jclp.22081

Muris, P. (2007). Normal and abnormalfear and anxietyinchildren and adolescents. Oxford, UK:Elsevier.

Muris, P., Huijding, J., Mayer, B., van As, W., \& van Alem, S. (2011). Reduction of verbally learned fear in children: A comparison between positive information, imagery, and a contro condition. Journal of Behavior Therapy and Experimental Psychiatry, 42(2), 139-144. doi: 10.1016/j.jbtep.2010.11.006

Muris, P., Rassin, E., Mayer, B., Smeets, G., Huiiding, J., Remmerswaal, D., \& Field, A. (2009). Effects of verbal information on fear-related reasoning biases in children. Behaviou Research and Therapy, 47(3), 206-214. doi: 10.1016/j.brat.2008.12.002

Olfson, M., Guardino, M., Struening, E., Schneier, F. R., Hellman, F., \& Klein, D. F. (2000) Barriers to the treatment of social anxiety. American Journal of Psychiatry, 157(4), 521 527. doi: 10.1176/appi.ajp.157.4.521

Orchard, F., Apetroaia, A., Clarke, K., \& Creswell, C. (2017). Cognitive bias modification of interpretation in children with social anxiety disorder. Journal of Anxiety Disorders, 45, 1-8. doi: 10.1016/j.janxdis.2016.10.012

Osofsky, J. D., \& O'Connell, E. J. (1972). Parent-child interaction: Daughters' effects upon mothers' and fathers' behaviors. Developmental Psychology, 7(2), 157-168. doi: 10.1037/ h0033016

Paquette, D., Carbonneau, R., Dubeau, D., Bigras, M., \& Tremblay, R. E. (2003). Prevalence of father-child rough-and-tumble play and physical aggression in preschool children. European Journal of Psychology of Education, 18(2), 171-189. doi: 10.1007/BF03173483

Paquette, D., \& Dumont, C. (2013). Is father-child rough-and-tumble play associated with attachment or activation relationships? Early Child Development and Care, 183(6), 760-773. doi: 10.1080/03004430.2012.723440

Pereira, A. I., Barros, L., Mendonça, D., \& Muris, P. (2014). The relationships among parental anxiety, parenting, and children's anxiety: the mediating effects of children's cognitive vulnerabilities. Journal of Child and Family Studies, 23(2). 399-409. doi: 10.1007/s10826-013-9767-5

Perez-Olivas, G., Stevenson, J., \& Hadwin, J. A. (2008). Do anxiety-related attentional biases mediate the link between maternal over involvement and separation anxiety in children? Cognition and Emotion, 22(3), 509-521. doi: 10.1080/02699930801886656

Remmerswaal, D., Huijding, J., Bouwmeester, S., Brouwer, M., \& Muris, P. (2014). Cognitive bias in action: Evidence for a reciprocal relation between confirmation bias and fear in children Journal of Behavior Therapy and Experimental Psychiatry, 45(1), 26-32. doi: 10.1016/j. jbtep.2013.07.005
Remmerswaal, D. \& Muris, P. (2011). Children's fear reactions to the 2009 Swine Flu pandemic: The role of threat information as provided by parents. Journal of Anxiety Disorders, 25(3), 444-449. doi: 10.1016/j.janxdis.2010.11.008

Remmerswaal, D., Muris, P., \& Huijding, J. (2016). Transmission of cognitive bias and fear from parents to children: An experimental study. Journal of Clinical Child and Adolescent Psychology, 45(5). 642-654. doi: 10.1080/15374416.2014.987378

Remmerswaal, D., Muris, P., Mayer, B., \& Smeets, G. (2010). “Will a Cuscus bite you, if he shows his teeth?" Inducing a fear-related confirmation bias in children by providing verbal threat information to their mothers. Journal of Anxiety Disorders, 24(5), 540-546. doi: 10.1016/ J. janxdis.2010.03.012

Reuland, M. M. \& Teachman, B. A. (2014). Interpretation bias modification for youth and their parents: A novel treatment for early adolescent social anxiety. Journal of Anxiety Disorders, 28(8), 851-864. doi: 10.1016/j.janxdis.2014.09.011

Scaini, S., Belotti, R., Ogliari, A., \& Battaglia, M. (2016). A comprehensive meta-analysis of cognitive-behavioral interventions for social anxiety disorder in children and adolescents. Journal of Anxiety Disorders, 42, 105-112. doi: 10.1016/j.janxdis.2016.05.008

Sicouri, G., Sharpe, L., Hudson, J. L., Dudeney, J., Jaffe, A.. Selvadurai, H... .. Hunt, C. (2017) Threat interpretation and parental influences for children with asthma and anxiety. Behaviour Research and Therapy, 89, 14-23. doi: 10.1016/j.brat.2016.11.004

Siqueland, L., Kendall, P. C., \& Steinberg, L. (1996). Anxiety in children: Perceived family environments and observed family interaction. Journal of Clinical Child Psychology, 25(2). 225-237. doi: 10.1207/s15374424jccp2502 12

Sportel, B. E., de Hullu, E., de Jong, P. J., \& Nauta, M. H. (2013). Cognitive bias modification versus CBT in reducing adolescent social anxiety: A randomized controlled trial. PLoS One 8(5), e64355. doi: 10.1371/journal.pone.0064355

Vassilopoulos, S. P.. Banerjee, R. \& Prantzalou, C. (2009). Experimental modification of interpretation bias in socially anxious children: Changes in interpretation, anticipated interpersonal anxiety, and social anxiety symptoms. Behaviour research and therapy, 47(12). 1085-1089. doi: 10.1016/j.brat.2009.07.018 


\title{
VALORIZATION
}

\author{
ADDENDUM
}


The knowledge acquired from the performed studies in this dissertation is of added value to help prevent and treat anxiety problems in children and their parents, by developing individually tailored treatments. In this valorization addendum, implications for science, society, and policy makers are given. First, the relevance of the findings presented in the current dissertation will be addressed and an overview of potential target groups is given for whom the research findings might be relevant. Next, possible activities and products as well as innovative aspects of our studies will be discussed. Finally, the planning and implementation of the findings will be outlined.

\section{Relevance}

Childhood anxiety constitutes an important health care problem as it is one of the most common psychological disorders in children and adolescents (Costello, Mustillo, Erkanli, Keeler, \&Angold, 2003; Ford, Goodman, \& Meltzer, 2003; Polanczyk, Salum, Sugaya, Caye, \& Rohde, 2015; Roza, Hofstra, van der Ende, \& Verhulst, 2003). About one third of the general population has experienced an anxiety disorder at least once during their lifetime, and it is clear that this problem oftentimes has its onset during the childhood years (Kessler et al., 2005). The risk for other types of psychopathology, specifically depression, is also increased (Cole, Peeke, Martin, Truglio, \& Seroczynski, 1998; Cummings, Caporino, \& Kendall, 2014).

Next to the high prevalence rates, childhood anxiety is also a financial burden for society as well as for individual families. With respect to costs, the total costs for anxiety disorders in adults were highest of all mental illnesses in the USA (DuPont et al., 1996). Societal costs of families with clinically anxious children who are living in the Netherlands are almost 21 times as high compared to families from the genera population (Bodden, Dirksen, \& Bögels, 2008).

It is important to find the most optimal and effective treatment for childhood anxiety disorders. One way to address this issue would be to get insight into the underlying mechanism in the acquisition of anxiety disorders. One of these mechanisms might be threat-related cognitive biases. We know from research that these biases are only to some extent genetically determined (Zavos, Rijsdijk, Gregory, \& Eley, 2010) and that there is a substantial role for environmental factors in the emergence of these cognitive distortions. To this end, we investigated parenting behaviors in relation to children's threat-related cognitive biases as well as anxiety problems. It is important to note that parenting behaviors should not only be perceived as risk behaviors, but could also serve as a protective factor in the development of childhood anxiety. In our research, we have found indications that parental rough-and-tumble (R\&T) play may act as a protective factor, while parental modeling and threat information transmission were shown to be potential risk factors for the development of childhood anxiety.

\section{Target groups}

This dissertation aimed to gain more insight in the relations between parenting behaviors, threat-related cognitive biases, and childhood anxiety. Since these cognitive biases are conceived as a vulnerability factor for anxiety disorders and in view of the continuum from normal to abnormal anxiety, it is important to test not only clinically referred samples but also non-clinical populations. This was done in the studies presented in this dissertation, thereby contributing to a better understanding of the relation between parenting, cognitive biases and childhood anxiety in a non-clinical population.

The results are of interest to a broader public of researchers and clinicians who have the goal to better understand the transmission of anxiety problems from parents to children and the role of cognitive biases in this relation. The studies in this dissertation might also be useful for patients with anxiety disorders and their parents as the results might contribute to the improvement of treatment.

The results of the studies presented in this dissertation could furthermore be relevant for policy makers, since interventions aimed at reducing cognitive distortions such as a cognitive bias modification (CBM) training might be a promising new lead in the treatment of anxiety disorders (Hakamata et al., 2010). This could eventually have a positive impact on society through the reduction of economic costs.

\section{Activities/products}

The results of the studies in this dissertation have confirmed that parenting behaviors as well as threat-related cognitive biases are involved in childhood anxiety. The findings enhance our understanding about risk and protective factors in the origin and maintenance of childhood anxiety disorders. The findings of this thesis could have clinical implications for the treatment as well as the prevention of childhood anxiety. First of all, when including parents in therapy, it is important to educate them about their role in the development and maintenance of anxiety problems in their children. Several parental behaviors are of influence on children's anxious cognitions and it is in this respect very important to include mothers as well as fathers, since we know that they both have different roles. The results of our longitudinal study showed that children's cognitive biases and anxiety symptoms had an enhancing influence on detrimental parenting. This implies that the relation between parenting and children's anxiety symptoms is not unidirectional, and that it is therefore also important to inform parents on the effect their children could have on their parenting behavior.

A second important clinical implication is related to the involvement of cognitive biases in childhood anxiety. CBM training, which explicitly aims at reducing threat- 
related cognitive biases, has the potential to become an alternative treatment for children with this type of internalizing problems (Lau, 2013). CBM training has many advantages over cognitive behavioral therapy (CBT). First of all, no therapist has to be involved in CBM. The intervention is highly accessible as it can be provided online, making it an attractive treatment option for some anxiety patients. For example, people with social anxiety disorder have the lowest rates of treatment utilization of the anxiety disorders. The vast majority never seek treatment for their social anxiety problems and those who do so make an initial appointment with a therapist only after several years with the disorder (Grant et al., 2005; Olfson et al., 2000). For CBM programs, the threshold to seek help would be much lower as compared to CBT and therefore such an intervention could be an interesting alternative for people with this type of anxiety problem. Furthermore, CBM could also be a good solution for less severe cases of anxiety problems in general and could serve as a preventive method (See, MacLeod, \& Bridle, 2009), which could be implemented in a variety of contexts e.g., schools or healthcare settings).

\section{Innovation}

The studies in the dissertation are innovative as they were not only focused on risk factors for the development of anxiety disorders, but also protective factors. Furthermore, previous experimental research on cognitive biases mostly used animals as stimuli. In our studies we increased the ecological validity by using stories about situations relating to children's everyday life. Furthermore, whereas most studies in this domain have focused on studying only one type of bias, our research included two biases, providing the opportunity to examine whether such biases are inter-related and make independent contributions to anxiety. Another innovative aspect is that previous studies mostly used correlational designs, where we used a longitudina set-up making it possible to examine prospective time effects. A final innovative aspect was that we took the behavior of mothers as well as fathers into account, which can be seen as an improvement to previous studies that have mainly focused on the role of mothers (e.g., Bögels \& Phares, 2008).

\section{Planning and implementation}

All chapters in this dissertation are published in international peer-reviewed scientific journals. This allows other scientists and clinicians to easily access the findings of our studies. Several of the questionnaires and paradigms that were developed for the studies in this dissertation have also been used in other studies. Furthermore, our paradigms to measure cognitive biases could be redesigned to paradigms that can be used to reduce cognitive biases (CBM training). This could lead to individually tailored treatments, for which content specific CBM could be used to target each specific anxiety disorder, thereby enabling health care providers to deliver an evidence-based intervention with minimal guidance. It could possibly also be used as an intervention while patients are waiting for standard treatment or as a method to prevent relapse. 


\section{References}

Bodden, D. H. M., Dirksen, C. D., \& Bögels, S. M. (2008). Societal burden of clinically anxious youth referred for treatment: A cost-of-illness study. Journal of Abnormal Child Psychology 36(4), 487-497. doi: 10.1007/s10802-007-9194-4

Bögels, S. M., \& Phares, V. (2008). Fathers' role in the etiology, prevention and treatment of child anxiety: A review and new model. Clinical Psychology Review, 28(4), 539-558. doi: 10.1016/j.cpr.2007.07.011

Cole, D. A., Peeke, L. G., Martin, J. M., Truglio, R., \& Seroczynski, A. D. (1998). A longitudina look at the relation between depression and anxiety in children and adolescents. Journa of Consulting and Clinical Psychology, 66(3), 451-460. doi: 10.1037/0022-006x.66.3.451

Costello, E., Mustillo, S., Erkanli, A., Keeler, G., \& Angold, A. (2003). Prevalence and development of psychiatric disorders in childhood and adolescence. Archives of General Psychiatry, 60(8), 837-844. doi: 10.1001/archpsyc.60.8.837

Cummings, C. M., Caporino, N. E., \& Kendall, P. C. (2014). Comorbidity of anxiety and depression in children and adolescents: 20 years after. Psychological Bulletin, 140(3), $816-$ 845. doi: 10.1037/a0034733

DuPont, R. L., Rice, D. P., Miller, L. S., Shiraki, S. S., Rowland, C. R., \& Harwood, H. J. (1996). Economic costs of anxiety disorders. Anxiety, 2(4), 167-172. doi: 10.1002/(SICI)15227154(1996)2:4<167::AID-ANXI2>3.0.CO;2-L

Ford, T., Goodman, R., \& Meltzer, H. (2003). The British child and adolescent mental health survey 1999: The prevalence of DSM-IV disorders. Journal of the American Academy of Child and Adolescent Psychiatry, 42(10), 1203-1211. doi: 10.1097/00004583-20031000000011

Grant, B. F., Hasin, D. S., Blanco, C., Stinson, F. S., Chou, S. P., Goldstein, R. B., ... Huang, B. (2005). The epidemiology of social anxiety disorder in the United States: Results from the National Epidemiologic Survey on Alcohol and Related Conditions. The Journal of Clinica Psychiatry, 66(11), 1351-1361. doi: 10.4088/JCP.v66n1102

Hakamata, Y., Lissek, S., Bar-Haim, Y., Britton, J. C., Fox, N. A., Leibenluft, E., ... Pine, D. S. (2010). Attention bias modification treatment: A meta-analysis toward the establishmen of novel treatment for anxiety. Biological Psychiatry, 68(11), 982-990. doi: 10.1016/j. biopsych.2010.07.021

Kessler, R. C., Berglund, P., Demler, O., Jin, R., Merikangas, K. R., \& Walters, E. E. (2005). Lifetime prevalence and age-of-onset distributions of DSM-IV disorders in the Nationa Comorbidity Survey Replication. Archives of General Psychiatry, 62(6), 593-602. doi: 10.1001/archpsyc.62.6.593

Lau, J. Y. F. (2013). Cognitive bias modification of interpretations: A viable treatment for child and adolescent anxiety? Behaviour Research and Therapy, 51(10), 614-622. doi: 10.1016/j. brat.2013.07.001

Olfson, M., Guardino, M., Struening, E., Schneier, F. R., Hellman, F., \& Klein, D. F. (2000) Barriers to the treatment of social anxiety. American Journal of Psychiatry, 157(4), 521 527. doi: 10.1176/appi.ajp.157.4.521

Polanczyk, G. V., Salum, G. A., Sugaya, L. S., Caye, A., \& Rohde, L. A. (2015). Annual Research Review: A meta-analysis of the worldwide prevalence of mental disorders in children and adolescents. Journal of Child Psychology and Psychiatry, 56(3), 345-365. doi: 10.1111/ jcpp.12381
Roza, S. J., Hofstra, M. B., van der Ende, J., \& Verhulst, F. C. (2003). Stable prediction of mood and anxiety disorders based on behavioral and emotional problems in childhood: A 14year follow-up during childhood, adolescence, and young adulthood. American Journal of Psychiatry, 160(12), 2116-2121. doi: 10.1176/appi.ajp.160.12.2116

See, J., MacLeod, C., \& Bridle, R. (2009). The reduction of anxiety vulnerability through the modification of attentional bias: A real-world study using a home-based cognitive bias modification procedure. Journal of Abnormal Psychology, 118(1), 65-75. doi: 10.1037/ a0014377

Zavos, H. M., Rijsdijk, F. V., Gregory, A. M., \& Eley, T. C. (2010). Genetic influences on the cognitive biases associated with anxiety and depression symptoms in adolescents. Journal of Affective Disorders, 124(1), 45-53. doi: 10.1016/i.jad.2009.10.030 
NederLANDSE SAMENVATTING 


\section{Angst bij kinderen}

Angst kan worden gedefinieerd als een emotie die iemand helpt te reageren op gevaar. Voor kinderen en adolescenten is het normaal en onder bepaalde omstandigheden ook adaptief om angstig te zijn. Deze angsten ontwikkelen zich parallel aan de sociaal-emotionele en cognitieve ontwikkeling van kinderen. Op jonge leeftijd zijn kinderen vaak bang voor harde geluiden of separatie van hun ouders. Daarna worden de angsten complexer en zijn kinderen vaak bang voor dieren, het donker, of fantasiefiguren. Vanaf 8 jaar beginnen angsten over fysieke verwonding, sociale acceptatie en schoolprestaties (Muris, Merckelbach, Meesters, \& van den Brand, 2002; Vasey, 1993; Westenberg, Drewes, Goedhart, Siebelink, \& Treffers, 2004). Bij sommige kinderen is de angst op enig moment in de ontwikkeling zo frequent, intens en aanhoudend dat hij zich ontwikkelt tot een angststoornis.

Volgens het Handboek voor de classificatie van psychische stoornissen (DSM-5; American Psychiatric Association, 2013) kunnen de volgende angststoornissen worden onderscheiden: separatie angst stoornis (een ongebruikelijk sterke angst om gescheiden te worden van belangrijke personen in je leven), selectief mutisme (iemand is in sommige sociale situaties niet in staat om te spreken, terwijl hij of zij dat in andere situaties heel goed kan), specifieke fobie (een intense en irrationele angst voor een specifiek object of situatie), sociale angststoornis (een aanhoudende angst voor sociale situaties waarbij schaamte kan optreden en waar iemand mogelijk negatief beoordeeld of vernederd kan worden door anderen), paniekstoornis (uit zich voornamelijk in de vorm van paniekaanvallen: episodes van intense angst zonder duidelijke externe oorzaak), agorafobie (een buitensporige angst voor openbare plekken), en gegeneraliseerde angststoornis (buitensporige angst en zorgen over verschillende onderwerpen, gebeurtenissen, of activiteiten).

Angststoornissen zijn een van de meest voorkomende psychische problemen bij kinderen en jongeren (Costello, Mustillo, Erkanli, Keeler, \& Angold, 2003; Ford, Goodman, \& Meltzer, 2003; Polanczyk, Salum, Sugaya, Caye, \& Rohde, 2015; Roza, Hofstra, van der Ende, \& Verhulst, 2003). Ongeveer 29\% van de algemene populatie heeft minstens één angststoornis gehad tijdens zijn of haar leven en vaak begint dit probleem in de kindertijd (Kessler et al., 2005). Gegeven de hoge prevalentie van angststoornissen is het van groot belang om meer inzicht te krijgen in de risicofactoren, maar ook de beschermende factoren bij het ontwikkelen van angst. Het belangrijkste doel van de studies in deze dissertatie is om hieraan bij te dragen.

\section{Ouderlijke gedragingen die een rol spelen bij de ontwikkeling van angst bij kinderen}

Ongeveer 30\% van de variatie in angststoornissen kan worden toegeschreven aan genetische invloeden (Eley \& Gregory, 2004). Dit laat nog genoeg ruimte voor omgevingsfactoren die een rol spelen in het ontwikkelen van angst bij kinderen. Ouderlijke gedragingen zijn hierbij zeer relevant (Murray, Creswell, \& Cooper, 2009).

Een belangrijke kanttekening bij eerder onderzoek naar de rol van ouderlijke gedragingen bij de ontwikkeling van angst bij kinderen is dat de studies vooral zijn uitgevoerd met moeders. De studies in deze dissertatie hebben betrekking op beide ouders. Hoewel de rol van vaders vaak genegeerd is in dit onderzoeksveld, is er toch enig bewijs dat zij een unieke en vaak andere rol spelen dan moeders bij de ontwikkeling van angst bij kinderen (e.g., Bögels \& Phares, 2008).

Verschillende ouderlijke risicofactoren blijken gerelateerd aan angst bij kinderen, waaronder overbescherming, een controlerende opvoedingsstijl, een inconsistente opvoedingsstijl, vijandigheid, gebrek aan warmte, angstig model-leren en bedreigende informatieoverdracht (Fisak \& Grills-Taquechel, 2007; Hudson \& Rapee, 2001 Moore, Whaley, \& Sigman, 2004; Moss, Cyr, \& Dubois-Comtois, 2004; Wolfradt, Hempel, \& Miles, 2003). Naast deze risicofactoren bestaan er ook beschermende factoren die het ontstaan van een angststoornis mogelijk kunnen voorkomen. Een van deze beschermende factoren is "rough-and-tumble play" (R\&T play), waarbij de ouder op een fysieke, enigszins ruwe manier speelt met het kind en er sprake is van positieve gevoelens naar elkaar toe (Pellegrini, 1995). Naast het fysieke spelen heeft R\&T play ook een sociaal-emotionele component. Ouders die vaak R\&T play vertonen, leren hun kinderen om de interne gewaarwordingen die wordt opgewekt tijdens deze activiteiten (bijvoorbeeld een versnelde hartslag) op een plezierige manier te interpreteren in plaats van op een angstige manier. Hierdoor worden deze kinderen meer tolerant voor deze gewaarwordingen in andere sociale en fysiek uitdagende situaties (Bögels \& Perotti, 2011; Bögels \& Phares, 2008).

R\&T play van ouders als een mogelijke beschermende factor voor de ontwikkeling van angst bij kinderen werd onderzocht in Hoofdstuk 2 van dit proefschrift. Moeders en vaders van 105 kinderen (in de leeftijd van 2 tot 6 jaar) werden gevraagd om een aantal vragenlijsten in te vullen over angst bij hun kinderen, hun eigen angst en de mate waarin ze zich bezighielden met R\&T play en verzorgende activiteiten. Laatstgenoemde constructen werden gemeten met een vragenlijst die speciaal was ontwikkeld voor deze studie: de "Parental Play and Care Questionnaire" (PPCQ). Uit de resultaten bleek dat vaders zich meer bezighouden met R\&T play (bijvoorbeeld stoeien), terwijl moeders zich meer bezighouden met verzorgende taken (bijvoorbeeld 
knuffelen). Deze bevinding was in lijn met onze verwachtingen en de resultaten van eerdere studies (Bögels \& Phares, 2008; Lindsey \& Mize, 2001; Paquette, Carbonneau, Dubeau, Bigras, \& Tremblay, 2003). Verder verwachtten we dat R\&T play negatief geassocieerd zou zijn met angst van het kind, omdat dit ouderlijk gedrag een mogelijke beschermende factor kan zijn voor het ontwikkelen van angst. Deze hypothese werd niet ondersteund door onze data: er was geen negatieve correlatie tussen R\&T play en angst bij het kind. Een verklaring voor de afwezigheid van dit verband zou kunnen zijn dat onze operationalisatie van R\&T play te 'smal' was: onze maat van R\&T play omvatte geen sociale elementen zoals plagen, of meer extreme gedragingen zoals het expliciet aanmoedigen om risicovolle situaties aan te gaan. Ondanks het feit dat we geen directe relatie hebben gevonden tussen R\&T play en angst bij kinderen, werd er wel een significant interactie-effect gevonden tussen R\&T play en angst van de vader op angst bij het kind. Deze interactie liet zien dat minder angstige vaders die vaker R\&T play vertoonden, kinderen hadden die hoger scoorden op angst. Een mogelijke verklaring voor deze bevinding is dat R\&T play van laag angstige vaders te ruw is en daardoor onbedoeld het angstniveau van hun kinderen verhoogt.

\section{Angst-gerelateerde cognitieve biases en het verband met angst bij kinderen}

Cognitieve theorieën stellen dat denkfouten in de informatieverwerking (ook wel cognitieve biases genoemd) een rol spelen in het ontstaan en instandhouden van angststoornissen (e.g., Mathews \& MacLeod, 2005). Neem als voorbeeld interpretatie bias, waarbij neutrale informatie op een specifieke (angstopwekkende) manier wordt geïnterpreteerd (Muris \& Field, 2013). Stel dat iemand een presentatie geeft en een persoon in het publiek moet lachen. Als de persoon die de presentatie geeft last heeft van sociale angst, dan zal hij/zij geneigd zijn om het lachen van de persoon in het publiek sneller als negatief te interpreteren.

Een studie over de relatie tussen interpretatie bias en angst bij kinderen werd gedaan door Miers, Blöte, Bögels, en Westenberg (2008). De onderzoekers vergeleken 37 sociaal angstige adolescenten met een controlegroep van 36 niet sociaal-angstige adolescenten in de leeftijd van 11 tot 16 jaar. Beide groepen moesten de waarschijnlijkheid beoordelen van verschillende interpretaties van ambigue sociale en niet-sociale situaties. De resultaten lieten zien dat de angstige kinderen negatieve interpretaties van sociale situaties als waarschijnlijker beoordeeld werden dan de kinderen in de controlegroep. Er werd geen verschil gevonden tussen de angstige kinderen en de kinderen in de controlegroep met betrekking tot de ingeschatte waarschijnlijkheid van positieve interpretaties. Verder lieten de onderzoekers zien dat de interpretatie bias inhoudsspecifiek was: sociaal angstige kinderen lieten deze denkfout alleen maar zien bij sociale situaties en niet bij niet-sociale situaties. Andere studies hebben vergelijkbare resultaten laten zien (Constans, Penn, Ihen, \& Hope, 1999; Stopa \& Clark, 2000; Voncken, Bögels, \& de Vries, 2003).

Een andere denkfout die voorkomt bij angst is confirmatie bias. Deze denkfout houdt in dat iemand op zoek gaat naar informatie die zijn of haar angst bevestigt, terwijl informatie die de angst kan ontkrachten wordt genegeerd (Muris \& Field, 2013). Confirmatie bias kan worden gemeten met behulp van een experimentele taak waarbij kinderen de mogelijkheid krijgen om extra positieve of negatieve informatie te vergaren over een nieuw en potentieel bedreigende stimulus (vaak een onbekend dier) of situatie. Studies die gebruik maakten van een dergelijke taak hebben inderdaad laten zien dat angstige kinderen een sterkere neiging hebben om naar negatieve informatie te zoeken en minder vaak op zoek zijn naar positieve informatie (Dibbets, Fliek, \& Meesters, 2015; Dibbets \& Meesters, 2017; Muris et al., 2009b; Remmerswaal, Huijding, Bouwmeester, Brouwer, \& Muris, 2014).

In Hoofdstuk 3 hebben wij de relatie tussen een angst-gerelateerde confirmatie bias en angst onderzocht in een groep van 80 kinderen van 7 tot 13 jaar oud. Eerdere studies hebben confirmatie bias onderzocht door het geven van (in)directe negatieve informatie, waardoor de resultaten mogelijk werden beïnvloed door een geheugencomponent. In de huidige studie werd onderzocht of de confirmatie bias ook optreedt zonder dat er expliciete verbale informatie wordt gegeven. De kinderen kregen een plaatje van een neutraal dier (quokka) en twee plaatjes van eng uitziende dieren (aye aye en possum) te zien (plaatjes van deze dieren zijn te vinden in hoofdstuk 3). Vragenlijsten werden gebruikt om de mate van angst en waargenomen dreiging van elk dier te meten. Confirmatie bias werd gemeten middels een taak waarbij kinderen de mogelijkheid hadden om extra bedreigende of niet-bedreigende informatie in te winnen over de dieren. Uit de resultaten bleek dat kinderen die meer bedreiging en angst voelden in relatie tot de eng uitziende dieren, ook een hogere mate van confirmatie bias lieten zien. Dit zagen we in de resultaten doordat ze meer bedreigende informatie en minder niet-bedreigende informatie over deze dieren te weten wilden komen. Deze resultaten werden niet gevonden bij het neutrale dier Tijdens een gedragstaak waarbij de kinderen de opdracht kregen om de drie dieren te voeren, viel op dat de kinderen het neutrale dier meestal als eerste benaderden. Deze resultaten bevestigen onze verwachtingen dat confirmatie bias in kinderen geobserveerd kan worden zonder het gebruik van een verbale angst-inductie en de resultaten zijn in lijn met eerder onderzoek over confirmatie bias bij kinderen (Muris, Huijding, Mayer, van As, \& van Alem, 2011; Muris et al., 2009b). 


\section{Ouderlijke gedragingen, angst-gerelateerde cognitieve biases en angst bij kinderen}

Naast R\&T play als een mogelijke beschermende factor in de ontwikkeling van angst bij kinderen, werden in dit proefschrift ook twee ouderlijke risicofactoren onderzocht, te weten model-leren en bedreigende informatieoverdracht. Modelleren is het laten zien van angst in de aanwezigheid van het kind (Fisak \& GrillsTaquechel, 2007). Bedreigende informatieoverdracht betreft de verbale expressie van angst en dreiging over een bepaalde stimulus of situatie. Beide gedragingen zijn waar te nemen bij ouders en werden in eerder onderzoek in verband gebracht met angst bij kinderen (zie reviews van Askew \& Field, 2008; Muris \& Field, 2010). Het exacte mechanisme waardoor angst wordt overgedragen van ouders op kinderen is echter nog niet duidelijk. Angst-gerelateerde cognitieve biases zouden hier een rol bij kunnen spelen. Eerder onderzoek heeft immers uitgewezen dat model-leren en bedreigende informatieoverdracht van ouders een cognitieve bias kunnen induceren in niet-angstige individuen (Muris \& Field, 2013; Muris, Huijding, Mayer \& Hameetman, 2008; Muris, Huijding, Mayer, Remmerswaal, \& Vreden, 2009a; Muris et al., 2009b; Remmerswaal, Muris, Mayer, \& Smeets, 2010). Cognitieve biases zouden daarom als een mediator kunnen fungeren in de relatie tussen schadelijke ouder-gedragingen (model-leren en bedreigende informatieoverdracht) en angst bij kinderen. Eenvoudiger gezegd betekent dit dat cognitieve biases van kinderen de verbinding vormen in de relatie tussen schadelijke ouderlijke gedragingen aan de ene kant en angst bij kinderen aan de andere kant.

Deze hypothese hebben we zowel cross-sectioneel (Hoofdstuk 4) als longitudinaal

(Hoofdstuk 5) onderzocht. Aan beide studies deden 258 kinderen in de leeftijd van 7 tot 12 jaar en hun ouders mee.

In Hoofdstuk 4 werden de relaties tussen ouderlijke gedragingen (model-leren en bedreigende informatieoverdracht), cognitieve denkfouten (confirmatie bias en interpretatie bias) en angst bij kinderen onderzocht. Zowel ouders als kinderen vulden de "Parental Enhancement of Anxious Cognitions (PEAC) vragenlijst" in waarmee de ouderlijke gedragingen model-leren en bedreigende informatieoverdracht kunnen worden gemeten. Ook vulden de kinderen een vragenlijst over angst in en deden ze een aantal taken op de computer om beide cognitieve biases te meten, terwijl hun ouders ook vragenlijsten over angst en overbescherming invulden. De resultaten lieten zien dat onze hypothese gedeeltelijk werd bevestigd. Beide biases (interpretatie en confirmatie) fungeerden als mediatoren in de relatie tussen bedreigende informatieoverdrach van (beide) ouders en angst bij kinderen. Alleen interpretatie bias (confirmatie bias niet) was een mediator in de relatie tussen model-leren (van alleen moeders) en angst bij kinderen. De bevinding dat het mediatie-effect in het geval van model-leren minder overtuigend was dan bij bedreigende informatieoverdracht kan te maken hebben met onze operationalisatie van cognitieve bias, die nogal verbaal van aard was. Met andere woorden, de biases waren duidelijker gerelateerd aan bedreigende informatieoverdracht, omdat dit ook een verbaal proces is. Het mechanisme tijdens model-leren is minder verbaal en meer gerelateerd aan impliciete processen, zoals "social referencing", waarbij iemand in een ambigue situatie het voorbeeld van anderen volgt (de Rosnay, Cooper, Tsigaras, \& Murray, 2006). De resultaten die worden gepresenteerd in Hoofdstuk 4 lieten ook significante correlaties aan tussen angst en overbescherming van de ouders aan de ene kant, en model-leren en bedreigende informatieoverdracht aan de andere kant. Dit kan worden gezien als voorzichtig bewijs voor de validiteit van de subschalen van de PEAC. Het ligt namelijk in de lijn der verwachting dat angstige ouders vaker deze angst bevorderende gedragingen vertonen.

Longitudinale verbanden tussen de schadelijke ouderlijke gedragingen (model leren en bedreigende informatieoverdracht) en cognitieve biases en angst bij kinderen werden onderzocht in Hoofdstuk 5. In deze studie werden alle relevante constructen op drie opeenvolgende momenten over de periode van een jaar gemeten. We hebben in dit hoofdstuk alleen de data meegenomen die bij het kind werden gemeten, omdat die vaker beschikbaar waren en dus een betere representatie gaven van de totale steekproef. De resultaten van de longitudinale studie waren niet helemaa in lijn met onze hypotheses en de bevindingen van de cross-sectionele studie. Ten eerste vonden we geen longitudinale associaties tussen de ouderlijke gedragingen, cognitieve biases en angst. Op elk van de drie tijdpunten apart vonden we wel een aantal interessante resultaten. We vonden dat cognitieve biases en angst elkaar bi-directioneel beïnvloedde, waarbij interpretatie bias een versterkend effect had op confirmatie bias, wat weer een versterkend effect had op angst, wat weer een versterkend effect had op interpretatie bias. Dit is in lijn met eerdere bevindingen die ook lieten zien dat er een wederkerige relatie is tussen cognitieve bias en angst (e.g., Remmerswaal et al., 2014). Een andere onverwachte bevinding was dat de cognitieve biases en angst een effect hadden op schadelijke ouderlijke gedragingen in plaats van andersom. Dit resultaat kan te maken hebben met de methode van ons onderzoek omdat we alleen de zelfrapportage data van de kinderen gebruikt hebben, kan dit ook betekenen dat angstige kinderen de angstige gedragingen van hun ouders sneller waarnemen. Men zou op basis van dit resultaat echter ook kunnen concluderen dat het waarschijnlijker is dat angstige kinderen bepaalde ouderlijke gedragingen uitlokken in plaats van andersom, een scenario dat ook in verschillende eerdere onderzoeken naar voren is gekomen (Brunk \& Henggeler, 1984; Hudson, Doyle, \& Gar, 2009; Osofsky \& O'Connell, 1972). Daarom is het belangrijk om de wederkerige relatie 
tussen ouderlijke gedragingen en angst bij kinderen te benadrukken in plaats van een unidirectioneel effect van ouders op angst bij het kind (Gouze, Hopkins, Bryant, \& Lavigne, 2017).

\section{Conclusie}

Het doel van dit proefschrift was om de kennis over de ontwikkeling van angst bij kinderen te vergroten. Daarbij werd specifiek gekeken naar de verbanden tussen ouderlijke gedragingen, angst-gerelateerde cognitieve biases en angst bij kinderen. Als uitgangspunt hebben we een theoretisch model gebruikt waarbij schadelijke ouderlijke gedragingen (model-leren en bedreigende informatieoverdracht) een cognitieve bias bij het kind installeert, die vervolgens angst opwekt. Dit proefschrift leverde een aantal waardevolle bevindingen op. De resultaten van de studies in deze dissertatie hebben bevestigd dat zowel ouderlijke gedragingen als cognitieve biases gerelateerd zijn aan angst bij kinderen.

De volgende conclusies kunnen worden getrokken uit de studies in deze dissertatie: (1) Moeders en vaders spelen een verschillende rol in de opvoeding van hun kinderen en hebben ook een andere invloed op het angstniveau van het kind. Met betrekking tot R\&T play hebben we gevonden dat vaders meer van dit gedrag vertoonden dan moeders, terwijl moeders meer verzorgende gedragingen lieten zien. Met betrekking tot de andere ouderlijke gedragingen die onderzocht zijn in dit proefschrift, bleek dat kinderen vaker model-leren en bedreigende informatieoverdracht waarnemen bij hun moeder dan bij hun vader. De invloed van deze twee ouderlijke gedragingen bleek echter wel grotendeels gelijk te zijn voor moeders en vaders: model-leren en bedreigende informatieoverdracht hebben bij beide ouders eenzelfde relatie met de angst en cognitieve biases van het kind. Een andere belangrijke conclusie is dat (2) angst bij kinderen en cognitieve biases elkaar wederzijds beïnvloeden. Er is een circulaire relatie vastgesteld waarbij interpretatie bias een effect heeft op confirmatie bias, welke weer een effect heeft op de angst, die interpretatie bias weer beïnvloedt. Naast het feit dat angst en bias elkaar bi-directioneel beïnvloeden, lijkt dit ook zo te zijn voor de relatie tussen angst bij kinderen en schadelijke ouderlijke gedragingen. In onze cross-sectionele studie hebben we bewijs gevonden dat (3) schadelijke ouderlijke gedragingen (model-leren en bedreigende informatieoverdracht) een invloed hebben op angst. In onze longitudinale studie vonden we juist het omgekeerde, namelijk dat angst bij kinderen schadelijke ouderlijke gedragingen uitlokt. Als laatste punt kunnen we concluderen dat (4) ons bewijs voor een theoretisch model waarbij cognitieve biases als een mediator fungeren in de relatie tussen schadelijke ouderlijke gedragingen en angst bij kinderen tamelijk zwak was. We hebben gedeeltelijke steun voor dit model gevonden in de cross-sectionele studie in Hoofdstuk 4, maar vonden geen bewijs hiervoor in de methodologisch betere, longitudinale studie in Hoofdstuk 5. Het blijft dus belangrijk voor vervolgonderzoek om het effect van cognitieve biases op angst in een familiaire context te bestuderen, zowel voor betere theorievorming alsook voor het verbeteren van interventies voor angstige kinderen.

De bevindingen van het onderzoek hebben klinische implicaties voor zowel behandeling als preventie van angst bij kinderen. Ten eerste kunnen we ons afvragen of het goed is om ouders in de therapie te betrekken. Onderzoeken naar de betrokkenheid van ouders in therapie laten gemengde resultaten zien (zie review van Barmish \& Kendall, 2005). In onze studies kwam het verband tussen schadelijke ouderlijke gedragingen en angst naar voren. Andere onderzoeken hebben bekeken of positieve informatiegegeven door ouders kan zorgen voor een vermindering van angst bij kinderen (Kelly, Barker, Field, Wilson, \& Reynolds, 2010; Muris et al., 2011; Remmerswaal et al., 2010). Dit bleek inderdaad het geval te zijn. Daarom zou het includeren van ouders in therapie een veelbelovende aanvulling op bestaande interventies kunnen zijn.

Een tweede vraag is of deze cognitieve biases een nieuwe ingang geven voor de behandeling van angst bij kinderen. Dit is gerelateerd aan onze bevindingen over de relatie tussen cognitieve biases en angst bij kinderen. De meest gebruikte therapie voor angst is cognitieve gedragstherapie (CGT), waarbij het draait om cognitieve herstructurering, exposure-gebaseerde gedragsinterventies en relaxatie training (Heimberg, 2002). CGT is een effectieve therapie voor het verminderen van angst bij jongeren (zie meta-analyse van Scaini, Belotti, Ogliari, \& Battaglia, 2016), maar er zijn nog altijd mensen die niet verbeteren door deze therapie. Volgens cognitieve theorieën spelen fouten in de informatieverwerking een belangrijke rol in het ontstaan en instandhouden van angst (e.g., Mathews \& MacLeod, 2005). Daarom zou cognitieve bias modificatie (CBM) training een goede oplossing kunnen zijn. Dit zijn trainingsprogramma's die via de computer worden aangeboden met als doel om denkfouten in de informatieverwerking te corrigeren. In het geval van een interpretatie bias worden deelnemers getraind om ambigue informatie op een positieve manier te interpreteren, terwijl bij een confirmatie bias deelnemers worden getraind om te zoeken naar positieve in plaats van negatieve informatie door ze te voorzien van feedback over hun keuzes. Onderzoeken naar CBM-training laten niet alleen maar positieve resultaten zien (Cristea, Kok, \& Cuijpers, 2015; Eldar et al., 2012; Hakamata et al., 2010; Hallion \& Ruscio, 2011; Heeren, Mogoaşe, Philippot, \& McNally, 2015; Mogoaşe, David, \& Koster, 2014).

Desalniettemin laat onderzoek zien dat CBM succesvol kan zijn wanneer er aan bepaalde voorwaarden is voldaan. De eerste voorwaarde is dat de interventie 
meerdere sessies moet omvatten (Hallion \& Ruscio, 2011; Lisk, Pile, Haller, Kumari, $\&$ Lau, 2018). Een tweede kenmerk van een goed CBM-programma is dat meerdere biases moeten worden aangepakt om een gecombineerd effect te veroorzaken (de Hullu, Sportel, Nauta, \& de Jong, 2017; Hirsch, Clark, \& Mathews, 2006; Sportel, de Hullu, de Jong, \& Nauta, 2013). Een derde belangrijk element is dat de training ecologisch valide moet zijn door de deelnemers situaties voor te leggen die ze in het echte leven ook kunnen tegenkomen en waarmee ze zich kunnen identificeren (Hallion \& Ruscio, 2011). Verder is het zo dat CBM meer toepasbaar is bij bepaalde angststoornissen. Mensen met sociale angst zijn zeer terughoudend om in behandeling te gaan (Grant et al., 2005; Olfson et al., 2000). Voor CBM-programma's is de drempel om hulp te zoeken lager in vergelijking met reguliere CGT en daarom zouden dit soort interventies een interessant alternatief zijn voor mensen met dit type angstproblemen. Verder kan CBM een oplossing zijn voor minder ernstige gevallen van angstproblematiek als een preventieve methode.

\section{References}

American Psychiatric Association. (2013). Diagnostic and statistical manual of mental disorders. (5th ed.). Washington, DC.

Askew, C., \& Field, A. P. (2008). The vicarious learning pathway to fear 40 years on. Clinical Psychology Review, 28(7), 1249-1265. doi: 10.1016/j.cpr.2008.05.003

Barmish, A. J., \& Kendall, P. C. (2005). Should parents be co-clients in cognitive-behavioral therapy for anxious youth? Journal of Clinical Child and Adolescent Psychology, 34(3), 569581. doi: 10.1207/s15374424jccp3403_12

Bögels, S. M., \& Perotti, E. C. (2011). Does father know best? A formal model of the paternal influence on childhood social anxiety. Journal of Child and Family Studies, 20(2), 171-181. doi: 10.1007/s10826-010-9441-0

Bögels, S. M., \& Phares, V. (2008). Fathers' role in the etiology, prevention and treatment of child anxiety: A review and new model. Clinical Psychology Review, 28(4), 539-558. doi: 10.1016/j.cpr.2007.07.011

Brunk, M. A., \& Henggeler, S. W. (1984). Child influences on adult controls: An experimental investigation. Developmental Psychology, 20(6), 1074-1081. doi: 10.1037/00121649.20.6.1074

Constans, J. I., Penn, D. L., Ihen, G. H., \& Hope, D. A. (1999). Interpretive biases for ambiguous stimuli in social anxiety. Behaviour Research and Therapy, 37(7), 643-651. doi: 10.1016/ S0005-7967(98)00180-6

Costello, E., Mustillo, S., Erkanli, A., Keeler, G., \& Angold, A. (2003). Prevalence and development of psychiatric disorders in childhood and adolescence. Archives of General Psychiatry, 60(8), 837-844. doi: 10.1001/archpsyc.60.8.837

Cristea, I. A., Kok, R. N., \& Cuijpers, P. (2015). Efficacy of cognitive bias modification interventions in anxiety and depression: Meta-analysis. The British Journal of Psychiatry, 206(1), 7-16. doi: DOI: 10.1192/bjp.bp.114.146761

de Hullu, E., Sportel, B. E., Nauta, M. H., \& de Jong, P. J. (2017). Cognitive bias modification and CBT as early interventions for adolescent social and test anxiety: Two-year follow-up of a randomized controlled trial. Journal of Behavior Therapy and Experimental Psychiatry, 55, 81-89. doi: 10.1016/j.jbtep.2016.11.011

de Rosnay, M., Cooper, P. J., Tsigaras, N., \& Murray, L. (2006). Transmission of social anxiety from mother to infant: An experimental study using a social referencing paradigm. Behaviour Research and Therapy, 44(8), 1165-1175. doi: 10.1016/j.brat.2005.09.003

Dibbets, P., Fliek, L., \& Meesters, C. (2015). Fear-related confirmation bias in children: A comparison between neutral-and dangerous-looking animals. Child Psychiatry and Human Development, 46(3), 418-425. doi: 10.1007/s10578-014-0481-3

Dibbets, P. \& Meesters, C. (2017). The influence of stimulus valence on confirmation bias in children. Journal of Behavior Therapy and Experimental Psychiatry, 54, 88-92. doi: 10.1016/i. jbtep.2016.07.007

Eldar, S., Apter, A., Lotan, D., Edgar, K. P., Naim, R., Fox, N. A., ... Bar-Haim, Y. (2012). Attention bias modification treatment for pediatric anxiety disorders: A randomized controlled trial. American Journal of Psychiatry, 169(2), 213-230. doi: 10.1176/appi.aip.2011.11060886

Eley, T. C., \& Gregory, A. M. (2004). Behavioral genetics. In T. M. Morris \& J. S. March (Eds.), Anxiety disorders in children and adolescents (pp. 71-97). New York: Guilford Press. 
Fisak, B., \& Grills-Taquechel, A. E. (2007). Parental modeling, reinforcement, and information transfer: Risk factors in the development of child anxiety? Clinical Child and Family Psychology Review, 10(3), 213-231. doi: 10.1007/s10567-007-0020-x

Ford, T., Goodman, R., \& Meltzer, H. (2003). The British child and adolescent mental health survey 1999: The prevalence of DSM-IV disorders. Journal of the American Academy of Child and Adolescent Psychiatry, 42(10), 1203-1211. doi: 10.1097/00004583-20031000000011

Gouze, K. R., Hopkins, J., Bryant, F. B., \& Lavigne, J. V. (2017). Parenting and Anxiety: Bidirectional Relations in Young Children. Journal of Abnormal Child Psychology, 45(6), 11691180. doi: 10.1007/s10802-016-0223-z

Grant, B. F., Hasin, D. S., Blanco, C., Stinson, F. S., Chou, S. P., Goldstein, R. B., .. Huang, B. (2005). The epidemiology of social anxiety disorder in the United States: Results from the National Epidemiologic Survey on Alcohol and Related Conditions. The Journal of Clinica Psychiatry, 66(11), 1351-1361. doi: 10.4088/JCP.v66n1102

Hakamata, Y., Lissek, S., Bar-Haim, Y., Britton, J. C., Fox, N. A., Leibenluft, E., ... Pine, D. S. (2010). Attention bias modification treatment: A meta-analysis toward the establishment of novel treatment for anxiety. Biological Psychiatry, 68(11), 982-990. doi: 10.1016/j. biopsych.2010.07.021

Hallion, L. S., \& Ruscio, A. M. (2011). A meta-analysis of the effect of cognitive bias modification on anxiety and depression. Psychological bulletin, 137(6), 940-958. doi: 10.1037/a0024355

Heeren, A., Mogoase, C., Philippot, P., \& McNally, R. J. (2015). Attention bias modification for social anxiety: A systematic review and meta-analysis. Clinical Psychology Review, 40, 76-90. doi: 10.1016/j.cpr.2015.06.001

Heimberg, R. G. (2002). Cognitive-behavioral therapy for social anxiety disorder: Current status and future directions. Biological Psychiatry, 51(1), 101-108. doi: 10.1016/S00063223(01)01183-0

Hirsch, C. R., Clark, D. M., \& Mathews, A. (2006). Imagery and Interpretations in Social Phobia: Support for the Combined Cognitive Biases Hypothesis. Behavior Therapy, 37(3), 223-236. doi: 10.1016/j.beth.2006.02.001

Hudson, J. L., Doyle, A. M., \& Gar, N. (2009). Child and maternal influence on parenting behavior in clinically anxious children. Journal of Clinical Child \& Adolescent Psychology, 38(2), 256-262. doi: 10.1080/15374410802698438

Hudson, J. L., \& Rapee, R. M. (2001). Parent-child interactions and anxiety disorders: An observational study. Behaviour Research and Therapy, 39(12), 1411-1427. doi: 10.1016/ S0005-7967(00)00107-8

Kelly, V. L., Barker, H., Field, A. P., Wilson, C., \& Reynolds, S. (2010). Can Rachman's indirect pathways be used to un-learn fear? A prospective paradigm to test whether children's fears can be reduced using positive information and modelling a non-anxious response. Behaviour Research and Therapy, 48(2), 164-170. doi: 10.1016/j.brat.2009.10.002

Kessler, R. C., Berglund, P., Demler, O., Jin, R., Merikangas, K. R., \& Walters, E. E. (2005). Lifetime prevalence and age-of-onset distributions of DSM-IV disorders in the Nationa Comorbidity Survey Replication. Archives of General Psychiatry, 62(6), 593-602. doi 10.1001/archpsyc.62.6.593

Lindsey, E. W., \& Mize, J. (2001). Contextual differences in parent-child play: Implications for children's gender role development. Sex Roles, 44(3-4), 155-176. doi 10.1023/a:1010950919451
Lisk, S. C., Pile, V., Haller, S. P. W., Kumari, V., \& Lau, J. Y. (2018). Multisession cognitive bias modification targeting multiple biases in adolescents with elevated social anxiety. Cognitive Therapy and Research, 42(5), 581-597. doi: 10.1007/s10608-018-9912-y

Mathews, A., \& MacLeod, C. (2005). Cognitive vulnerability to emotional disorders. Annual Review of Clinical Psychology 1, 167-195 doi: 10.1146/annurev clinpsy.1.102803.143916

Miers, A. C., Blöte, A. W., Bögels, S. M., \& Westenberg, P. M. (2008). Interpretation bias and social anxiety in adolescents. Journal of Anxiety Disorders, 22(8), 1462-1471. doi: 10.1016/j. janxdis.2008.02.010

Mogoase, C., David, D., \& Koster, E. H. W. (2014). Clinical efficacy of attentional bias modification procedures: An updated meta-analysis. Journal of Clinical Psychology, 70(12), 1133-1157. doi: doi:10.1002/jclp.22081

Moore, P. S., Whaley, S. E., \& Sigman, M. (2004). Interactions between mothers and children: Impacts of maternal and child anxiety. Journal of Abnormal Psychology, 113(3), 471-476. doi: 10.1037/0021-843x.113.3.471

Moss, E., Cyr, C., \& Dubois-Comtois, K. (2004). Attachment at early school age and developmental risk: examining family contexts and behavior problems of controllingcaregiving, controlling-punitive, and behaviorally disorganized children. Developmental Psychology, 40(4), 519-532. doi: 10.1037/0012-1649.40.4.519

Muris, P. \& Field, A. (2013). Information processing biases. In Essau C. A. \& Ollendick T. H. (Eds). The Wiley-Blackwell handbook of the treatment of childhood and adolescent anxiety (pp. 141-156). Chichester: Wiley-Blackwel.

Muris, P., \& Field, A. P. (2010). The role of verbal threat information in the development of childhood fear. "Beware the Jabberwock!". Clinical Child and Family Psychology Review, 13(2), 129-150. doi: 10.1007/s10567-010-0064-1

Muris, P., Huijding, J., Mayer, B., \& Hameetman, M. (2008). A space odyssey: experimental manipulation of threat perception and anxiety-related interpretation bias in children. Child Psychiatry and Human Development, 39(4), 469-480. doi: 10.1007/s10578-008-0103-z

Muris, P., Huijding, J., Mayer, B., Remmerswaal, D., \& Vreden, S. (2009a). Ground control to Major Tom: Experimental manipulation of anxiety-related interpretation bias by means of the "space odyssey" paradigm and effects on avoidance tendencies in children. Journal of Anxiety Disorders, 23(3), 333-340. doi: 10.1016/j.janxdis.2009.01.004

Muris, P., Huijding, J., Mayer, B., van As, W., \& van Alem, S. (2011). Reduction of verbally learned fear in children: A comparison between positive information, imagery, and a control condition. Journal of Behavior Therapy and Experimental Psychiatry, 42(2), 139-144. doi: 10.1016/j.jbtep.2010.11.006

Muris, P., Merckelbach, H., Meesters, C., \& van den Brand, K. (2002). Cognitive development and worry in normal children. Cognitive Therapy and Research, 26(6), 775-787. do: 10.1023/a:1021241517274

Muris, P. Rassin, E. Mayer, B. Smeets, G.,Huiiding, J., Remmerswaal, D. \& Field, A. (2009b). Effects of verbal information on fear-related reasoning biases in children. Behaviour Research and Therapy, 47(3), 206-214. doi: 10.1016/j.brat.2008.12.002

Murray, L., Creswell, C., \& Cooper, P. J. (2009). The development of anxiety disorders in childhood: An integrative review. Psychological Medicine, 39(9), 1413-1423. doi: 10.1017/ s0033291709005157

Olfson, M., Guardino, M., Struening, E., Schneier, F. R., Hellman, F., \& Klein, D. F. (2000). Barriers to the treatment of social anxiety. American Journal of Psychiatry, 157(4), 521 527. doi: 10.1176/appi.ajp.157.4.521 
Osofsky, J. D., \& O'Connell, E. J. (1972). Parent-child interaction: Daughters' effects upon mothers' and fathers' behaviors. Developmental Psychology, 7(2), 157-168. doi: 10.1037 h0033016

Paquette, D., Carbonneau, R., Dubeau, D., Bigras, M., \& Tremblay, R. E. (2003). Prevalence of father-child rough-and-tumble play and physical aggression in preschool children. European Journal of Psychology of Education, 18(2), 171-189. doi: 10.1007/BF03173483

Pellegrini, A. D. (1995). A longitudinal study of boys' rough-and-tumble play and dominance during early adolescence. Journal of Applied Developmental Psychology, 16(1), 77-93. do 10.1016/0193-3973(95)90017-9

Polanczyk, G. V., Salum, G. A., Sugaya, L. S., Caye, A., \& Rohde, L. A. (2015). Annual Research Review: A meta-analysis of the worldwide prevalence of mental disorders in children and adolescents. Journal of Child Psychology and Psychiatry, 56(3), 345-365. doi: 10.1111/ jcpp.12381

Remmerswaal, D., Huijding, J., Bouwmeester, S., Brouwer, M., \& Muris, P. (2014). Cognitive bias in action: Evidence for a reciprocal relation between confirmation bias and fear in children. Journal of Behavior Therapy and Experimental Psychiatry, 45(1), 26-32. doi: 10.1016/j. jbtep.2013.07.005

Remmerswaal, D., Muris, P., Mayer, B., \& Smeets, G. (2010). "Will a Cuscus bite you, if he shows his teeth?" Inducing a fear-related confirmation bias in children by providing verbal threat information to their mothers. Journal of Anxiety Disorders, 24(5), 540-546. doi: 10.1016/3. janxdis.2010.03.012

Roza, S. J., Hofstra, M. B., van der Ende, J., \& Verhulst, F. C. (2003). Stable prediction of mood and anxiety disorders based on behavioral and emotional problems in childhood: A 14year follow-up during childhood, adolescence, and young adulthood. American Journal of Psychiatry, 160(12), 2116-2121. doi: 10.1176/appi.ajp.160.12.2116

Scaini, S., Belotti, R., Ogliari, A., \& Battaglia, M. (2016). A comprehensive meta-analysis of cognitive-behavioral interventions for social anxiety disorder in children and adolescents. Journal of Anxiety Disorders, 42, 105-112. doi: 10.1016/j.janxdis.2016.05.008

Sportel, B. E., de Hullu, E., de Jong, P. J., \& Nauta, M. H. (2013). Cognitive bias modification versus CBT in reducing adolescent social anxiety: A randomized controlled trial. PLoS One, 8(5), e64355. doi: 10.1371/journal.pone.0064355

Stopa, L., \& Clark, D. M. (2000). Social phobia and interpretation of social events. Behaviour Research and Therapy, 38(3). 273-283. doi: 10.1016/S0005-7967(99)00043-1

Vasey, M. W. (1993). Development and cognition in childhood anxiety: The example of worry. Advances in Clinical Child Psychology, 15, 1-39.

Voncken, M. J., Bögels, S. M., \& de Vries, K. (2003). Interpretation and judgmental biases in social phobia. Behaviour Research and Therapy, 41(12), 1481-1488. doi: https://doi. org/10.1016/S0005-7967(03)00143-8

Westenberg, P. M., Drewes, M. J., Goedhart, A. W., Siebelink, B. M., \& Treffers, P. D. A. (2004). A developmental analysis of self-reported fears in late childhood through mid-adolescence: social-evaluative fears on the rise? Journal of Child Psychology and Psychiatry, 45(3), 481 495. doi: 10.1111/j.1469-7610.2004.00239.x

Wolfradt, U., Hempel, S., \& Miles, J. N. V. (2003). Perceived parenting styles, depersonalisation, anxiety and coping behaviour in adolescents. Personality and Individual Differences, 34(3), 521-532. doi: 10.1016/S0191-8869(02)00092-2 


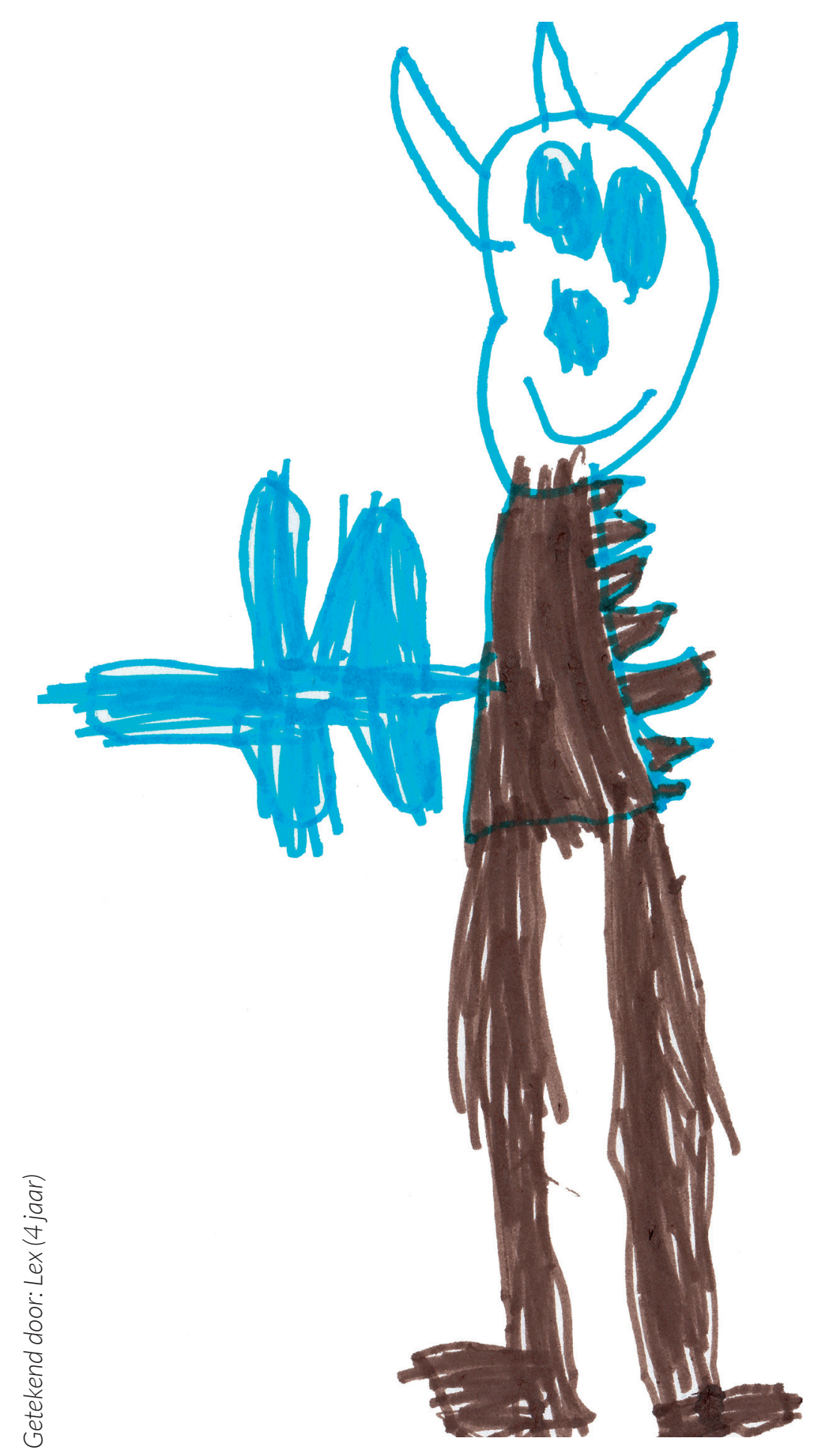

DANKWOORD 
Ten eerste wil ik alle kinderen en ouders bedanken die meegedaan hebben aan mijn onderzoek. Zonder jullie zou dit proefschrift er niet geweest zijn. Tevens dank aan de scholen die mee hebben gewerkt: Basisschool Scharn, Basisschool de Maasköpkes, Basisschool Franciscus en Basisschool de Schakel.

Verder wil ik mijn begeleiders bedanken. Dankjewel Peter en Jeffrey voor het vertrouwen dat jullie mij de afgelopen jaren hebben gegeven. Peter, mijn promotor, in de eerste plaats bedankt dat je met me meeging om scholen te werven voor mijn onderzoek. Het maakte toch wel meer indruk als de professor erbij was. Ook bedankt voor de waardevolle (en zeer snelle) feedback op mijn papers; jouw oog voor detail zorgde ervoor dat de kleinste foutjes uit mijn artikelen werden gehaald. Het was ook fijn dat jouw deur altijd open stond. Jeffrey, mijn copromotor, bedankt voor al je feedback. Ik heb er bewondering voor hoe jij al je banen, opleiding en gezinsleven met elkaar kunt combineren. Ik kijk met veel plezier terug op de gezamenlijke overleggen met jullie twee. leder overleg met jullie gaf mij vertrouwen om weer met nieuwe motivatie door te gaan.

Prof. dr. Frenk Peeters, prof. dr. Sandra Mulkens, dr. Daniëlle Remmerswaal, prof. dr. Frans Feron, prof. dr. Maaike Nauta, prof. dr. Henry Otgaar \& dr. Cor Meesters, bedankt dat jullie zitting wilden nemen in mijn promotiecommissie en mijn proefschrift zo grondig hebben willen bestuderen.

Henry, bedankt dat je mij bij Peter hebt aanbevolen voor dit promotietraject. Ik ben blij dat ik bij jou in de bachelor het MARBLE-project mocht doen. Ik bewonder jouw bevlogenheid en enthousiasme als onderzoeker. Ook Arie en Pascal bedankt dat jullie mijn mentor waren in de bachelor en research master. Bedankt voor alle kansen en waardevolle adviezen.

Gerard, bedankt voor je onmisbare statistische hulp bij hoofdstuk 5 van dit proefschrift. Je hebt een talent om moeilijke materie begrijpelijk te maken.

Charlie en Michiel, bedankt voor het programmeren van de taken in mijn studies. Bedankt voor jullie geduld bij alle kleine aanpassingen aan de taken en voor jullie hulp toen de dingen niet helemaal liepen zoals ze zouden moeten lopen.

Alle studenten die mee hebben gewerkt aan mijn projecten wil ik bedanken. In het bijzonder Milou, Judith, Veerle, Ilias, Chrissy, Gerjanne en Raf voor jullie onmisbare hulp bij de data-verzameling.

Ik wil graag alle kinderen bedanken die een prachtige tekening voor de omslag en hoofdstukken van mijn proefschrift hebben gemaakt (ook voor de tekeningen die helaas geen plekje hebben gekregen): Lilly, Olivia, Julie, Emma-Fay, Saar, Liza, Lex \& Renée, bedankt!

Ook dank aan mijn collega's met wie ik een kantoor heb gedeeld. Marjolein, Marlies en Ivo, jullie waren mijn eerste kamergenootjes. Marjolein, bedankt dat je me in het begin wegwijs hebt gemaakt. We hebben niet lang een kamer gedeeld, maar sinds die tijd kan ik altijd bij je terecht voor advies. Bedankt voor de gezelligheid en je optimisme (jij denkt in oplossingen en niet in problemen). Marlies, bedankt voor de gezellige dagen op kantoor. Ik was altijd zeer onder de indruk van alle verschillende kleuren nagellak! Ik vond het leuk om onlangs te ontdekken dat we nu weer collega's zijn bij Adelante. Ivo, ik ben blij dat ik van toegevoegde waarde mocht zijn als proefkonijn voor je blarenstudie (de littekens waren tijdens mijn bruiloft gelukkig redelijk weggetrokken). Pim, je zat een kantoor verder. Vanaf mijn eerste werkdag zijn we vaak samen gaan lunchen. Ik waardeer je betrokkenheid en eerlijkheid.

Anna, Jantine en - iets later - Astrid, jullie waren de volgende kantoorgenoten. Anna, it was my pleasure to share a room with you. Thank you for all the talks. It was nice to get to know a bit more about the Greek culture. Astrid, bedankt voor de goede balans tussen gezelligheid en productiviteit op kantoor. Jantine, wij hadden samen niet alleen overeenkomsten qua werk, maar ook in ons privéleven. Daarom hadden wij nooit een gebrek aan gespreksonderwerpen op kantoor. Zo zijn we tijdens onze PhD allebei getrouwd en hebben we een kind gekregen (jij beide net iets eerder dan ik) Voor wijze raad ben ik bij jou altijd aan het goede adres. Ik gun iedereen een vriendin als jij. Bedankt dat je mijn paranimf wil zijn!

Mijn laatste kantoor heb ik gedeeld met Linda. Bedankt voor de leuke tijd op kantoor en dat jij er was tijdens de laatste loodjes van mijn proefschrift. Ook bedankt voor het meedenken over mijn stellingen als "planningen zijn er om gewijzigd te worden" en "perfect bestaat niet".

Graag wil ik ook al mijn (ex-)collega's van de CP-sectie bedanken voor hun betrokkenheid en de fijne werksfeer. Bedankt Pauline, Nicole, Peter, Jeffrey, Martijn, Marisol, Jill, Sanne, Marleen, Eline, Maarten, Dalena, Anke, Brechje, David, Suzanne, Frenk, Lotte, Cor, Rosanne, Anne, Conny, Linda, Tom en Pim. Daarnaast wil ik ook mijn andere CPS-collega's bedanken.

Ghislaine, ik kende je al van tijdens de Research Master, maar op het werk hebben we elkaar echt goed leren kennen. Tijdens het afronden van jouw proefschrift waren we nog ren- en pumpmaatjes, tegenwoordig zijn we meer koffie-, lunch- en dinermaatjes ("wijnen, wijnen, wijnen"). Ik bewonder jouw positieve instelling! Met jou is het altijd gezellig. Ik hoop dat we nog lang maatjes blijven, op welke manier dan ook. Bedankt dat je mijn paranimf wil zijn!

Lotte, bedankt voor de gezellige lunchmomenten en je luisterend oor. Ik zal vooral ook je muzikale ondersteuning op mijn bruiloft altijd onthouden. Anke, naast al het onderzoeken was het een leuke afleiding om samen met jou les te geven. Het is fijn om met iemand samen te werken die op eenzelfde manier over zaken denkt. Martijn, het is fijn om in stressvolle tijden jouw nuchtere kijk op dingen te horen. Sophie, we hebben 
maar kort samengewerkt, maar toch een hechte band opgebouwd. Bedankt voor je luisterend oor, oprechte interesse en bemoedigende woorden. Jessica, bedankt voor je positiviteit. Ik vind het heel gezellig dat je samen met Kai en Sem ook in Amby woont. Natalja, bedankt dat je mijn voorbeeld was tijdens het lesgeven op de universiteit.

Graag wil ik iedereen van het secretariaat bedanken voor de praktische ondersteuning en de gezellige gesprekken, in het bijzonder Lindy, Jessie, Marionne en Caroline.

Verder wil ik mijn nieuwe collega's bij Adelante Arbeid bedanken. Dank dat jullie mij het vertrouwen hebben gegeven om jullie team te komen versterken. Ik heb in deze korte tijd al heel veel van jullie geleerd. Ik kijk ernaar uit om met jullie samen te werken aan dit nieuwe hoofdstuk in mijn leven.

Lieve vrienden en vriendinnen: Iris \& Monsif, Joany \& Ralph, Jeroen \& Chantal, Charel \& Emiel, Germaine \& Rob, Marije \& Peter, Robbert \& Joke, Wilbert \& Susan, Roland \& Hannah, Charley \& Jolaine, Céline, jullie maken mijn leven een stuk leuker.

Charell en Marije, jullie zijn niet alleen lieve vriendinnen, maar jullie waren tijdens mijn promotietraject ook een waardevolle ondersteuning bij de data-verzameling. Bedankt dat jullie mee zijn geweest naar de scholen om alle kinderen in toom te houden.

Germaine, wij waren als kinderen dikke vriendinnen en zijn elkaar toen uit het oog verloren. Tijdens dansles bij Bernaards zijn we elkaar weer tegengekomen en ik ben blij dat we sindsdien weer dikke vriendinnen zijn!

Jeroen en Chantal, bedankt dat jullie er zijn. We komen elke week wel bij elkaar over de vloer en dat is heel gezellig! Bedankt voor alle fijne uitstapjes samen en dat jullie er zijn op minder leuke momenten, maar zeker ook bij alle leuke momenten.

Iris en Joany, het heeft even op zich laten wachten, maar ik ben heel blij dat we nu eindelijk ons weekendje gaan plannen. Jullie weten als geen ander wat het betekent om een promotietraject te doorlopen. Daarom was jullie steun van onschatbare waarde als er weer eens iets niet ging zoals het zou moeten gaan. Ik kijk uit naar onze volgende aperol-spritz-pyjama-party. Ik ben trots dat jullie mijn vriendinnen zijn!

Robbert en Joke, bedankt voor jullie humor en gezelligheid. Joke bedankt voor je hulp en waardevolle tips bij het solliciteren.

Céline, lieve krullenbol, tijdens ons bijbaantje in de schoonmaak hebben we al veel over onze studie en onze toekomstdromen gepraat. Maar bovenal hadden we ook vee ol. Hier denk ik met plezier aan terug. Nu ga jii in New York je droom achterna! Ik heb veel bewondering voor je doorzettingsvermogen en je vastberadenheid.
Lieve familieleden, jullie allemaal bedankt voor jullie betrokkenheid en de leuke afleidingen die jullie me hebben gegeven. Ook bedankt voor het oppassen op Renée zodat ik tijd had om aan mijn proefschrift te werken, in het bijzonder pap en mam, Denise \& Robbert, Niny \& Wim, Lilian \& Math en Phil.

Rachel, bedankt dat je er bent, soms als mijn schoonzus en een enkele keer als mijn stiefmoeder. Bedankt voor je hulp bij het ontwerp van mijn cover. Ik ben blij dat wij zoveel leuke dingen doen met jou en die ene. Matti, ik ken niet veel mensen die zo grappig zijn als jij. Bedankt, ik heb altijd veel succes met jouw grapjes.

Lieve Anke, jij bent voor mij als een grote zus. Ik geniet van onze uitstapjes (naar de Efteling) en ik bewonder hoe positief jij in het leven staat.

Karen, we zien elkaar niet zo vaak, maar als we samen zijn dan vind ik onze gesprekken heel fijn. Jij laat me altijd de andere kant van zaken zien, dat is een mooie eigenschap. Ellen A., ik vind onze etentjes bij jou of bij ons altijd erg gezellig. Snel weer eens doen? Ellen B., bedankt dat jij er altijd bent met de make-up kwast en krultang op de bijzondere dagen in mijn leven.

Papa en mama, bedankt voor jullie steun en hulp. Papa, bedankt dat je het voorbeeld voor mij bent geweest om ook psychologie te gaan studeren. Mama, bedankt dat we altijd mochten blijven eten als het weer eens laat op kantoor was geworden. Ook bedankt dat jullie zo'n lieve en ondernemende opa en oma van Renée zijn. Jullie hulp is van onschatbare waarde.

Joël, bedankt voor je nuchterheid. Bedankt dat je Marianne in ons leven hebt gebracht. Marianne, thank you for all the crazy things we do together. Together with you, life never gets boring!

Harmen, jij bent al 15 jaar de liefste. Sorry dat je zo vaak het eten al had gekookt en ik dan toch nog ietsje later thuis was. Bedankt voor het proeflezen van mijn artikelen. Bedankt dat je altijd zo kritisch bent op psychologisch onderzoek. Ik ben blij dat jij precies weet wat het inhoudt om te promoveren en me daarbij heel goed hebt gesteund. Daarnaast bedankt dat je me altijd een luisterend oor biedt, bedankt voor je humor (soms) en bedankt dat je bent zoals je bent. Ik hou van jou en ik ben er trots op dat jij mijn man bent!

Lieve Renée, met jou is het leven nooit meer saai. Jij maakt elke dag van je papa en mij een stukje avontuurlijker, zwaarder, gezelliger, confronterender en grappiger. Wat ben ik ontzettend blij en trots dat jij er bent! Wat niet is gelukt voor jouw eerste verjaardag, is me dan toch gelukt voor je derde verjaardag: mijn proefschrift is af!

Lief kleintje, bedankt dat ik mijn proefschrift niet alleen hoef te verdedigen. We kijken uit naar je komst! 


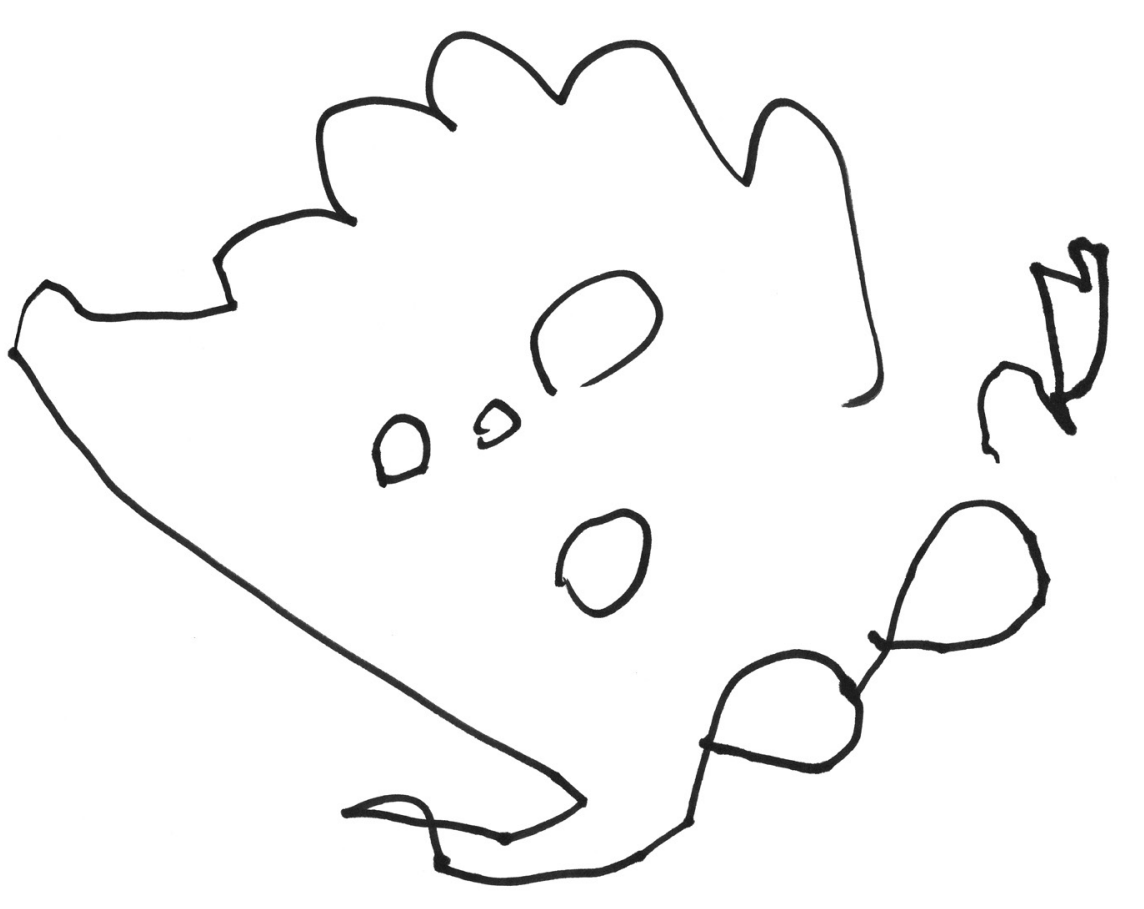

Curriculum Vitae 


\section{Curriculum Vitae}

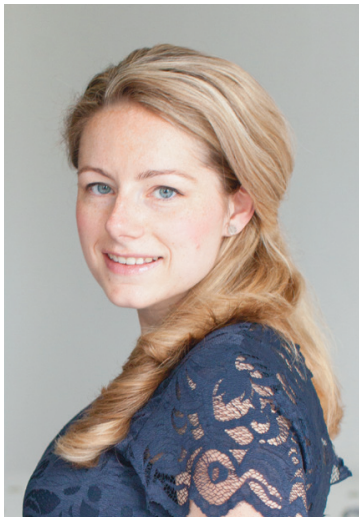

Lorraine Fliek was born on January 28th, 1989 in Maastricht, the Netherlands. In 2007, she graduated from secondary school (Sint Maartens College Maastricht) She completed her bachelor in Biological Psychology in 2010 at Maastricht University, where she also obtained her research master degree (Cognitive and Clinical Neuroscience; Specialisation: Neuropsychology) two years later. During this master, she did a combined clinical and research internship at the Memory Clinic, Maastricht University Medical Center (MUMC+). After receiving a grant from the NWO (top-talent), she started her doctorate in February 2013 under the supervision of Prof. Dr. Peter Muris and Dr. Jeffrey Roelofs at the Department of Clinical Psychological Science at Maastrich University. The studies in this project focused on the development and maintenance of childhood anxiety, with a special focus on threat-related cognitive biases and the influence of parents. During her PhD, she also worked as a teacher at the Faculty of Psychology and Neuroscience and the Faculty of Health, Medicine and Life Sciences and obtained her University Teaching Qualification. Lorraine currently works as an assessment psychologist at Adelante, Employment reintegration.

\section{Publications}

Fliek, L., Daemen, E., Roelofs, J., \& Muris, P. (2015). Rough-and-tumble play and other parental factors as correlates of anxiety symptoms in preschool children. Journal of Child and Family Studies, 24(9), 2795-2804.

Dibbets, P., Fliek, L., \& Meesters, C. (2015). Fear-related confirmation bias in children: A comparison between neutral-and dangerous-looking animals. Child Psychiatry and Human Development, 46(3), 418-425.

Ooi, J., Dodd, H. F., Fliek, L. \& Muris, P. (2016) The development of anxiety in childhood and adolescence: The transmission of cognitive biases. In R. G. Menzies, M. Kyrios,

N. Kazantzis (Eds.) Innovations and Future Directions in the Behavioural and Cognitive Therapies (pp. 3-7). Samford Valley, QLD: Australian Academic Press.

Fliek, L., Dibbets, P., Roelofs, J., \& Muris, P. (2017). Cognitive bias as a mediator in the relation between fear-enhancing parental behaviors and anxiety symptoms in children: A cross-sectional study. Child Psychiatry and Human Development, 48(1) 82-93.

Fliek, L., Roelofs, J., van Breukelen, G., \& Muris, P. (2019). A longitudinal study on the relations among fear-enhancing parenting, cognitive biases, and anxiety symptoms in non-clinical children. Child Psychiatry and Human Development, 50(4), 631-646.

Fliek, L., Roelofs, J., Widdershoven, R., Vennegoor, G., Broers, N. (in preparation). Cognitive bias modification versus regular cognitive-behavioral therapy: A case series of six children with subclinical social anxiety problems. 


\section{Presentations}

Fliek, L., Muris, P., \& Roelofs, J. (2013). Cognitive bias in action: The role of confirmation bias in the development and maintenance of childhood anxiety. Oral presentation at a meeting on Multilevel Analysis of Longitudinal Data. Maastricht, The Netherlands.

Fliek, L., Daemen, E., Roelofs, J., \& Muris, P. (2014). Parental play and challenge activities, anxiety, and overprotection as correlates of anxiety symptoms in preschoo children. Poster presented at the first Rome Workshop on Experimental Psychopathology. Rome, Italy.

Fliek, L., Daemen, E., Roelofs, J., \& Muris, P. (2014). Parental play and challenge activities, anxiety, and overprotection as correlates of anxiety symptoms in preschoo children. Poster presented at the Maastricht University Faculty of Psychology and Neuroscience Research Day. Rijckholt, The Netherlands.

Fliek, L., Muris, P., \& Roelofs, J. (2015). Confirmation bias, parental modeling, and verbal threat information as correlates of children's anxiety symptoms. Poster presented at the International Convention of Psychological Science (ICPS) Amsterdam, The Netherlands.

Fliek, L., Muris, P., \& Roelofs, J. (2015). Cognitive bias in action. Oral presentation at the Maastricht University Faculty of Psychology and Neuroscience Research Day. Rijckholt, The Netherlands.

Fliek, L., Muris, P., \& Roelofs, J. (2015). Cognitive bias in action. Oral presentation a the Dutch-Flemish Postgraduate School for Experimental Psychopathology (EPP). Utrecht, The Netherlands.

Fliek, L., Dibbets, P., Roelofs, J., \& Muris, P. (2016). Cognitive bias as a mediator in the relation between fear-enhancing parental behaviors and anxiety symptoms in children. Poster presented at the Maastricht University Faculty of Psychology and Neuroscience Research Day. Rijckholt. The Netherlands.

Fliek, L., Muris, P., \& Roelofs, J. (2016). The role of cognitive biases and parenting behaviors in the development of anxiety in children. Oral presentation at the DutchFlemish Postgraduate School for Experimental Psychopathology (EPP). Heeze, The Netherlands.
Fliek, L., Dibbets, P., Roelofs, J., \& Muris, P. (2017). The role of fear-enhancing parenting behaviors and cognitive biases in the development of anxiety in children. Oral presentation at the European Association for Behavioural and Cognitive Therapies (EABCT). Ljubljana, Slovenia. 